\title{
5. »NOUVELLE ÈRE« ODER »LÉGENDE NOIRE« DIE COMMUNE IM BILDGEDÄCHTNIS DER REPUBLIK
}

\section{1. »Le magnifique incendie du progrès, c'est Paris qui l'attise « Paris als »ville solaire « und mythisches Lichtzentrum der Revolution}

Die III. Französische Republik wurde am 4.September 1870 inmitten des deutsch-französischen Krieges gegründet und trat damit ein schweres Erbe an ${ }^{1}$ : Die während der Belagerung von Paris erlittenen Entbehrungen, der Verlust des Elsaß' und Lothringens und die erniedrigenden Friedensbedingungen $^{2}$ wurden als unmittelbarer Angriff auf das Selbstverständnis Frankreichs als führender Kulturnation empfunden. Eine dunkle Epoche schien somit angebrochen zu sein. Der enge Zusammenhang mit dem Mythos der lumières kommt klar in Honoré Daumiers Karikatur La France-Prométhée et l'aigle-vautour ${ }^{3}$ zum Ausdruck. Wie der Lichtbringer Prometheus ${ }^{4}$ wird auch die an den Felsen gekettete France grausam bestraft. Dabei läßt die Mutation des (preußischen) Adlers zum aigle-vautour im Unklaren, ob Frankreich überhaupt noch am Leben ist, denn der Geier als Aasfresser vergreift sich eigentlich nur an Kadavern ${ }^{5}$. Nicht zufällig erinnert dieses Blatt an ein früheres: Page d'histoire, erschienen in Le Charivari am 16. November 1870, zeigt den Adler als kaiserliches Wappentier des II. Empire, erschlagen von Victor Hugos Gedichtband Les Châtiments und gleichzeitig getroffen von einem

1 Zur Republikgründung vgl. Jacques Chastenet, Histoire de la Troisième République, Bd. 1: Enfance et jeunesse, Paris 1952; CARON, Frankreich im Zeitalter des Imperialismus, S.217-229. Zum deutsch-französischen Krieg in der Karikatur vgl. Angela Bork u.a. (Hg.), Die politische Lithographie im Kampf um die Pariser Kommune, Ausstellungskata$\log$, Köln 1976; Die Zeitschrift »La Charge« und Karikaturen von 1871. Ausstellungskata$\log$, hg. v. d. Staatlichen Museen Preußischer Kulturbesitz, Berlin 1991; Ouriel ResheF, Guerre, mythes et caricature. Au berceau d'une mentalité française, Paris 1984.

2 Insgesamt mußte Frankreich 5 Mrd. Goldfrancs Entschädigung an das Deutsche Reich zahlen und verlor ca. $15000 \mathrm{~km}^{2}$ Territorium. Vgl. CARoN, Frankreich im Zeitalter des Imperialismus, S.241. $\mathrm{Zu}$ den kulturellen Konsequenzen der Niederlage nach $1871 \mathrm{vgl}$. Wolfgang Schivelbusch, Die Kultur der Niederlage. Der amerikanische Süden 1865 Frankreich 1871 - Deutschland 1918, Berlin 2001, S. 123-224.

3 Le Charivari, Actualités, 13.2.1871. Abgebildet bei Lethève, Caricature, S. 13.

${ }^{4}$ Vgl. dazu Kap.2.1.2.

5 Eine ähnliche Haltung kommt in Daumiers Karikatur über die Annexion des Elsaß' und Lothringens zum Ausdruck. Während andere Künstler diese als grausame Amputation darstellen, die - gewöhnlich von Thiers - am makellos schönen Leib der blühenden France vorgenommen wurde, zeigt Daumier die regungslose Gestalt einer offenbar toten Frau auf dem Seziertisch, umgeben von einer schweigenden Menge, nur kommentiert durch den Satz: »Qui prendra le couteau«?, in: Le Charivari, 16.2.1871 (D 3458). 


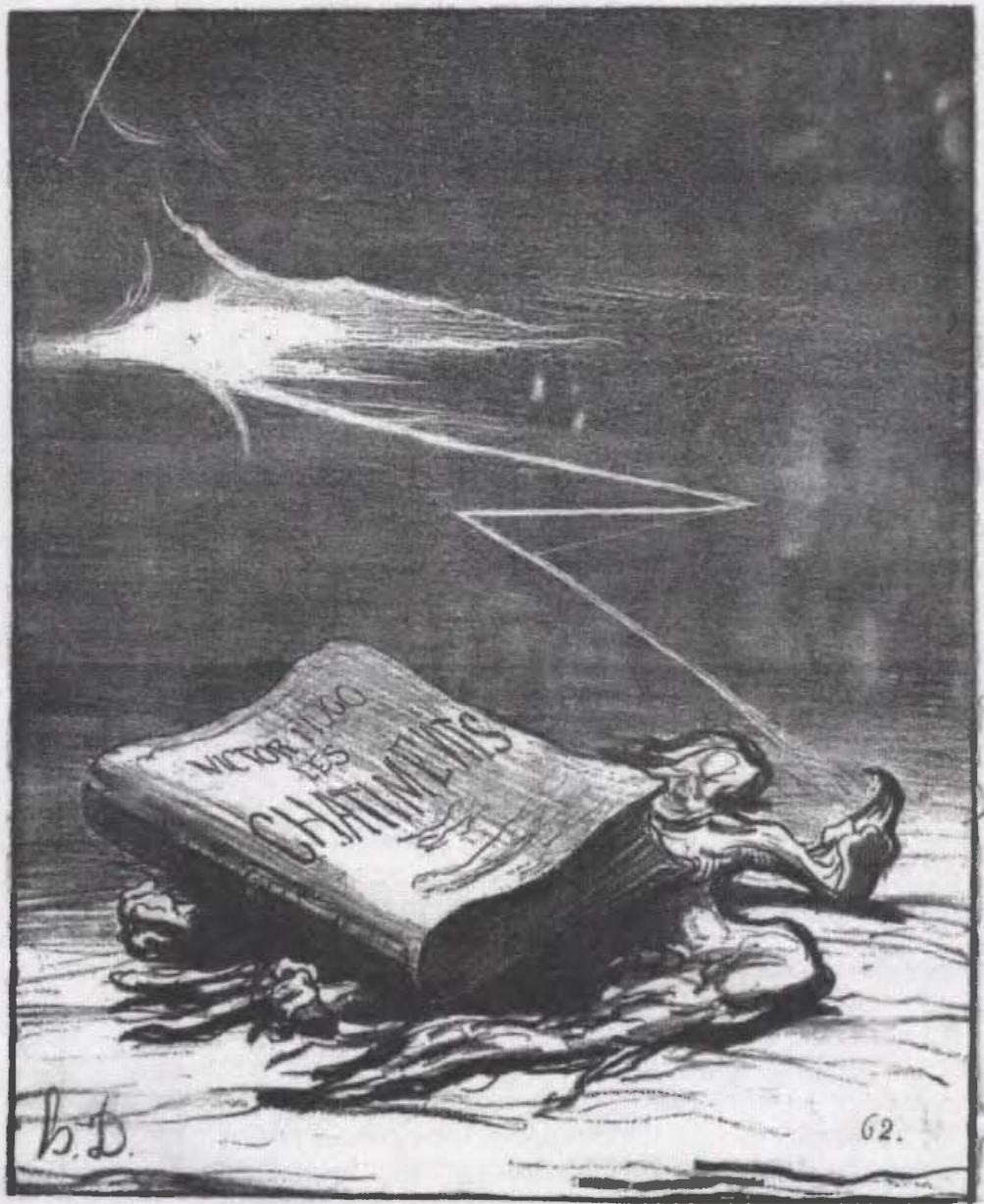

PAGE D'HISTOIRE.

$A b b .3$ Honore Daumier: Page d'histoire, in: Le Charivari, 16.11.1870. UB Frankfurt.

gleißenden Blitz, der kraftvoll den von schwarzen Wolken verhangenen Himmel durchbricht (Abb.3). Diese zeitlich noch vor dem eigentlichen Triumph des Lichtes lokalisierte Szene könnte sich direkt auf die wohl berühmteste Stelle der Châtiments beziehen: »Ö Rejpublique universelle! / Tu n'es encore que l'etincelle, / Demain tu seras le soleil « ${ }^{6}$.

6 Victor Hugo, Lux 1, in: Les Châtiments, in: Ders., Euvres completes, Bd. 5, Paris 1985, S. 202. 
Der Funke aber ist nun zum Blitz geworden, der die Strafe vollzieht, ehe die Sonne der Republik aufgehen kann. Die beide Bilder verbindende Symbolik des Adlers verdeutlicht, daß die gerade überwunden geglaubte Unfreiheit des II. Empire durch eine andere ersetzt wird, die sich zudem in europäische Dimensionen ausdehnen könnte: Diese Befürchtung spricht aus der ebenfalls in der Serie Actualités erschienenen Lithographie L'Éclipse serat-elle totale?7: Vor die strahlende Sonne mit der Inschrift liberté, die den Kontinent Europa bescheint, schiebt sich drohend eine Hand mit der preußischen Pickelhaube, die eine künstliche Sonnenfinsternis erzeugt ${ }^{8}$. Nur einen Tag nach der Veröffentlichung dieses Blattes, am 18. März 1871, scheiterte der Versuch, die Pariser Nationalgarde zu entwaffnen, und verschiedene Gruppierungen aus Jakobinern und Sozialisten jeder Couleur brachten die Stadt unter ihre Kontrolle. Noch in der Nacht besetzten die Vertreter der neuen, direkt demokratischen Republik das Hôtel de Ville ${ }^{9}$. Der satirisch-politische Diskurs verschob sich daraufhin in den Bereich der sozialen Spannungen und Gegensätze und manifestierte sich als direkte Kontroverse zwischen der Versailler Regierung und großen Teilen der Pariser Bevölkerung, die nach den Entbehrungen der Belagerung die Kapitulation Ende Februar als Verrat empfanden ${ }^{10}$.

${ }^{7}$ In: Le Charivari, 17.3.1871 (D 3820). Zu diesem Blatt Ursula E. KocH, Vom Völkerfrühling zum deutsch-französischen Krieg (1848 bis 1870/71). Das Bild des Nachbarn im satirischen Vergleich am Beispiel der Pariser Tageszeitung Le Charivari und des Berliner Wochenblattes Kladderadatsch, in: RüTrEN u.a. (Hg.), Die Karikatur zwischen Republik und Zensur, S. 427 (und ibid., Abb.456): "Wie wohl viele seiner Landsleute schenkte der Künstler der in der Kaiserproklamation ausgesprochenen Absage an weitere kriegerische Eroberungen keinen Glauben «.

${ }^{8}$ Zeitgleich existierten allerdings auch Bilder, die das neu gegründete deutsche Kaiserreich als kurzlebigen Anachronismus darstellten. Das 1871 entstandene Blatt Soleil levant von Mobb zeigt den preußischen König, der vor der Sonne der République allemande die Flucht ergreift. Vgl. Ducatel, Bd. I, S.57. Besonders interessant ist ein Blatt von Paul Klenck: La Dégringolade. BnF., Est., Eingangsstempel: 6.9.1871. Es zeigt den preußischen König und den Kronprinzen bei dem Versuch, die Sonne mit Seilen festzubinden. Auch Napoleon III. hatte ein solches Seil in der Hand, die sich unter ihm drehende Erdkugel hat ihn aber bereits auf seinem Standplatz Sedan den Boden unter den Füßen verlieren lassen und ihn - im wahrsten Sinne des Wortes - vom Erdboden hinweggefegt. Es ist also nur eine Frage der Zeit, bis die beiden deutschen Monarchen auf ihrem Standpunkt Berlin dasselbe Schicksal ereilen wird. Der verzweifelte Versuch, die Sonne so wie einst der biblische Josua anzuhalten, steht für ein überkommenes, traditionelles Weltbild. Wer nicht einmal erkennt, wo die Bewegung wirklich stattfindet, wird zwangsläufig von der $\mathrm{Er}$ eignissen überrollt: "Libre à vous d'essayer par un effort suprême / D'arrêter le soleil... Risibles Josués!... / La terre tournera... vous serez conspués«.

9 Vgl. Caron, Frankreich im Zeitalter des Imperialismus, S. 242-244; Charles Bloch, Die Dritte Französische Republik. Entwicklung und Kampf einer Parlamentarischen Demokratie (1870-1940), Stuttgart 1972, S.33.

10 Vgl. dazu Chastenet, Histoire de la Troisième République, Bd. 1, S. 56-64. Die unpopulärste Maßnahme war dabei die sofortige Fälligkeit der zwischen 13. August und dem 13. November 1870 gestundeten Mieten und Rechnungen. 
Die starke Sehnsucht nach sozialer Gerechtigkeit stellte Pilotell ${ }^{11}$ in einem Blatt seiner Einblattdruckserie Actualités dar: Die République sociale schlägt als Blitz über der Julisäule ein, vorbei an einer Reihe an éteignoirs erinnernden, für ihren Zweck ungeeigneten Blitzableitern: "Vos paratonnerres ne conjureront pas l'orage «' 12 .

Die Ähnlichkeit mit Daumiers bereits erwähnter Page d'histoire ${ }^{13}$ wirkt dabei wie eine bewußte Steigerung der strafenden Instanz zur handelnden Macht. Gleichzeitig wird die symbolische Szenerie durch die Julisäule eindeutig lokalisiert. An der legendären Stelle des Bastillesturms wird das durch die Französische Revolution begonnene Werk nun endgültig vollendet. Dabei wird die Julisäule jedoch nicht nur vom Mythos der Bastille überlagert: Als Hinterlassenschaft von Louis-Philippe ist sie ebenso das Symbol seines auf eine liberalistische Wirtschaftspolitik gegründeten Regimes, das dem Versprechen der République sociale diametral entgegensteht. Die materielle Symbolik des goldenen Genius wird vom blendenden Licht des Blitzes überstrahlt, die zum Himmel strebende Säule ${ }^{14}$ reicht nicht im Entferntesten an den mythischen Herkunftsort des Blitzes heran. Nichtsdestoweniger verwebt sich die Symbolik des überlegenen, natürlichen Lichtereignisses auf das Engste mit der Stadt Paris selbst. Auch Pilotells in derselben Serie publiziertes Blatt $L a$ lumière leur fait peur... ${ }^{15}$ zitiert den Lichtmythos von Paris: Als Zentrum der Revolution erscheint der Name der Stadt im Mittelpunkt der flammenden Sonne, vor deren Glanz die als Nachtvögel dargestellten Vertreter der Versailler Regierung in die Dunkelheit flüchten. Das Gegensatzpaar Paris - Versailles fügt sich im Rahmen des übermächtigen Revolutionsmythos nahtlos in das tradierte Modell Licht - Finsternis. Noch im Januar 1871 hatte Daumier die Sonne der Republik dargestellt, deren Leuchten die versammelten Monarchen Europas in Angst und Schrecken versetzt ${ }^{16}$. In Pilotells Karikatur aber

$11 \mathrm{Zu}$ Pilotells Engagement in der Commune vgl. SánCHEZ, Organizing Independence, S. 42; Tillier, La Commune de Paris, S. 316-325.

12 Blatt Nr.13., Lithographie, BnF., Est. Vgl. James A. Leirh, The War of Images Surrounding the Commune, in: Ders. (Hg.), Images of the Commune, Montreal, London 1987, S. 118, Abb. 33 .

${ }^{13}$ Schon der Titel der Sammlung - Actualités - lehnt sich explizit an die gleichnamige Serie in Le Charivari an.

14 Zur vertikalen Symbolik in der Französischen Revolution vgl. Kap. 3.1. Symbolisch war die Julisäule bereits am 24. Februar von der Revolution in Besitz genommen worden: Nach dem Vorabprotest gegen ihre Entlassung marschierten die Nationalgardisten an der Julisäule vorbei, die einer von ihnen mit der roten Fahne bekrönte. Vgl. ChaSTENET, Histoire de la Troisième République, Bd.1, S. 66. Die Fahne wurde so zum eindeutig übergeordneten Symbol erhoben.

15 Blatt Nr.21, Lithographie, BnF, Est. Vgl. Reichardr, Lumières, S. 166, Abb. 49; DuCATEL, Histoire, Bd. 1, S. 97.

16 In: Le Charivari, 21.1.1871: Leur Mane, Thecel, Phares (D 3841). Vgl. LE MEN, Lanterne magique, S.221. Die Erscheinung der flammenden Sonne nimmt Bezug auf das Gastmahl des Belsazar. 
schreckt das Licht diejenigen, die sich als die legitimen Vertreter der Republik sehen: Besonders Adolphe Thiers, als erklärter Gegner der Republik zunächst Chef der Exekutive, nach der Niederschlagung der Commune erster Präsident der Republik ${ }^{17}$, verdeutlicht die Absurdität im Verhältnis von Versailler Regierung und Republik. Die Reaktion ist dabei ebenso untrennbar und absolut mit Versailles verbunden wie der Begriff Commune mit Paris und seiner revolutionären Tradition ${ }^{18}$ : Paris allein garantiert nun die ungetrübte Leuchtkraft des republikanischen Lichts ${ }^{19}$. Wenn also in Saïds Karikatur Quelle tuile! ${ }^{20}$ Thiers und Außenminister Jules Favre hilflos vor der immensen Sonne des 18. März stehen, so ist hier der mythische Ort Paris mit dem symbolischen Neubeginn der Commune verschmolzen und erfährt so auch die Genese eines an den Ursprung zurückgeführten Revolutions- und Republikmodells.

Die Topik des neuen Tages, der die Nacht vertreibt, steht vordergründig noch ganz in der Tradition der Französischen Revolution, derer sich etwa die der Commune nahestehende Zeitung La Révolution politique et sociale häufig bedient: »Le vieux monde s'écroule. La nuit que recouvrait la terre déchire son linceul. L'aube apparaît. Salut, liberté! Salut, révolution bénie! [...] L'Aube se lève à l'horizon, la Liberté apparaît resplendissante. Il fait jour «21. Der zeitliche Abstand zwischen hoch am Himmel stehender Sonne und Morgenrot am Horizont aber spiegelt bereits den sich anbahnenden Konflikt zwischen fortschritts-optimistischer Erwartungshaltung und historischer Entwicklung. Schon in der Struktur der Commune scheint dieser Anachronismus begründet zu liegen: »C'est la première tentative historique d'un gouvernement de la classe ouvrière stimulée par une idéologie. C'est, par anticipation,

17 Zu Thiers vgl. John P. T. Bury, Robert Thombs, Thiers 1797-1877. A Political Life, London 1986; Patrick H. Hutron, Historical Dictionary of the Third French Republic, 1870-1940, London 1986, Bd.2, S. 1009 f. Auf einer etwa gleichzeitig entstandenen Karikatur von Moloch will Thiers, dargestellt als Eule, mit seinen Erlassen den Kämpfern der Commune in den Rücken fallen. Ans Licht gebracht wird seine Tat von der Personifikation der Commune mit phrygischer Mütze und entblößter Brust, die Thiers mit einem Spiegel blendet. Les Circulaires de M. Thiers. BnF., Est. Vgl. Paul DucAtel, Histoire de la III' République vue par la presse satirique et l'imagerie populaire, 4 Bde., Paris 1973-1978, Bd. 1 (1973), S. 108.

18 Chastenet, Histoire de la Troisième République, Bd. 1, S.82f.: „Pour la masse, le mot [Commune] évoquait surtout le souvenir des grandes journées révolutionnaires de 1793, alors que la Commune (c'est-à-dire la municipalité) parisienne faisait trembler la Convention et que, par son intermédiaire, le peuple de Paris régissait la France«. Darin manifestiert sich auch der Kontrast zu den größtenteils royalistischen, aus der Provinz stammenden Abgeordneten - den ruraux - der Assemblée nationale in Bordeaux. Ibid., S. 84.

19 Ibid.: »Paris est profondément, mystiquement républicain«.

20 Actualités, Blatt 2. Vgl. Brebeck, Charmeil, Entstehung der Dritten Republik, Kat.20; LeITH, War of Images, S. 119; DuCATEL, Histoire, Bd. 1, S. 97.

${ }^{21}$ In: La Révolution politique et sociale, 9.4.1871. Zu dieser Zeitung vgl. MaIlLARD, Histoire, S. 191. 
la première des révolutions du $\mathrm{XX}^{\mathrm{e}}$ siècle ${ }^{22}$. Das Scheitern der Commune als vorweggenommener Gesellschaftsentwurf wirkt sich explizit auf die sozialistische Lichtsymbolik der III. Republik aus. Die Sonne wird an den fernen Horizont entrücken, der den zeitlichen Abstand symbolisierende Raum muß erst noch überwunden werden ${ }^{23}$. Im Kontext der Commune jedoch ist dieser Schritt für Paris sowohl ideell als auch räumlich bereits vollzogen: Das Motiv der Sonne am Horizont symbolisiert in der Karikatur der Commune die unmittelbare Verwirklichung der verheißungsvollen Zukunft, wie ein weiteres Blatt von Saïd verdeutlicht ${ }^{24}$ : Die zweigeteilte Darstellung zeigt einen Angehörigen der besitzenden Klasse, der vor der aufsteigenden Sonne mit der Inschrift Commune - 1871 flieht: »Celui qui possède: ça va mal«. Der Reiche ist aber ausgemergelt, im Gegensatz zum wohlgenährten Arbeiter, der dieselbe Sonne genießt: „Celui qui n'a rien: ça va bien«. Vorweggenommen ist also eine Verschiebung des Reichtums in der Gesellschaft, und zwar gelöst von materiellen Werten: Die Geldsäcke und das Portefeuille, das der vor dem Licht fliehende Reiche mit sich trägt, haben offensichtlich keinen Wert mehr und können ihn nicht mehr ernähren. Die Hoffnungen, die der Arbeiter in die Republik setzt, werden dagegen durch die Commune garantiert ${ }^{25}$.

Die Machtergreifung findet ganz unverkennbar als (Rück-)Eroberung des (Licht-)Raumes statt, und manifestiert sich als Rückkehr der durch die Haussmannschen Reformen ${ }^{26}$ an die Peripherie abgedrängten ärmeren Bevölkerungsschichten ins Zentrum, als »reconquête de la Ville par la Ville ${ }^{27}$.

22 Alain Rex, Révolution. Histoire d'un mot, Paris 1989, S.221f. Die Stellung der Commune in der Revolutionsgeschichte ist zweifellos von verschiedenen Standpunkten aus unterschiedlich zu bewerten. Die große Häufung von Faktoren, die in der III. Republik Politik und Gesellschaft prägen sollten, verdeutlicht allerdings die Schlüsselstellung dieses Ereignisses für die Einleitung tiefgreifender gesellschaftlicher Paradigmenwechsel. René RÉMOND, L'anticléricalisme en France de 1815 à nos jours, Paris ${ }^{2} 1999$, S. 168, hebt den kompromißlosen Antiklerikalismus und Atheismus hervor: »son irreligion avance l'avenir «.

${ }^{23} \mathrm{Vgl}$. Kap.9.3. Vgl. auch Alain Pessin, Le mythe du peuple et la société française du XIX ${ }^{c}$ siècle, Paris 1992, S.23: »Ainsi, s'il est vrai que spiritualiser le progrès, c'est le mettre à distance, en faire un objectif plus lointain, sinon un but incertain, réciproquement c'est concevoir la philosophie de l'histoire autrement que comme exercice de style et de pure logique $\ll$.

${ }^{24}$ LeITH, War of Images, S.122, Abb. 39.

25 Chastenet, Histoire de la Troisième République, Bd. 1, S. 84: „C'est avec enthousiasme qu'au Quatre Septembre l'ouvrier parisien a salué la proclamation de la République. La République, c'est pour lui la justice sociale, le relèvement de sa condition, l'avènement politique de la classe à laquelle il appartient «.

26 Dazu Jeanne Gaillard, Paris, la ville. 1852-1870, Paris ${ }^{2} 1997$. Zur bildlichen Darstellung vgl. Margret Kampmeyer-Käding, Paris unter dem zweiten Kaiserreich. Das Bild der Stadt in Presse, Guidenliteratur und populärer Graphik, Marburg 1990.

27 Jacques Rougerie, Paris libre 1871, Paris 1971, S. 19: »La Commune de 1871, ce sera, pour une large part, la reprise du Paris central, du Paris véritable, avec son hôtel de ville par les exilés des quartiers extérieurs, de Paris par ses vrais Parisiens, la reconquête de la Ville par la Ville« (Großschreibung von Rougerie). 
Die Beseitigung des unüberschaubaren, für Unruhen geradezu prädestinierten Gewirrs der mittelalterlichen Gassen durch die baulichen Maßnahmen Napoleons III. stellte sich ihrerseits als »conquête politique ${ }^{28}$ dar, mehr noch, als »une manifestation d'ordre social ${ }^{29}$, die eine Schaffung zweier gegensätzlicher Städte zu Folge hatte, »celle des riches et celle des autres $\aleph^{30}$. Die Umgestaltung des Zentrums, die raumöffnenden percements, die Anlage großzügiger Plätze und Boulevards sowie die konsequente Begrünung der Stadt wurden als veritabler Ausdruck zivilisatorischen Fortschritts begrüßt, wie besonders in Théophile Gautiers berühmtem Vergleich mit der Schaffung einer Kulturlandschaft durch die amerikanischen Siedler:

La civilisation, qui a besoin d'air, de soleil, d'espace pour son activité effrénée et son mouvement perpétuel, se taille de larges avenues dans le noir dédale des ruelles, des carrefours, des impasses de la vieille ville; elle abat les maisons comme le pionnier d'Amérique abat les arbres. Dans son genre, elle aussi défriche ${ }^{31}$.

Dabei tritt der Aspekt der Reinigung besonders in den Vordergrund, und zwar in direkter Verbindung zur sozialen Hygiene:

La ville [...] s'aère, se nettoie, s'assainit et fait sa toilette de civilisation: plus de quartiers lépreux, plus de ruelles miasmatiques, plus de masures humides, où la misère s'accouple à l'épidémie et trop souvent au vice. Plus de tanières immondes, réceptacles du rachitisme et des scrofules. Les murailles pourries, salpêtrées et noires sont marquées du signe purificateur et s'effondrent pour laisser surgir de leurs décombres des habitations dignes de l'homme, dans lesquelles la santé descend avec l'air, et la pensée sereine avec la lumière du soleil ${ }^{32}$.

Die Zerstörung von günstigem Wohnraum in den vieux quartiers und die extreme Steigerung der Grundstückspreise zwangen große Teile der ärmeren Bevölkerungsschichten, in die neuen communes annexées im Osten der Stadt zu ziehen ${ }^{33}$, wo die ungesunden Lebensbedingungen ihre Fortsetzung fanden. Im Jahr 1870 prangerte Louis Lazare diese als véritables Sibéries ${ }^{34}$ an, wo es von Straßenbeleuchtung und -befestigung bis hin $\mathrm{zu}$ sauberem Wasser an allem mangelte - »droits refusés à la Ville de Paris, d'où part le rayonnement qui éclaire le monde! «35. Das neue Paris präsentierte sich im Gegenzug als

28 Gaillakd, Paris, la ville, S. 30 .

29 Ibid., S.430.

${ }^{30}$ Ibid., S. 67.

31 Théophile Gautier, Mosaïue des ruines, in: Paris et les Parisiens au XIXe siècle, Paris 1856, S. 40. Der Abriß des Alten als unabdingbare Voraussetzung für die Entstehung des Neuen findet sich auch in der Bildsprache des Anarchismus wieder, worin sich die Wechselwirkung von conquête - reconquête fortsetzt. (Vgl. dazu Kap.9.2.1 und 9.3.)

32 Ibid., S. 42.

33 Galllakd, Paris, la ville, S. 430: "Ce projet propose une hiérarchisation de l'espace urbain qui refoule les populations les plus pauvres vers la périphérie«. Vgl. auch John M. Merriman, Aux marges de la ville. Faubourgs et banlieues en France 1815-1870, Paris 1994 , S. 289 f.

${ }^{34}$ Louis Lazare, Les quartiers de l'est de Paris et les communes suburbaines, Paris 1870 , S. 63 .

35 Ibid., S. 235. 
gesäuberter und befreiter Fortschrittsraum, in dem die Lichtsymbolik der modernen Großstadt ihren Ursprung hat ${ }^{36}$.

Die Rückeroberung durch die Commune betrifft aber nicht nur den äußerlich sichtbaren Lichtraum, sondern auch den ideellen Lichtmythos von Paris als Wiege und Verfechterin der lumières, wie es besonders Victor Hugos »Introduction « zum anläßlich der Weltausstellung von 1867 verfaßten Paris Guide zum Ausdruck bringt:

La fonction de Paris, c'est la dispersion de l'idée. Secouer sur le monde l'inépuisable poignée des vérités, c'est son devoir et il le remplit. [...] Paris est un semeur. Où sème-t-il? Dans les ténèbres. Que sème-t-il? Des étincelles. [...] Le magnifique incendie du progrès, c'est Paris qui l'attise. [...] Voilà trois siècles surtout que Paris triomphe dans ce lumineux épanouissement de la raison, qu'il envoie de la civilisation aux quatre vents ${ }^{37}$.

Hinter der vorgeschobenen Übersteigerung des Besuchs der Weltausstellung versteckt er dabei den in die Zukunft weisenden Entwurf einer universalen Republik mit Paris als Zentrum:

Ces yeux saturés de nuit viennent regarder la vérité. Le lever lointain du Droit Humain a blanchi leur sombre horizon. La Révolution française a jeté une traînée de flamme jusqu'à eux. Les plus reculés, les plus obscurs, les plus mal situés sur le ténébreux plan incliné de la barbarie ont aperçu le reflet et entendu l'écho. Ils savent qu'il y a une ville soleil; ils savent qu'il existe un peuple de réconciliation, une maison de démocratie, une nation ouverte ${ }^{38}$.

Die Inbesitznahme dieser mythischen ville solaire - wie sie in Pilotells Karikatur La lumière leur fait peur ihren visuellen Ausdruck findet - als espace populaire und espace révolutionnaire ${ }^{39}$ verdeutlicht den Anspruch auf das Erbe

36 Vgl. Alain Corbin, Le sang de Paris. Réflexions sur la généalogie de l'image de la capitale, in: Ders., Le temps, le désir et l'horreur. Essais sur le dix-neuvième siècle, Paris, 1991, S. 222: "La ville, épurée, que le peuple n'ensanglante plus, semble sortir du cauchemar. La netteté de l'espace public, nettoyé, désodorisé, protégé de toutes sortes d'épanchements, de stagnations et de fermentations, le déferlement des lumières, la circulation salutaire des produits et des êtres vulgivagues préparent le temps de l'extraversion, de l'ostentation, de l'exposition, la prolifération de la vitrine et le règne de la marchandise «. Allg. zur Entwicklung von Paris zum Modell der modernen Stadt vgl. Andreas Wirsching, Paris in der Neuzeit (1500-2000), in: Andreas SoHN, Hermann Weber (Hg.), Hauptstädte und Global Cities an der Schwelle zum 21. Jahrhundert, Bochum 2000, S. 103-128.

37 Victor Hugo, Introduction, in: Paris Guide, Paris 1867, S. XXVIf. Vgl. dazu Priscilla Parkhurst Ferguson, Paris as Revolution. Writing the Nineteenth Century City, Berkeley 1994, S. 75: "Hugo finds in the Revolution the metaphor that will unify that fragmented civilization and the city that is its center $\ll$.

Von seinem Exil auf der Kanalinsel Guernsey aus findet Hugo dabei einen Weg, den Lichtmythos Paris als direkten Gegensatz zum II. Empire zu metaphorisieren: »Au moment où nous sommes, la coalition nocturne des vieux préjugés et des vieux régimes triomphe et croit Paris en détresse, à peu près comme les sauvages croient le soleil en danger pendant l'éclipse «. Hugo, Introduction, S. XXXIV.

38 Ibid., S.XLIII.

39 Vgl. dazu Jacques Rougerie, Espace populaire et espace révolutionnaire: Paris 1870-71, in: Institut d'histoire économique et sociale de l'université de Paris I: recherches et travaux. Bulletin 5 (1977), S. 77: »Et c'est surtout peut-être à la lumière [...] des événements 
des Licht- und Freiheitsmythos ${ }^{40}$. Der durch die Haussmannschen Reformen äußerlich geweitete und geöffnete Raum wird nun auch im ideellen Sinne für alle zugänglich ${ }^{41}$ und fügt sich so in das Muster des revolutionären Neubeginns und der Neuerstehung des Menschen ${ }^{42}$.

révolutionnaires de 1870-1871 qu'on peut tester cette capacité de lutte et de résistance qui me paraît l'un des caractères fondamentaux de cet espace populaire révolutionnaire«.

40 Albert Borme, Art and French Commune. Imagining Paris after War and Revolution, Princeton 1995, S. 5: "The Commune tried to carve out a democratic public space where people of all classes could meet and interact on a plane of equality. Despite their fumbling and differences, the Communards shared a hope of maximizing freedom and autonomy the city offered and of making these available to all classes and groups. The cessation of normal work and trade during the brief Commune period granted a rare opportunity to working-class men and women to promenade along the boulevards and in the parks and to mingle with other classes during weekdays".

${ }^{41}$ Auch im Werk des Schriftstellers und aktiven Communarden Jules Vallès wird das Paris der Commune als geöffnetes Zentrum dargestellt. Vgl. dazu Marie-Claire BancQuarT, Paris »fin-de-siècle«. De Jules Vallès à Remy de Gourmont, Paris 2002, S. 63 f.

${ }^{42} \mathrm{Vgl}$. Jacques Rougerie, Paris insurgé: La Commune de 1871, Paris 1995, S.87: »Les hommes de 1871 eurent [...] l'immense ambition - ou l'extraordinaire illusion - d'en finir avec le vieux monde, de réaliser enfin le rêve d'une humanité réconciliée. De même la Révolution avait voulu accomplir la régénération de l'homme«. 


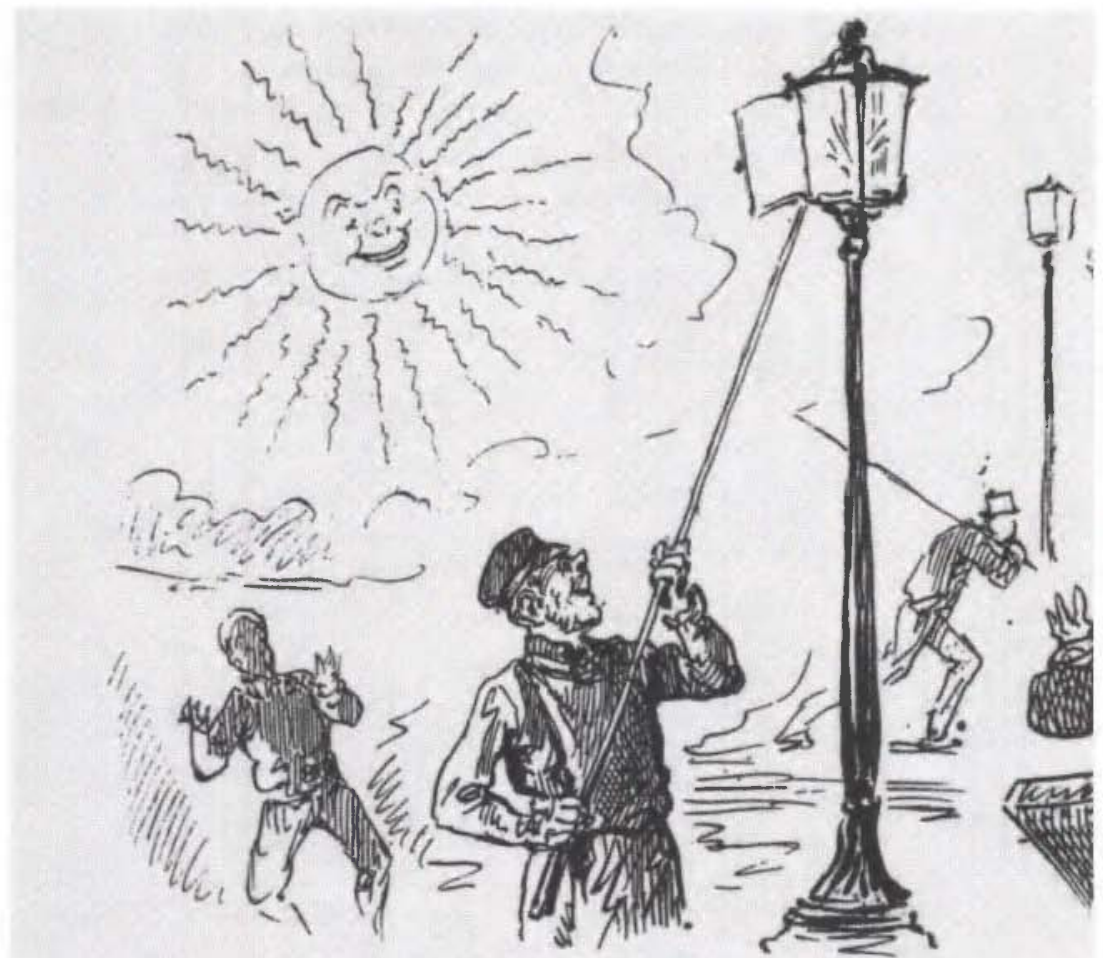

Los allumeuss de gal aynonl demande, eux aussi, a lmaviller fo joul.

Abb. 4 Darjou: Revue du mois de mai. Les allumeurs de gaz ayant demande, eux aussi, à travailler le jour, in: Le Grelot, 4.6.1871. Bibl. Forney, Paris.

\section{2. »Paris brûlait! Mais pourquoi Paris brûlait-il?« Das $>$ Licht $<$ der Commune: Aufklärung >von unten< und Feuerinferno}

Gerade die Demokratisierung von Raum und Zeit wurde in der gegen die Commune gerichteten Bildpropaganda als Angriff auf die Ordnung empfunden, der den Verlust jeglicher Orientierung nach sich zog: Wenige Tage nach der Niederschlagung der Commune etwa veröffentlichte das Satiremagazin Le Grelot eine Zeichnung von Darjou: Revue du mois de mai. Les allumeurs de gaz ayant demandé, eux aussi, à travailler le jour ${ }^{43}$ (Abb.4). Die Zeichnung bezieht sich konkret auf das am 29. April unter der Commune erlassene Dekret, das die Nachtarbeit in Bäckereien verbot ${ }^{44}$. Das Beispiel des Laternenanzünders, der durch die Verlegung seiner Arbeitszeit den Sinn seiner Tätigkeit ad absurdum führt, beschuldigt die Communarden der Verbreitung eines

43 In: Le Grelot, 4.6.1871.

44 William Serman, La Commune de Paris, Paris 1986, S. 579. 


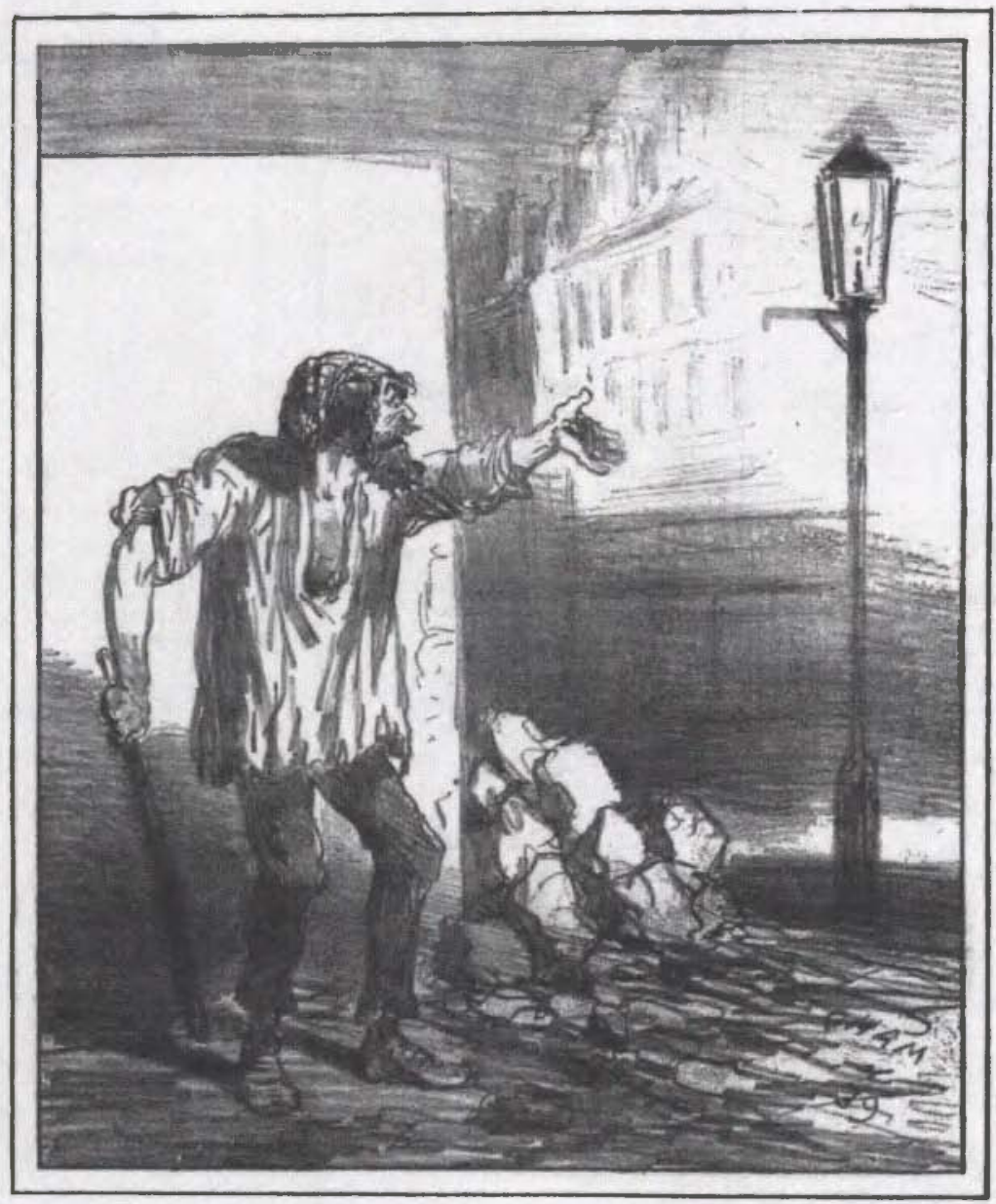

- Allons, bonl le gue qui revient artéter los aflifics:

Abb. 5 Cham: Allons, bon! Le gaz qui revient arreter les affaires!, in: Le Charivari, 23. 3.1871. UB Frankfurt.

überflüssigen Lichts, während gleichzeitig die erhellende Funktion des Laternenlichts in der Nacht aufgehoben wird. Das Licht als ordnendes Element im städtischen Raum erscheint so als eine Art natürlicher Feind des Unruhestifters, wie auch aus einer Karikatur von Cham hervorgeht, die am 23. März 1871 in Le Charivari veröffentlicht wurde: Angesichts einer brennenden Gaslaterne ruft ein abgerissener Communarde aus: "Allons, bon! Le gaz qui revient arreter les affaires!« (Abb.5) Nur wenige Tage nach dem 18. März scheint die 


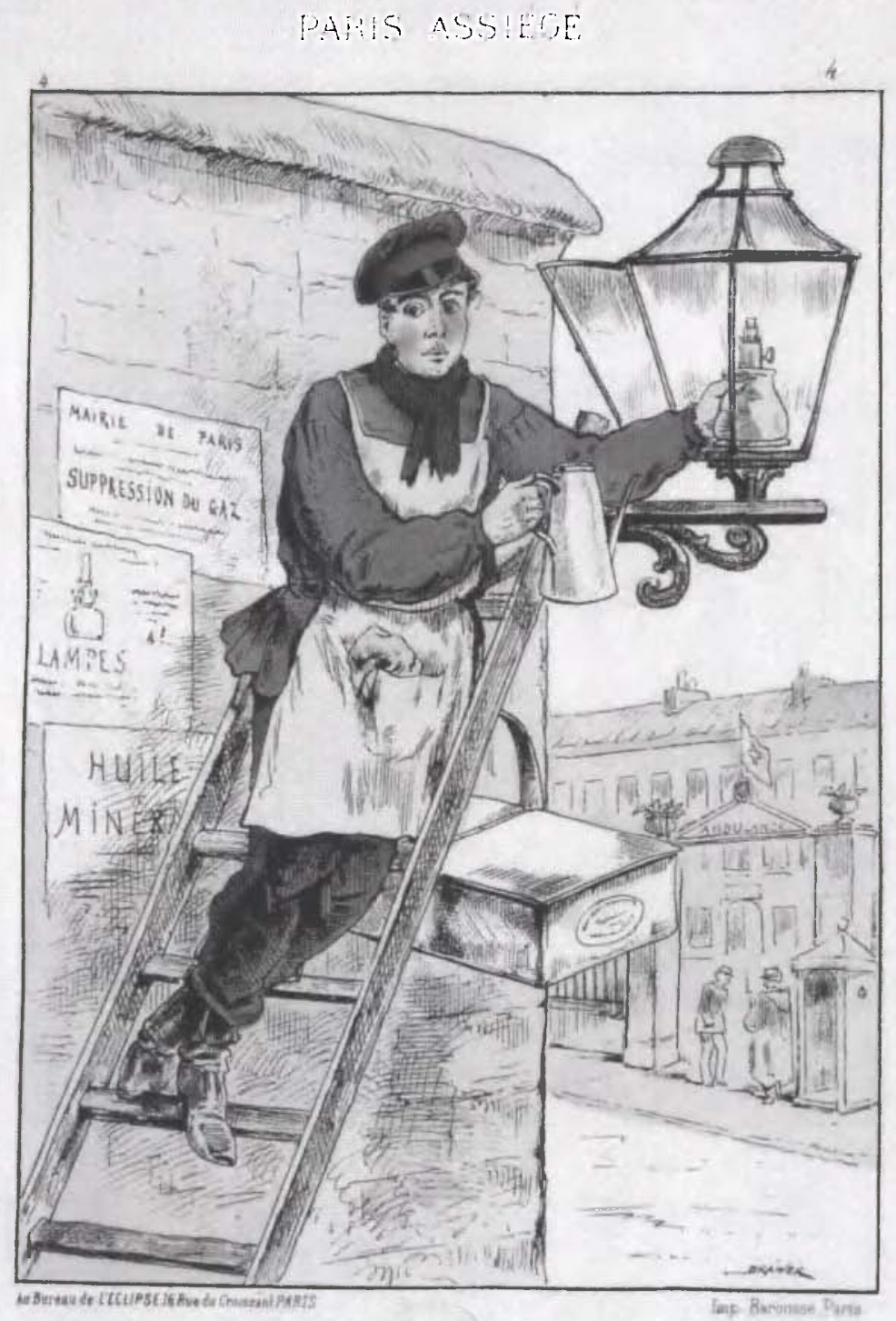

L'ECLAIRAGE:

- Ea parle de civilisation, les Allethunds, el ca voudrail nons priver de lumere.... Ah ! malheur! . etet le petrole done!

Abb. 6 Draner: L'Éclairage. Ça parle de civilisation, les Allemands, et ça voudrait nous priver de lumiere... Ah! malheur! Et le petrole donc!, in: Paris assiege. Scenes de la vie parisienne pendant le siege, Bild 4. Bibl. Forney, Paris. 
Ordnung noch garantiert zu sein, scheint das durch die Laterne domestizierte Licht noch seine Zivilisations- und Überwachungsfunktion zu erfüllen, wodurch es gleichzeitig ins Visier der Aufrührer gerät. Während der Belagerung war die Kulturleistung des Straßenlichts schon einmal in Gefahr: Draner zeigt in seinem kurz nach der Niederschlagung der Commune veröffentlichten Album Paris assiégét ${ }^{45}$, wie ein französischer Soldat eine Straßenlaterne mit Petroleum befüllt, was er folgendermaßen kommentiert: »Ça parle de civilisation, les Allemands, et ça voudrait nous priver de lumière... Ah! malheur! et le pétrole donc!«(Abb.6). Die strenge Rationierung der Straßenbeleuchtung $^{46}$ und der Rückfall in eine überwunden geglaubte nächtliche Dunkelheit war das sinnfälligste Zeichen eines gefühlten Niedergangs der Stadt ${ }^{47}$. Die gedankliche Verbindung zwischen Zivilisation und Licht auf der einen und dem Petroleum nicht nur als schlechtem Ersatz, sondern als Unglückssymbol auf der anderen Seite beinhaltet eine vielschichtige Verquickung von positiven und negativen Lichtassoziationen.

Die Ambivalenz kommt dabei schon im Symbol der Straßenlaterne zum Ausdruck: Als Medium des Aufklärungslichts durchlief die Laterne in der Französischen Revolution eine erstaunliche Karriere, die in direkter Verbindung zu ihrer sozialgeschichtlichen Bedeutung stand: Im Jahr 1667 wurde die Laternenbeleuchtung von Ludwig XIV. eingeführt ${ }^{48}$. Eine im selben Jahr geprägte Medaille verherrlicht ihn dafür als Erheller der Nacht ${ }^{49}$. Die Lichtsymbolik des Sonnenkönigs wurde so direkt auf die Überwindung der natürlichen Nacht bezogen: Die Laternen fungierten dabei als »die neuen Hoheitszeichen, die demonstrierten, in wessen Namen sie die Straße beleuchteten und beherrschten ${ }^{50}$. In den im 17. und 18. Jahrhundert in Paris immer wieder ver-

${ }^{45}$ L'Éclairage: Abbildung 4 des Albums. Allg. zu diesem Album Gerhard LANGemeYer (Hg.), Bilderwelten. Französische Illustrationen des 18. und 19. Jahrhunderts aus der Sammlung von Kritter, Dortmund 1985, S.214, Kat. 123. Vgl. zu diesem Blatt auch Kap. 5.2.2.

46 Auf einem im Hintergrund angeschlagenen Plakat steht Suppression du gaz zu lesen, andere werben für Petroleumbeleuchtung oder Mineralöl. Victor Hugo notierte am 13.4.1871: "Paris, muré de nouveau, s'éclaire de nouveau au pétrole. Plus de gaz«. Victor Hugo, Carnets de la guerre et de la Commune 1870 et 1871, in: Ders., CEuvres complètes. Bd. 13, Paris 1985, S. 1125. Zur Beleuchtung während der Belagerung vgl. Victor DeBuchY, La vie à Paris pendant le siège 1870-1871, Paris 1999, S.67f.

47 Dazu Hollis Clayson, Paris in Despair. Art and Everyday Life under Siege (1870-71), Chicago 2002, S.51-55. Ibid., S.52: „From the standpoint of the Parisian elite, the lack of gaslight in even the best parts of town was a conspicious marker of the city's diminshed prestige, and an eminently visual reminder of its destruction, changed ambiance, and tarnished luster. The submersion into unwanted, old-fashioned dark was invoked as a sign of the physical and moral decline of Paris

48 Ernst Rebske, Lampen - Laternen - Leuchten. Eine Historie der Beleuchtung. Stuttgart 1962, S. 17.

49 Schivelbusch, Lichtblicke, Abb.S.88.

50 Ibid., S. 88. Craig Koslofsxy, Court Culture and Street Lighting in Seventeenth-Century Europe, in: Journal of Urban History 28 (2002), S. 743-768, legt dar, daß die Einführung der Straßenbeleuchtung im 17. Jahrhundert in London, Paris und deutschen Städten stets vom Hof und nicht von der Stadtverwaltung ausging. 
meldeten, jedoch nicht systematischen Laternenzerstörungen ${ }^{51}$ lassen sich Rebellionen gegen die Allgegenwärtigkeit des königlichen Lichts erkennen und der Wille, »symbolisch die Herrschaft auszulöschen, die die Laterne repräsentierte $\aleph^{52}$. Die Verfügbarkeit der Nachtbeleuchtung schuf gleichzeitig aber ein stetig wachsendes Bedürfnis nach Licht und auch Sicherheit, was Daniel Roche treffend als »changement culturel profond et global« bezeichnet ${ }^{53}$.

Die blutigen Ausschreitungen zu Beginn der Revolution markierten als Steigerung dieses neuen Verhältnisses zum Licht die Entwicklung der StraBenlaterne zum politischen Symbol. Seinen prägnanten Ausdruck fand dies in dem Lied Ça ira, dessen Refrain lautete: »Les aristocrates à la lanterne $\ll^{54}$.

In der Bildpublizistik stempelt die Laterne alle $\mathrm{zu}$ Lichtfeinden, die vor ihr fliehen und erinnert wie ein memento mori an die Allgegenwart des strafenden Lichts ${ }^{55}$. Das Blatt Les Aristocrates à Lanternopolis ${ }^{56}$ etwa zeigt, wie der Gang durch die Rue de la Lanterne in der Laternenstadt für Adel und Geistliche zum Spießrutenlauf wird: »La peste soit des lanternes, elles feront notre perte«. Die Angst der alten Eliten vor der Laterne wird so zur Bestätigung für ihre Lichtscheuheit: Auf der Darstellung Les Voyageurs de nuit ${ }^{57}$ wird die nächtliche Flucht eines Adeligen und eines Geistlichen von einem Bauern sans Licht gebracht،. Die Laterne wird von dem Aristokraten sofort als Schreckenssymbol erkannt: "je crois voir la fatale lanterne de la place de Grève«. Die Bevorzugung der Nacht spielt auch auf die als dekadent angeprangerte Umkehrung von Tag und Nacht durch die höfische Gesellschaft an $^{58}$ und die Umkehrung der natürlichen Ordnung.

\section{SChivelbusch, Lichtblicke, S.98-100. \\ 52 Ibid., S. 98.}

53 Daniel Roche, Histoire des choses banales. Naissance de la consommation XVII ${ }^{\mathrm{e}}$ XIX siècle, Paris 1997, S.126: Besonders wenn aus Gründen der Sparsamkeit die Laternen in 15 bis 30 Nächten pro Jahr nicht entzündet wurden, protestierten die Pariser, wie vor allem im Jahr 1698, als der Unmut sich in einem Lied äußerte, das in aller Munde war. Ibid.: »On peut dater précisément de cette affaire la manifestation d'un besoin collectif. Enfin, cette sensibilité nouvelle atteste le déplacement qui s'est produit entre le diurne et le nocturne, le recul d'une situation naturelle grâce à l'action des aménagements dans la police de la cité. Éclairer la nuit [...] est devenu indispensable«.

54 Dazu Schivelbusch, Lichtblicke, S. 100: "Die Laternen herunterzuholen und statt ihrer die Vertreter der alten Ordnung aufzuhängen, das war eine blutige Umdeutung der alten Ordnungssymbolik «. Zu Ursprung und Verbreitung des Ça ira vgl. Alexandre RoGer, Les mots qui restent. Répertoire de citations françaises, expressions et formules proverbiales, avec une indication précise des sources, Paris 1901, S.3.

55 Dazu Reichardt, Lumières, S. $125 \mathrm{f}$.

56 Vovelle, Image et récit, Bd.2, S.323. Vgl. dazu auch Klaus Herding, Diogenes als Bürgerheld, in: Ders., Zeichen, S. 174.

57 Ibid., S. 205.

58 Richard Alewyn, Das große Welttheater. Die Epoche der höfischen Feste, München 21985, S. 38: „Erst nach Sonnenuntergang beginnt das höfische Fest. [...] Und wenn in der Dämmerung die Karossen vom Hofe heimkehren, begegnen sie in den Gassen den Bürgern, die sich an ihre Arbeit begeben«. Die Scheu vor dem Licht als Zeichen der Dekadenz hat ihre Ursprünge bereits in der römischen Republik, wo die vita umbratilis den 
Aufgrund dieser Radikalisierung erschien die Laterne nach der Französischen Revolution in der Bildpublizistik vorwiegend als unheilvolles Relikt der jakobinischen Terreur: Eine anonyme Karikatur in La Charge ${ }^{59}$, seit 1832 das offizielle Gegenorgan zu Philipons Zeitschrift La Caricature, zeigt die Republik als heruntergekommene Alte mit phrygischer Mütze, Beil und einem Korb, der neben einer Miniaturguillotine und Dolchen auch Textrollen wie Liberté de la presse oder Liberté individuelle enthält. Als Kolporteurin bietet die Alte das republikanische Glück an: »Régalez-vous, Messieurs, Mesdames. Voilà l'plaisir! « ${ }^{60}$ Hinter ihr hängt an einem Galgengestell eine Laterne, in der ein Schmetterling eingeschlossen ist. Das aus der barocken Emblematik stammende Bild des Falters, der dem verlockenden Kerzenschein nicht widerstehen kann und darin zugrunde geht ${ }^{61}$, symbolisiert die verderbliche Wirkung des republikanischen Lichts und nimmt das Schicksal derer vorweg, die sich auf das Angebot der Alten einlassen.

Vierzig Jahre später werden in den Laternenszenen von Darjou und Cham dagegen die Attribute Lichtfeindschaft und Umkehrung der natürlichen Ordnung wieder aufgegriffen, nun aber den Revolutionären selbst, den Communarden zugeteilt. Die öffentliche Beleuchtung wird also auf ihren ursprünglichen semantischen Kosmos als Herrschaftssymbol und Vergegenwärtigung der domestizierten, zivilisierten Nacht zurückgeführt.

Dabei offenbart Chams vor dem Licht kapitulierender Communarde bereits einen Bruch in der revolutionären Tradition des 19. Jahrhunderts: Während der Revolution von 1830 und den Unruhen unter der Julimonarchie begleitete die systematische Zerstörung der gesamten Straßenbeleuchtung alle Volkserhebungen gegen die Obrigkeit ${ }^{62}$. Zu der symbolischen Komponente trat die strategische Ausnutzung der Dunkelheit bei Straßen- und Barrikadenkämpfen ${ }^{63}$. Schon während der Revolution von 1848 aber nahmen die Laternenzerstörungen proportional zur Ersetzung der Ölbeleuchtung durch

Gegensatz zur militärischen Zucht darstellte. Die christlichen Autoren übernahmen den Begriff der vita umbratilis als Ausdruck des sündigen, den irdischen Vergänglichkeiten verhafteten Lebens. Vgl. dazu Volkmar Hölzel, Umbra. Vorstellung und Symbol im Leben der Römer, Marburg 1955, bes. S. 108, S. 146-149.

${ }^{59}$ La Charge, 29.9.1833. Vgl. dazu Raimund Rürten, Die republikanische Opposition und die Zensur, in: Ders. u.a. (Hg.), Die Karikatur zwischen Republik und Zensur, S. 87: "Der ikonographische Diskurs der Charge verarbeitet die soziale Bedrohung, die das 'juste milieu < [...] seitens der arbeitenden Klassen erfährt«.

60 Ibid. S. 89, Abb. 99.

61 Otto van Veen, Brevis et damnosa voluptatis, in: Ders., Amorum emblemata, Anvers 1608, S. 103. Vgl. dazu auch Paulette CHONÉ, L'Atelier des nuits. Histoire et signification du nocturne dans l'art d'Occident, Nancy 1992, S.82f.; zum politischen Kontext vgl. Fischer, Wer löscht das Licht, S.130-138.

62 SChivelbusch, Lichtblicke, bes. S. 104-106; ibid., S. 100; »In den Pariser Revolutionen und Aufständen des 19. Jahrhunderts fand die bis dahin individuell-libertine Laternenzerstörung eine Steigerung ins Kollektiv-Plebejische«.

${ }^{63}$ Ibid., S. 105 . Vgl. dazu ausführlich Simone Delattre, Les douze heures noires. La nuit à Paris au XIX ${ }^{\mathrm{e}}$ siècle, Paris 2000, S. 106-111: »La nuit des insurgés«. 
Gaslaternen $\mathrm{ab}^{64}$. Die Laterne wurde im Zeitalter der Gasbeleuchtung nicht mehr "als Individuum wahrgenommen, dessen Licht stellvertretend ausgelöscht werden konnte « ${ }^{65}$. Wurden noch 1848 die Pariser Gaswerke als neue Ziele der kollektiven Lichtauslöschung militärisch vor den Aufständischen geschützt ${ }^{66}$, so konnte die monopolistische Compagnie parisienne d'éclairage et de chauffage par le gaz $^{67}$ die Communarden 1871 mit der Drohung, die Gaslaternen auszuschalten, in Schach halten ${ }^{68}$. Diese Entwicklung belegt, daß die Straßenbeleuchtung nunmehr als positives Instrument nutzbar gemacht wurde. Die Aufständischen suchten ihren Vorteil nicht mehr in der Erzeugung von absoluter Finsternis: Die Verfügbarkeit des künstlichen Lichts hatte sich somit seit dem 17.Jahrhundert allmählich von einem kulturellen zu einem politisch-demokratischen Anliegen gewandel $t^{69}$.

Die Macht der Commune über das Licht aber stellte sich für das bürgerliche Lager ausschließlich als Machtmißbrauch von Feuer und von zur Brand-

64 Schivelbusch, Lichtblicke, S.105. Vgl. auch Delattre, Les douze heures noires, S. 85-90. Allg. zur Rolle der Arbeiter in der Revolution von 1848 vgl. Andreas Wirsching, Arbeiter und Arbeiterbewegung in Paris in vergleichender Perspektive, in: Jürgen Voss u. a. (Hg.), Paris und Berlin in der Revolution 1848, Sigmaringen 1996, S. 161-185.

65 Schivelbusch, Lichtblicke, S. 110.

66 Ibid., S. $110 \mathrm{f}$.

${ }^{67}$ Jean GAY, L'amélioration de l'existence à Paris sous le règne de Napoléon III, Genf 1986, S.73f.: Die Compagnie wurde am 19.September 1855 durch die Fusionierung mehrerer Einzelgesellschaften gegründet.

68 Leonard R. Berlanstein, Big Business and Industrial Conflict in Nineteenth Century France. A Social History of the Parisian Gas Company, Berkeley u.a. 1991, S.37. Auf diese Weise erhielt die Gesellschaft auch die ihr gestohlene Summe von 183000 Francs zurück. Zudem war es nicht gelungen, die Gasarbeiter auf die Seite der Commune zu ziehen. Vgl. Maxime Du CAMP, Paris. Ses organes, ses fonctions, et sa vie dans la seconde moitié du XIX ${ }^{\mathrm{e}}$ siècle, Bd. 5, Paris ${ }^{3} 1875$, S. 304: »Pendant cette époque détestable, tout le personnel de l'usine fut à son poste [...]. Ce n'est pas qu'on ne l'ait sollicité de se joindre à l'insurrection, mais il fut inébranlable. [...] les ouvriers gaziers levèrent les épaules, mirent les faiseurs de propagande à la porte et les engagèrent à n'y plus revenir«.

69 Vgl. dazu Kap.9.1.1.: Im Laufe der III. Republik entwickelte sich die Gaslaterne zum Armutssymbol, das ein System repräsentierte, dem es nicht gelang, das Lichtbedürfnis der unteren Schichten zu befriedigen. Der hierin liegende Symbolcharakter der Gaslaterne als stummer und tatenloser Zeugin des Elends und - wiederum - allgegenwärtigem Überwachungsinstrument entstand in dem Moment neu, als die herrschenden Schichten die hierarchische Ordnung wieder herstellten. Exemplarisch wird dieser Wendepunkt durch Edouard Manets 1873 entstandende Lithographie La Barricade markiert, auf der die Erschießung eines Aufständischen dargestellt ist. Vgl. BLÜHM, LIPPINCoTT, Light, S.156: »The street lamp plays the role of mute spectator to these events. Not coincidentally, it is placed exactly at the vanishing point. It is a symbol of modernity and enligthenment, of the rule of law and humanity - principles which here fell victim to willful despotism«. Vgl. dazu auch Tillier, La Commune de Paris, S. 280-282, der das Blatt als Vorstudie zu einem nicht ausgeführten Gemälde identifiziert. Auch die bereits auf den Stein übertragene Lithographie blieb bis zum Tod des Künstlers 1883 unausgeführt: »Perceptible chez Manet, l'autocensure des artistes de cette génération devant la Commune fut à l'œuvre et indique qu'ils ne parvinrent pas à faire de cet événement le sujet de leur œuvre« (ibid., S.282). Zum Phänomen der kulturellen Verdrängung der Commune vgl. Kap. 5.3. 
legung verwendetem Petroleum dar, was sofort zur Identifikation von Communarden und Brandstiftern führte. Diese Verbindung wurde durch eine tiefsitzende Angst vor der politisch motivierten Feuerlegung und Verbrennung, die das ganze 19. Jahrhundert durchzieht, um so brisanter ${ }^{70}$. Die feste Verankerung dieses Bildes im Bewußtsein der III. Republik ist nicht zuletzt darauf zurückzuführen, daß ein Großteil der gegen die Commune gerichteten Karikatur erst nach der semaine sanglante entstand ${ }^{71}$ und somit bereits den geronnenen Mythos von brandschatzenden Anarchisten und furiosen pétroleuses reflektiert und ausschmückt $\mathrm{t}^{72}$.

Die Mutation des gleichermaßen kontrollierenden und kontrollierten (Laternen-)Leuchtlichts zum sich rasch ausbreitenden Feuer korrespondiert so mit der verheerenden Wirkung einer entfesselten Masse ${ }^{73}$. Besonders das Requisit der Fackel markiert den neuralgischen Punkt zwischen Lichtbeherrschung und Lichtentgleisung:

La souveraineté apparemment immuable que symbolise la fixité des lanternes publiques est alors bafouée au profit d'une nouvelle légitimité, d'une lueur provisoire qui cherche à résister, puis à s'étendre et à durer, celle de la torche qui voudrait se débarrasser des ses reflets de sang pour se faire pur flambeau ${ }^{74}$.

Der Gegensatz zwischen der Brandfackel (torche) und der Leuchtfackel (flambeau) beschreibt treffend das enorme Konfliktpotential, das dem Volk als Lichtbringer innewohnt ${ }^{75}$.

70 Zur Bedeutung der Brandstiftung als Mittel des sozialen und politischen Protests im Frankreich des 19. Jahrhunderts vgl. Jean-Claude Caron, Les feux de la discorde: Conflits et incendies dans la France du XIX ${ }^{\mathrm{e}}$ siècle, Paris 2006. Ibid., S. 268: "L'insurrection, la révolte antifiscale, la révolution, la guerre civile sont pourvoyeuses d'usages incendiaires où s'entremêlent le social, le politique, le stratégique. L'apparente diversité de ces usages se fond dans la volonté qui les commande et qui autorise à les réunir pour les confronter«.

${ }^{71}$ Insofern stellt Chams Blatt Allons bon! Le gaz qui revient arrêter les affaires vom März 1871 eine Ausnahme dar. Um so interessanter ist in diesem Zusammenhang die Gegenüberstellung des Communarden und der Laterne als sich widersprechende Komponenten bereits zu diesem frühen Zeitpunkt. Vgl. Raimund Rütren, Das Neue im Blick?, in: Ders. u. a. (Hg.), Die Karikatur zwischen Republik und Zensur, S.457: Der Grund für den nicht existierenden Bild-Dialog ist das Versailler Pressegesetz vom 15. April 1871, das politische Karikaturen verbot.

72 Ibid.: »Dieser satirische Diskurs ist nicht mehr Teil einer revolutionären Volksbewegung, nicht mehr eingreifendes Medium einer politischen Öffentlichkeit, sondern ein von verschärfter Zensur kontrollierter Legitimations-Diskurs der royalistischen Republik seit Juli 1871, ein satirisch sich gebender Rückblick auf das Geschehen, das politisch-militärisch bereits unterdrückt ist und blutig verfolgt wird«.

73 Dazu Elias Canetri, Masse und Macht, Hamburg ${ }^{3} 1973$, S. 17: "Die Masse, die Feuer legt, hält sich für unwiderstehlich. Alles wird zu ihr stoßen, während es um sich greift. [...] Es ist [...] das kräftigste aller Symbole, das es für die Masse gibt «.

74 Delattre, Les douze heures noires, S. 108.

75 Der scharfe Gegensatz zwischen Leucht- und Brandfackel ist der barocken Emblematik und Allegorese zunächst fremd. Bei Filippo Picinelli, Mundus Symbolicus, Cologne 1694, werden die als Synonyme gebrauchten Wörter facula und lampas jeweils doppelt aufgeladen: Beide können etwa sowohl für den Glauben als auch für die Zügellosigkeit 
Die Verbreitung des ideellen Lichts wie auch die Verfügung über das künstliche Licht wird zur Gefahr für Zivilisation und Kultur, sobald diese Macht von unten ausgeht ${ }^{76}$.

Jeglicher konstruktive Aspekt wird der sich selbst erleuchtenden Masse dabei abgesprochen: Die torche und der Petroleumkanister werden als Synekdochen für Feuer und Brandstiftung zum sinnfälligsten Symbol der Commune in der Karikatur.

Die Unberechenbarkeit der Volksmacht bringt Cham schon im Titel seiner in Le Charivari erschienenen und später als Album veröffentlichten Serie Les Folies de la Commune zum Ausdruck. Eines des Blätter zeigt einen bärtigen, wild aussehenden Communarden, der einem entsetzt reagierenden, bürgerlich gekleideten Mann eine qualmende Brandfackel und einen Petroleumbehälter überreichen will: Le conservateur des musées de la Commune recevant l'insigne de ses attributions ${ }^{77}$ (Abb.7). Die von der Commune mit der Aufsicht über die Museen beauftragte Fédération des artistes ${ }^{78}$ hatte unter der Präsidentschaft des Malers Gustave Courbet das Kuratorium des Louvre entlassen. Die Neuorganisation des Verwaltung des Museums war beim Einmarsch der Versailler Truppen am 22. Mai in vollem Gange ${ }^{79}$; wobei die mit der Leitung des Louvre betrauten Künstler - in der Hauptsache der Maler Jules

stehen und verweisen so auf die Ambivalenz des Feuers (Bd.2, index rerum, nicht paginiert). Bei Cesare RIPA, Iconologia, Padua 1611, einem äußerst einflußreichen Kompendium für die Darstellung allegorischer Figuren in der Malerei, findet sich für Brand- und Leuchtfackel gleichermaßen das Wort facella accesa: Die Allegorie der Ira trägt diese ebenso wie die Figur des Crepusculo della mattina (ibid., S. 264 bzw. S. 109). Die Qualität des Feuers erklärt sich allein aus dem Kontext. Schon die moralisierende französische Übersetzung von Ripas Werk durch I. BaudoIN, Iconologie ou explication nouvelle, Paris 1644, dagegen unterscheidet zwischen torche und flambeau: Die mit Ripas Ira im wesentlichen identische Ire trägt nun eine torche allumée (ibid., S. 163). Der lichtspendende flambeau ist dagegen Allegorien wie der Connoissance vorbehalten. Diese Spezifizierung ist jedoch noch nicht zwingend: Bei Jean-Baptiste BoudarD, Iconologie tirée de divers auteurs, Vienne 1766, werden Colère und Connoissance gleichermaßen ausgestattet mit einem flambeau allumé, der somit die zerstörerische und die lichtspendende Kraft des Feuers gleichermaßen widerspiegeln kann (ibid., S.93 bzw. S.111). In dem berühmten Werk von H.-F. Gravelot, Charles-Nicolas Cochin, Iconologie, Paris 1791, dagegen wird genau zwischen torche und flambeau unterschieden: Letzterer ist als geistiges wie sichtbares Licht der Doctrine oder der Aurore zugeordnet. Die torche allumée ist das alleinige, unheilvolle Attribut der Anarchie, »allusion au crimes qu'elle [die Anarchie] fait naître« (ibid., Bd.3, S.77). Die Fackel der Allegorie des Krieges dagegen wird keineswegs zufällig als flambeau déstructeur bezeichnet: Der Krieg, gleichwohl als fléau gebrandmarkt, entspringt dennoch einer auf einem System der Ordnung beruhenden Machthierarchie und ist somit der Anarchie nicht gleichzusetzen. Zu flambeau und torche vgl. auch Kap. 6.2.1. sowie 9.1.2. und 9.2.1.

${ }^{76}$ Dieses Denken spielt eine wichtige Rolle in der Propagierung der instruction obligatoire. Vgl. dazu Kap. 6.2.

${ }^{77}$ Erschienen am 17.6.1871. Die unter der Signatur des Künstlers vermerkte Nr.46 zeigt allerdings, daß es vor dem zweiten hier besprochenen Blatt entstand, welches die Nr. 45 trägt.

${ }^{78}$ Dazu ausführlich SáNCHEZ, Organizing Independance.

79 Ibid., S.56. 


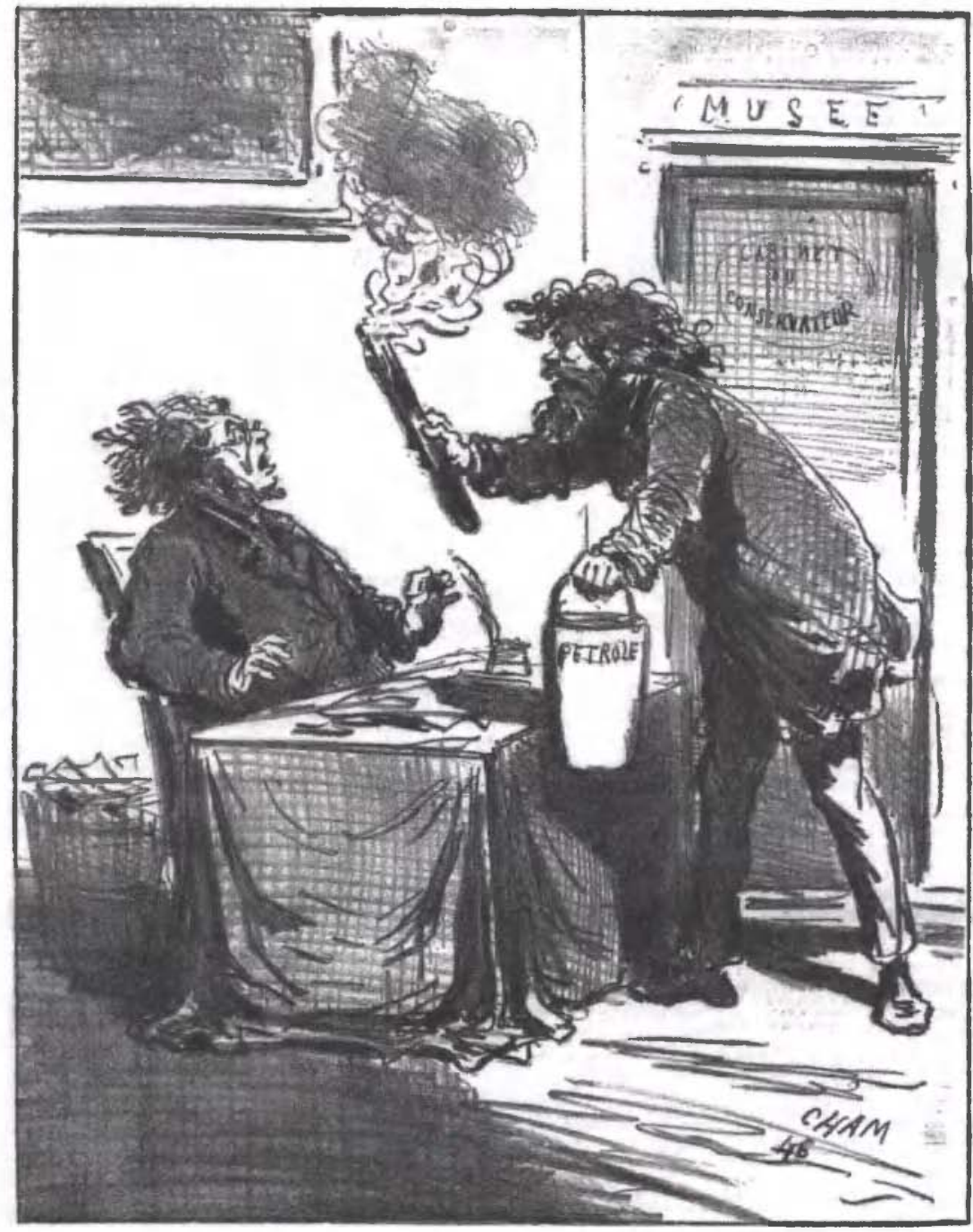

Le conservateur des Musces de la Commune recevant l'insigne de ses attributions.

Abb. 7 Cham: Le conservateur des musees de la Commune recevant l'insigne de ses attributions, in: Le Charivari, 17.6.1871. UB Frankfurt. 
Héreau und der Bildhauer Jules Dalou - ihre eigentliche Aufgabe darin sahen, einen bewaffneten Konflikt innerhalb des Museums mit allen Mitteln $\mathrm{zu}$ verhindern, und die Bestände sowohl vor den Communarden als auch den Versailler Truppen zu schützen ${ }^{80}$. Allein die Kooperation mit der Commune aber hatte für den Ruf der Fédération fatale Konsequenzen ${ }^{81}$ :

Since artillery was being fired around Paris, the Commission's decision to run the museums under the threat of destruction [...] bultressed the case of those who were to charge the Fédération's artists as being in league with the pétroleuses and other imagined furies ${ }^{82}$.

Chams Karikatur differenziert zweifellos: Der an seinem Schreibtisch sitzende conservateur will sein Amt offenbar gewissenhaft ausüben. Er muß jedoch erkennen, daß er in ein System integriert ist, welches dem Sinn seiner Tätigkeit, der Bewahrung, völlig zuwiderläuft.

Die angeblich beabsichtigte Vernichtung des Louvre als Herzstück des kulturellen Erbes wurde in düsteren Farben ausgemalt. Man unterstellte der Commune, die Auslöschung der kulturellen und nationalen Identität Frankreichs geplant zu haben. Obwohl der Louvre ebenso wie der Palais-Royal und Notre-Dame von den Bränden der semaine sanglante kaum oder nicht betroffen war ${ }^{83}$, wurde der Mythos vom allumfassenden, akribisch geplanten Feuerinferno immer weiter ausgeschmückt, wie etwa von Victor Fournel in Paris et ses ruines en mai 1871 :

Le Louvre, les Tuileries, le Palais de Justice, l'Hôtel de Ville, le Palais-Royal, flambant, crépitant, sautant dans cette énorme fournaise, dont ils étaient comme les tisons gigantesques; des rues entières noyées de pétrole et dont les maisons s'allumaient comme des becs de gaz; [...] tous les prodiges de l'art, tous les trésors de la science et des lettres, toutes les richesses d'une ville grande comme un monde [...] jetés en proie au foyer et versés à pleins tombereaux dans la flamme; et à travers ces lueurs sinistres, des bandes de démons courant, la torche à la main, par les rues jonchées de cadavres, badigeonnant les maisons de pétrole en vidant de pleins seaux par les soupiraux des caves [...] bombardant sans relâche, du haut des buttes Chaumont et du Père-Lachaise, les quartiers incendiés pour attiser la flamme, et en écarter ceux qui cherchaient à l'éteindre; luttant, avec la rage d'une troupe de bêtes fauves acculées contre les soldats qui s'efforçaient de les écraser à temps pour les empêcher d'achever Paris ${ }^{84}$.

80 Ibid., S. 57.

81 Zur ideologischen Selbständigkeit der Vereinigung ibid., S. 49: $»$ The Fédération was an initiative under the Commune, not of the Commune. This difference is more than semantic and has led to much historical misinformation «. Zur Rolle der Künstler in der Commune vgl. ausführlich Tiluser, La Commune de Paris, S. 100-142.

82 SÁnchez, Organizing Independance, S. 55. Hierzu trug in erster Linie Courbets aktive Teilnahme an der Zerstörung der Vendôme-Säule bei. John MILNER, Art, War and Revolution in France 1870/71. Myth, Reportage and Reality, New Haven, London 2000, S.154-157. Neben Courbet wurden auch Héreau und Dalou durch Militärtribunale verurteilt. Ibid., S. $112 \mathrm{f}$.

${ }^{83} \mathrm{Zu}$ den Bränden in Paris vgl. ausführlich Caron, Les feux de la discorde, S. 59-103. Zur geographischen Ausbreitung ibid., S.60-65. Vgl. auch RougerIe, Paris insurgé, S. 108.

84 Victor Fournel, Paris et ses ruines en mai 1871, Paris 1875, S. VII. Zu Fournel vgl. Borme, Art and French Commune, S. 43: »The former cynical critic of Haussmannization before 1870 changed his tune when confronted with the devastation of the Commune. He 
Der Angriff auf den Lichtmythos von Paris - "Les ruines de Paris après sa splendeur! $\ll^{85}$ - machte die Täter zu Gegnern der lumières, wie Louis Énault in seiner Schrift Paris brûlé par la Commune unmißverständlich klarstellt:

Paris brûlait! Mais, pourquoi Paris brûlait-il? Comment, dans un siècle qui se vante à bon droit de ses lumières, qui se décerne à lui-même un brevet de civilisation, qui a pris pour devise le grand nombre de progrès, [...] comment s'est-il trouvé des intelligences assez perverses pour concevoir la pensée d'un tel attentat contre l'humanité? l' $^{86}$

Dieselbe Frage scheint sich Chams fiktiver conservateur zu stellen. Sein Schrecken gilt aber nicht nur den Insignien der negativen Macht: Tatsächlich ist es Courbet selbst, den Cham hier mit Fackel und Petroleumeimer darstellt. Auf den ersten Blick ist er mit seinem wilden Bart von den anonymen Communarden der Folies de la Commune nicht zu unterscheiden, trägt aber weder Uniform noch Lumpen, sondern die bäuerlich anmutende Malerkluft, mit der er als meistkarikierter Künstler des II. Empire stets dargestellt wurde ${ }^{87}$. Cham griff also auf einen satirischen Diskurs zurück, den er in den $1850 \mathrm{er}$ und 1860 er Jahren unter anderem im salon caricatural ${ }^{88}$ des Charivari gegen Courbet einsetzte und der schon zu diesem Zeitpunkt eminent politisch war ${ }^{89}$ : Bilder wie etwa Les Casseurs de pierres wurden aufgrund ihrer realistischen

fulminated against the vandals who lay waste to the spplendour of the monuments and boulevards created by the Second Empire «.

85 Fournel, Paris, S. I (Hervorhebung von Fournel). Zur Wahrnehmung der Feuer in der Commune vgl. Thllier, La Commune de Paris, S.335-340. Ibid., S.338: "Paris incendié cristallisa un imaginaire de la destruction complète de la ville promise à l'enlisement, l'ensevelissement et l'engloutissement «.

${ }^{86}$ Louis Énault, Paris brûlé par la Commune. Ouvrage illustré de douze gravures dessinées par L. BRETon, d'après des photographies et représentant les monuments des quartiers incendiés, Paris 1871, S. 7. Zur Publikationswelle von illustrierter Ruinenliteratur vgl. CARON, Les feux de la discorde, S. 87-98. Zu den Ruinenfotografien vgl. Eric FourniER, Les photographies des ruines de Paris en 1871 ou les faux-semblants de l'image, in: Revue d'histoire du XIX' siècle 32 (2006), S. 137-151.

87 Marie-Luise BuchINGER-FrüH, Karikatur als Kunstkritik. Kunst und Künstler in der Salonkarikatur des »Charivari« Zwischen 1850 und 1870, Frankfurt a. M. 1989, S.64. Zu Courbets Werk und Person in der Karikatur vgl. auch: Dies., Die Malerei des Second Empire in der Karikatur des „Charivari«, in: RÜTTEN u.a. (Hg.), Die Karikatur zwischen Republik und Zensur, S.378-385; Klaus Herding, Courbets Modernität im Spiegel der Karikatur, in: Courbet und Deutschland, Hamburg 1978, S.502-521. Das Blatt aus den Folies de la Commune wurde aber bisher nie als Courbet-Karikatur erkannt. Erwähnt wird das Blatt auch bei MiLnER, Art, S.168. Auf die Ähnlichkeit zwischen Courbet und den gescheiterten Communarden bei Cham (1874 in L'ouvrier) verweist Michel NaTHAN, Cham - ein Polemiker, in: RürTen u. a. (Hg.), Die Karikatur zwischen Republik und Zensur, S.209. Allg. zu Courbet in der Karikatur nach der Commune vgl. Bertrand Tillier, Courbet, Commune, colonne. Le peintre déboulonné par la caricature, in: Courbet et la Commune, Paris 2000, S.81-102. Vgl. auch Thller, La Commune de Paris, S.45-58. Zu Courbets Engagement für den Louvre vgl. auch Clayson, Paris in Despair, S. 199-207.

88 Allg. zu den salons caricaturaux vgl. BuchINGER-FrüH, Karikatur als Kunstkritik; Thierry Chabanne, Les Salons caricaturaux, Paris 1990.

$89 \mathrm{Vgl}$. dazu BuchINGER-FrüH, Karikatur als Kunstkritik, S.64-86. 
Darstellung des Arbeitslebens der unteren Schichten als sozialistisch abgelehnt. Mit seinen Karikaturen, die die fehlende Idealisierung als »häßlich, schmutzig, stinkend ${ }^{90}$ verurteilten, schloß sich Cham der zeitgenössischen Kunstkritik an. Die von Courbet angestrebte Demokratisierung der Kunst wurde als Vulgarisierung und letztlich »Zerstörung der Kunst schlechthin « ${ }^{91}$ angesehen, nicht zuletzt, weil durch die Erweiterung des künstlerischen Themenspektrums und der Bildwürdigkeit ein völlig neues Massenpublikum angesprochen werden sollte ${ }^{92}$. Diese Befürchtungen scheinen nun Wirklichkeit geworden zu sein: Courbet ist hier nicht nur tatsächlicher, sondern auch geistiger Brandstifter, der durch sein Werk die Commune mit vorbereitet hat. Als $»$ Bürgerschreck ${ }^{93}$ ist er der Vertreter einer nun triumphierenden Unterschicht, die den bisherigen Kunst- und Kulturbegriff >auslöschen ‘ will. Im Angesicht eines Malers, der die Kunst der Zerstörung preisgeben will, muß der conservateur darüber hinaus erkennen, daß er selbst unmittelbar davorsteht, gegen seinen Willen Teil der brandschatzenden Masse zu werden. Da er sich mit der Commune eingelassen hat, wird er von ihr mitgerissen - ob er will oder nicht. Die symbolische Gleichsetzung von Masse und Feuer ${ }^{94}$ wird in bezug auf das Element der Unkontrollierbarkeit präzisiert: »Masse« ist hier nicht nur die traditionelle classe dangereuse ${ }^{95}$, eine Horde von Kriminellen und Schwachsinnigen - so die zeitgenössischen Urteile über die Communarden ${ }^{96}$, sondern ein in sich durchaus heterogenes Konglomerat, das - besonders wenn man an Courbet denkt - um so mehr eine Gefahr für die Zivilisation und die Ideale der lumières darstellt ${ }^{97}$ und sich bei den Zeitgenossen im negativierten Naturzustand des >Wilden< äußerte: „La vérité est que, sous le vernis du peuple civilisé, on retrouve le sauvage; [...] et que les progrès dont l'Europe est si orgueilleuse n'ont servi qu'à perfectionner d'autant l'art de se détruire et de s'exterminer ${ }^{98}$.

Diese harsche Fortschritts- und Kulturkritik wird in der littérature anticommunarde allerdings allein auf die Aufständischen bezogen, die in völliger Übersteigerung beschrieben werden als »des êtres indéfinissables, mi-

90 Ibid., S. 83 .

91 Ibid.

92 Ibid., S. 84.

93 Ibid., S. 86.

94 Vgl. dazu die oben zitierte Passage von CANETTI, Masse und Macht (Anm.73).

95 Vgl. dazu Louis Chevalier, Classes laborieuses et classes dangereuses à Paris pendant la première moitié du XIX ${ }^{\mathrm{e}}$ siècle, Paris 1958.

96 Robert Thомвs, The war against Paris 1871, Cambridge 1981, S.117.

${ }_{97} \mathrm{Zu}$ diesem bereits modernen Begriff der Masse und seinen Modifikationen vgl. bes. Kap. 8.1. Die Erkenntnis, daß der einzelne in der Masse seine Individualität verliert, beeinflußt davon ausgehend entscheidend die Sozialtheorien der III. Republik. Dazu Susanna Barrows, Distorting Mirrors. Visions of the Crowd in Late Nineteenth Century France, New Haven, London 1981.

98 Fournel, Paris, S. VIII. 
hommes, mi-bêtes, laids, déséquilibrés, violents, sortis tout droit des égouts, des abîmes souterrains, des lieux immondes « $"$.

Das Leitmotiv der gegen die Commune gerichteten Bildpropaganda blieben folglich die aus den unteren Klassen stammenden Brandstifter beiderlei Geschlechts ${ }^{100}$ : Ein anderes Blatt aus der Serie Les Folies de la Commune zeigt einen verkommenen Nationalgardisten mit seiner Brandfackel, der zu einem Bild von Marat sagt: "Va donc, Berquin!« und somit sein eigenes Tun als Schreckensherrschaft entlarvt, die die Terreur der Französischen Revolution noch bei weitem übertrifft ${ }^{101}$. Die Zerstörung durch Brandstiftung ist hierbei nicht mehr Mittel zum Zweck, sondern zum Selbstzweck der Commune geworden - oder vielmehr, wie dieses Blatt zweifellos unterstellt, schon immer gewesen ${ }^{102}$. Als finstere Verkörperungen des sinnlos Bösen repräsentieren derartige Gestalten die Masse, die in der Karikatur dieser Zeit selbst nicht thematisiert wird ${ }^{103}$. Darin äußert sich auch ein gewisser Verdrängungsprozeß: Geht das Feuer nur von einer im großen und ganzen überschaubaren Anzahl von verdorbenen Individuen aus - deren Bestrafung zum Zeitpunkt der Entstehung dieses Bilddiskurses bereits vollzogen oder im Gange ist, so kann die Gefahr für die bürgerliche Republik als gebannt gelten und die Frage nach den Gründen aus dem sozial-politischen in den mythischen Kontext verschoben werden:

Indeed, the specific causes of the conflict were ignored, and its real nature was overshadowed in the Versaillais presentation of events by a version emphasizing the international and historical aspects of a supposedly eternal struggle between existing society and revolution, not only in France but throughout Europe ${ }^{104}$.

Zum selben Zeitpunkt wurde die Commune als Verrat an einem durch den Krieg ohnehin geschwächten Land verdammt und der angeblich hohe Anteil

99 Serman, Commune, S. 543. Vgl. dazu auch Caron, Les feux de la discorde, S. 72-76. Zur Instrumentalisierung der Brandstiftungen unter der Commune in der wissenschaftlichen Forschung über kollektiven Wahnsinn und weibliche Pyromanie bis zum Ersten Weltkrieg vgl. ibid., S.258-264.

$100 \mathrm{Zu}$ den pétroleuses vgl. Kap.5.4.

101 Abgebildet bei LeITH, War of Images, S.135, Abb. 71.

${ }^{102}$ Zur Festschreibung dieser Überzeugung trugen wohl nicht zuletzt Exilwerke von der Commune nahestehenden Künstlern und Literaten bei, wie etwa Eugène Vermerschs Gedicht Les Incendiaires, entstanden im September 1871 in London: Die erste Strophe endet mit den Zeilen: „Quand l'incendie horrible triomphait, / Une voix dans mon cœur criait: Ils ont bien fait!«

103 Die Darstellung der Masse in der Karikatur verlangt außerdem stilistische Mittel, die in der noch stark von Einzelsymbolen und Requisiten geprägten Karikatur um 1870 noch nicht sehr weit entwickelt waren.

104 Thombs, War, S. 118f. Vgl. auch die Präzisierung hinsichtlich der tatsächlichen Zusammensetzung der Gegenparteien: »Yet although the conflict of 1871 was in part one of class and of region, it was not primarly a spontaneous mass struggle. Enthusiasm on both sides was restricted to the few. Hordes of ruraux did not come to the aid of the Assembly; all the workers of Paris did not man the barricades. The struggle was one between institutions: government against government and army against army« (ibid., S. 199). 
von Ausländern an den Aufständischen hervorgehoben ${ }^{105}$, wodurch auch versucht wurde, den "patriotisme idéologique «106 der Communarden vergessen zu machen: Schließlich war schon der Widerstand gegen den Entwaffnungsversuch des 18. März mitgetragen von dem Willen, die zumeist während des Krieges aus privaten Spenden finanzierten Kanonen dem Zugriff einer Regierung zu entziehen, die diese den Feinden übergeben würde.

Um die Commune also radikal vom französischen Revolutionserbe zu trennen, erschien sie im Sprachgebrauch der III. Republik nicht mehr als révolution, sondern nur noch als insurrection ${ }^{107}$. Die Commune war somit in doppelter Hinsicht eine Bedrohung - als singuläres Ereignis auf nationaler Ebene, wie als Modell auf internationaler und allgemein kultureller Ebene. Beide Aspekte kommen in der Darstellung Les Misérables, die am 13. August 1871 in Le Grelot erschien, zum Ausdruck (Abb. 8): Ein verkommener Communarde zieht über das Land, am Horizont sind die Ruinen einer Stadt zu erkennen. In der Hand trägt er eine Brandfackel, von der eine immense Rauchwolke ausgeht, in der das Wort justice zu lesen steht. Die auf der Erde liegende Waage der Gerechtigkeit tritt er dagegen mit Füßen. Die Zerstörung von Paris, so verdeutlicht das Blatt, sollte nur der Anfang sein. Nach der Vollendung dieses Werks macht sich die Commune auf, ihre Untaten weiter auszudehnen. Als Repräsentant des Systems stellt der Communarde aber nicht nur die Masse, sondern auch die hinter dem Aufstand stehende Idee selbst dar. Diese kann sich, im Gegensatz zu den aufgehaltenen und bestraften Tätern, ebenso wie das Feuer immer weiter fortpflanzen. ${ }^{108}$ Die im Titel anklingende Anspielung auf Victor Hugos berühmten Roman kehrt dessen Bedeutung um: der Dargestellte leidet nicht im Elend, sondern er bringt es mit sich. Als Verkörperung von Charakteren wie Gavroche ist er eine stets latente Bedrohung, die mit den Mitteln der Gerechtigkeit bekämpft werden muß: »On demande des juges « - so lautet der Untertitel des Blattes, in dem die Aburteilung, ErschieBung oder Verbannung der Communarden letztlich gerechtfertigt wird ${ }^{109}$.

${ }^{105}$ Ibid., S.117. Vgl. BLoch, Republik, S.35f.: Die Regierung Thiers hatte hingegen, um die Commune schnell zu zerschlagen, selbst mit den Preußen kooperiert, die u.a. gefangene Generäle freiließen und Munitionslieferungen gestatteten. Im Gegenzug verhielt sich Thiers bei den Frankfurter Friedensverhandlungen äußerst entgegenkommend: »Ganz offen paktierte er mit dem äußeren Feind, um die soziale Revolution zu meistern, in der alle konservativen Strömungen jetzt ihre Hauptgefahr sahen «.

106 Chastenet, Histoire de la Troisième République, Bd.1, S. 83.

107 Rey, Révolution, S.224. Rey stützt sich auf folgende Larousse-Lexika: Nouveau Dictionnaire de la langue française (1882); Nouveau Dictionnaire illustré (1887); Dictionnaire complet illustré (1902); Petit Larousse (1905).

108 Das Bild des Wanderers findet sich mit vergleichbaren Konnotationen in der Bildsprache des Anarchismus wieder. Vgl. Kap.9.3.

109 Vermutlich spielt der Titel des Blattes direkt auf Victor Hugos Engagement für die Communarden an. Am 26.5.1871 hatte ein Brief des damals in Brüssel lebenden Schriftsteller in der Zeitung L'Indépendance belge einen Eklat verursacht, da Hugo sich für das Asylrecht der Communarden in Belgien einsetzte und trotz aller Kritik an den Taten der 


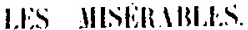

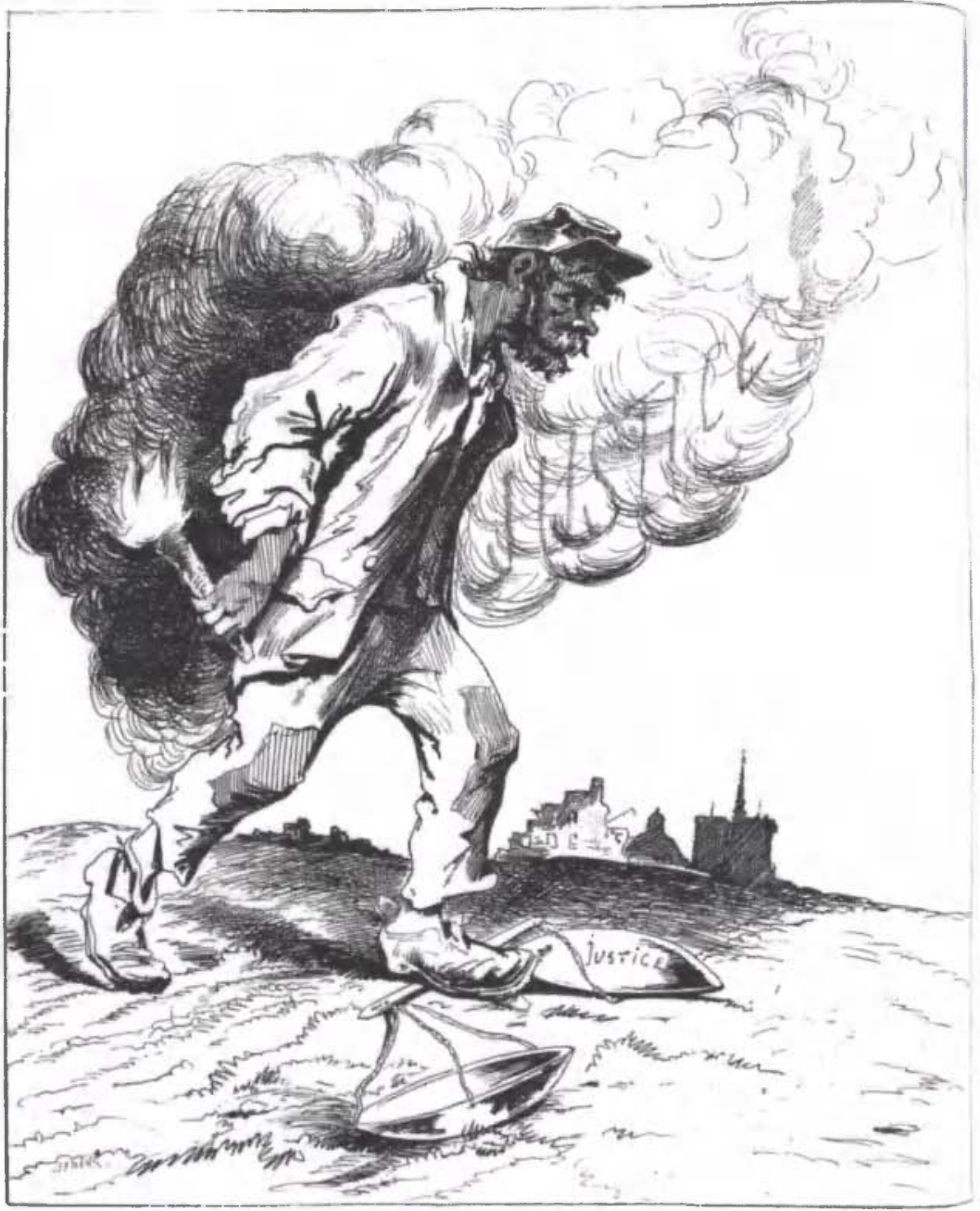

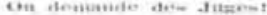

Abb. 8 Lefman: Les Miserables. On demande des juges!, in: Le Grelot, 13. 8.1871. Bibl. Forney, Paris. 
Insgesamt ist der Nachhall der Commune in der Karikatur der frühen III. Republik eher schwach, nicht nur aus Gründen der Zensur, sondern auch, da Künstler mit eher konservativ-republikanischer Einstellung dominierten, die sich dem allgemeinen Bedürfnis anschlossen, die Erinnerungen der année terrible durch Verdrängung zu kompensieren. Dies spricht auch aus Chams Neujahrsbild 1872 für Le Charivari mit dem Titel Le Départ de 1871'10 (Abb.9): Das Motiv der Vertreibung des rein negativ konnotierten alten Jahres erfährt hier eine zusätzliche Überblendung durch das Motiv der alten, mit Petroleumeimer ausgestatteten Brandstifterin, die von Chronos mit der Sense weggestoßen wird: »Hue donc! pétroleuse! « Das Leitbild der Commune, die pétroleuse, gehört nun also der Vergangenheit an, sie verkörpert das $>$ böse $<$ Jahr 1871, wie es auf ihrem Kleid geschrieben steht. Der antikisierende Stil des Kleides verweist aber darauf, daß die pétroleuse hier auch als Verkörperung der - alten - Republik in der Tradition von 1793 verstanden wird, von deren schädlichsten, anarchischen Auswüchsen die Zukunft befreit wird. Wie schon in der Bildpublizistik der Französischen Revolution tritt Chronos als Vollender der Zeit hervor, der die dargestellte Entwicklung als unumkehrbar kennzeichnet: Die Zeit selbst löscht die Erinnerung aus, wodurch der Commune letztlich jede Geschichtlichkeit abgesprochen wird.

Flüchtigen ( ${ }^{\prime} J$ 'accepte le principe de la Commune, je n'accepte pas les hommes «) ihre Schutzbedürftigkeit hervorhob: "Premièrement, pour tous les hommes civilisés, la peine de mort est abominable; deuxièmement, l'exécution sans jugement est infâme«. Vgl. Victor Hugo, Actes et Paroles III: Depuis l'exil 1870-1876, in: Ders., Euvres complètes, Bd.10, Paris 1985, S. 796-798. In der darauffolgenden Nacht warf eine aufgebrachte Menge in Hugos Haus mehrere Scheiben ein. Am 31. Mai beschloß die belgische Regierung seine Ausweisung.

110 Le Charivari, 3.1.1872. 


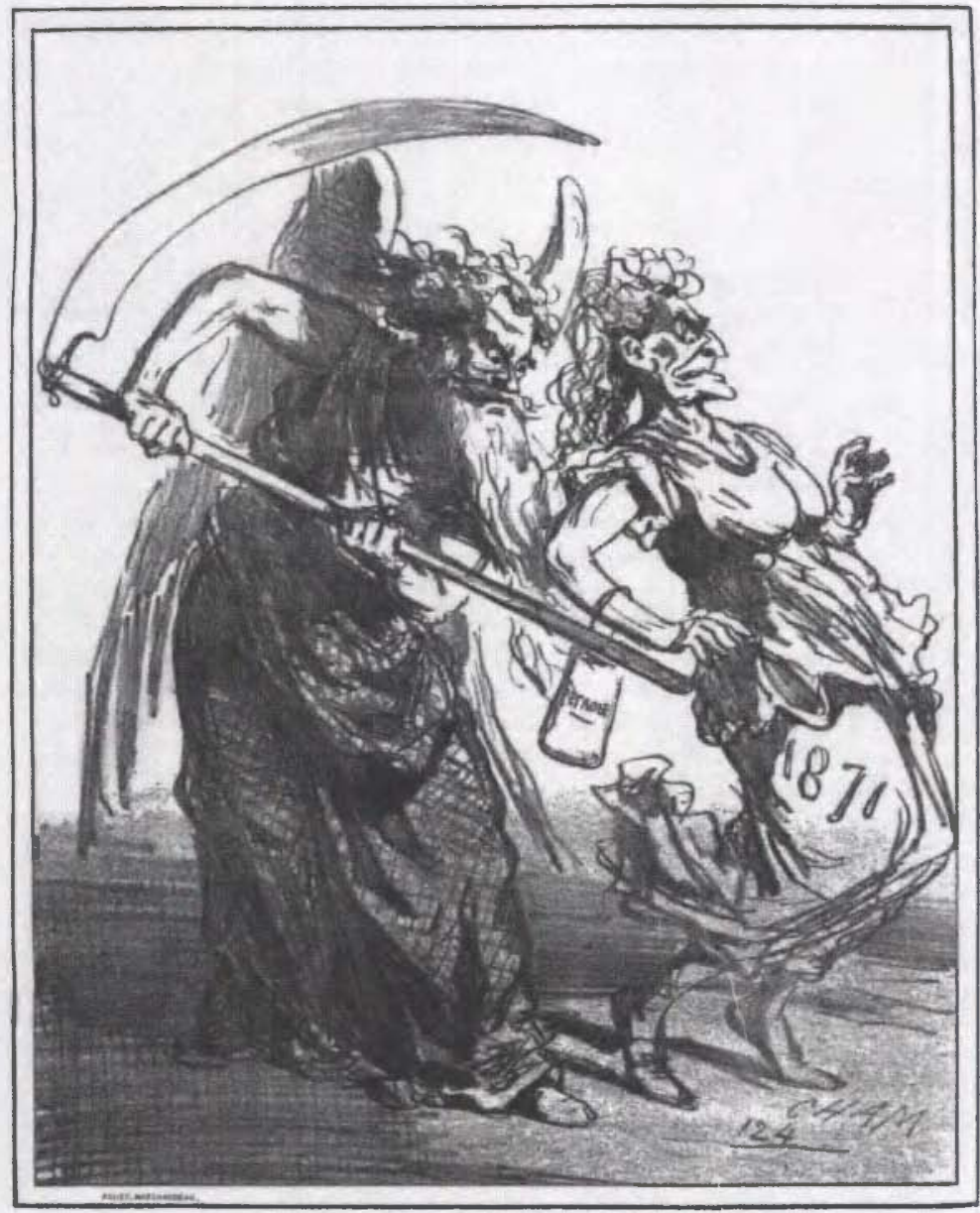

LE DEPART DE 1871 .

- Hue donc' petroleuse I

Abb. 9 Cham: Le Depart de 1871. Hue donc, petroleuse!, in: Le Charivari, 3.1.1872. UB Frankfurt. 


\section{3. »Le cadavre est à terre et l'idée est debout «: Restauration, Restitution und die Wiederkehr des Verdrängten ans Licht}

Verdrängungsmechanismen bestimmten auch die Versuche, die Commune innerhalb von Paris vergessen zu machen. Die komplexe Vielschichtigkeit dieses Restitutionsprozesses spiegelt sich, wie Albert Boime nachgewiesen hat, auch im Werk der Impressionisten in den 1870er und 1880er Jahren wider ${ }^{111}$. Dabei nimmt der Prozeß der Reinigung, ganz ähnlich wie in den Haussmannschen Reformen, eine zentrale Stelle ein: "Metaphorical allusions, whether textual or visual, to convalescence, purification, restoration, and regeneration are signifiers for the early Impressionist era «12. Die Darstellung der lichtund luftdurchfluteten, geordneten Stadt symbolisierte im soziopolitischen Kontext die letztendliche (Rück-)Eroberung des mythischen Raumes Paris durch die konservative Republik, die somit auch die Gesetzmäßigkeiten der Haussmannschen Reformen absorbierte und für sich nutzbar machte ${ }^{113}$.

111 Borme, Art and French Commune, z.B. S. 24: "What I hope to show is that the scenes of the Impressionists are complicit with the subsequent intensive campaign to rebuild Paris and its beautiful suburbs, coinciding with the official line of the period«. TILlier, La Commune de Paris, S. 376, zieht im Grunde dieselben Schlüsse: »Dans toutes ces compositions impressionnistes ressortissant du paysage urbain et montrant la ville haussmannienne comme territoire impressionniste, le souvenir de la Commune est souvent perceptible, mais toujours comme en creux «. Dennoch kritisiert Tillier Boimes Verdrängungstheorie: "Il faudrait plus certainement déchiffrer dans cette présence la capacité de perturbation profonde de la Commune et de sa postérité, dont témoigne l'impossibilité pour les peintres de se soustraire à cet événement qui, s'il ne fut pas véritablement un sujet, resta un objet implicite. Dans ces ouvres, le souvenir de la Commune est irréductible (ibid.). Nichts anderes aber belegt Boime: Gerade die angestrengten Versuche, die Commune vergessen zu machen, zeugen natürlich von ihrer Allgegenwart im Denken und besonders im Empfinden des öffentlichen Raums.

112 Borme, Art and French Commune, S.51.

113 Entgegen der Meinung von Boime ist die Wiederherstellung des Stadtraumes in seiner durch Haussmann modifizierten Form kein Widerspruch zum Herrschaftsanspruch der Republik (ibid., S.42). Als stark symbolisch aufgeladenes Dokument der Rückeroberung des Raumes gilt auch die berühmte Fotografie der erschossenen Communarden von André Disdéri. Vgl. Juerg Albrecht, Rolf Zainden, Honoré Daumiers »Rue Transnonain« Das Ende der Überzeichnung, in: RüTtEN u.a. (Hg.), Die Karikatur zwischen Republik und Zensur, S.138, Abb.135. Ibid., S. 138f.: "Es sind nicht bloß die Regeln plumper Abschreckung, die den überwundenen Gegner in normierte Holzkisten eingesargt vorzuführen verlangen, sondern es ist die Logik der Darstellung staatlicher Allmacht: Gegenüber der Turbulenzen und Kreativität der Pariser Volksherrschaft setzt sich ein Raster disziplinierter Einordnung absolut. So versperrt von Bildrand zu Bildrand die dichtgefügte Wand der Särge jeglichen Blick in die Weite und läßt Geschichte zum Stilleben gefrieren. [...] Diese Frontalansicht [...] ist im umfassenden Sinne des Begriffs perspektivlos - bliebe nicht jener Rest von Widerspenstigkeit, der noch im Tod die Körper der Aufständischen gegen aufgezwungene Schranken sich sperren läßt«. Zur Rolle der Fotografie in der Commune vgl. allg. Donald E. ENGLish, Political Uses of Photography in the Third French Republic, 1871-1914, Michigan 1981, S.21-80. Teil der Rückeroberung und symbolischen des ideellen sowie physischen Raumes war auch der Bau von Sacré-Cœur hoch über dem 
Der Maler Gustave Caillebotte etwa stellt in seinem Gemälde Jeune homme à sa fenêtre von 1876 einen Angehörigen der gehobenen Schicht dar, der aus seiner häuslichen Sicherheit heraus den unter (!) ihm liegenden, offenen Raum überblickt und von seinem privilegierten Standpunkt aus symbolisch beherrscht ${ }^{114}$.

Dieses Bild findet sein Gegenstück in dem Gemälde Intérieur. Femme à la fenêtre, das Caillebotte vier Jahre später malte. Im Gegensatz zum männlichen Betrachter sieht die gutbürgerliche Frau nicht auf einen offenen Platz, sondern auf den gegenüberliegenden, den Raum abschließenden Häuserblock. Der das Blickfeld verengende Vorhang verweist auf das Innere, das schon im Titel dominiert. Der im Hintergrund sitzende, die Zeitung lesende Mann macht das Motiv der Domestizierung und Abschottung des Raums wie der Frau perfekt - und somit die Behauptung patriarchalischer Strukturen im Gegensatz zur Emanzipation während der Commune ${ }^{115}$. Acht Jahre später setzt der junge Lucien Pissarro dieses Motiv auf einer seiner ersten Presseillustrationen in einen konkreten Kontext: »Pendant la fête du 14-Juillet: ceux qui boudent « ${ }^{116}$. Der seit 1880 begangene Nationalfeiertag - der theoretisch bereits Caillebottes Gemälde inspiriert haben könnte - stellte für das konservative Bürgertum ein Schreckgespenst dar, vor dem der heimische Salon eine Zuflucht bot. ${ }^{117}$ Die von Pissarro unterstellte Trotzreaktion - das »Schmollen « - hat einen durchaus ernsten Hintergrund: Denn die wiedererlangte und verteidigte Verfügung über den Raum schien an diesem Tag in Frage gestellt zu sein. Wenn die Frau, die auch hier ihrem lesenden Mann den Rücken zuwendet, nun vor dem Kamin statt vor dem Fenster steht, so unterstreicht diese Modifikation die Schutzfunktion des abgeschlossenen Raums ganz erheblich. Der Rückzug aus der Öffentlichkeit an diesem Tag soll der Herausforderung Vorschub leisten, sich in dem neu gegliederten Raum und der sich durchmischenden Gesellschaft einzuordnen. Die Frage nach der Gleichberechtigung der Geschlechter ist hinter dieser Klassendominanz zurückgetreten. Die bürgerlich-patriarchalische Kontrolle behauptet sich so vor der

Montmartre, wo die Commune am 18. März ihren Anfang genommen hatte. Vgl. Merriman, Marges, S. 297-280. Zu Sacré-Cœur vgl. Kap.6.3 und 6.4.

114 Öl auf Leinwand, $117 \times 78 \mathrm{~cm}$, Privatsammlung. Dazu Bolme, Art and French Commune, S. 89 und ibid., Abb.61. Der von Caillebotte hier dargestellte Boulevard Malesherbes gehörte während der semaine sanglante zu den meistumkämpften Zonen.

115 Öl auf Leinwand, $116 \times 89 \mathrm{~cm}$, Paris, musée d'Orsay. Dazu Borme, Art and French Commune, S. 90 f. und S.91, Abb.62, Zum Thema des eingeschränkten weiblichen Blickwinkels im Paris des 19. Jahrhunderts vgl. Marni KessLer, Dusting the Surface, or the Bourgeoise, the Veil, and Haussmann's Paris, in: Aruna D'SouzA, Tom McDonougr (Hg.), The Invisible Flâneuse? Gender, Public Space, and Visual Culture in NineteenthCentury Paris, Manchester, New York 2006, S. 49-64.

116 La Vie moderne, 22.7.1888. Vgl. Janine Bailly-Herzberg, Aline Dardel, Les illustrations françaises de Lucien Pissarro, in: Nouvelles de l'estampe 54 (1980), S. 8-16.

117 Vgl. zum Nationalfeiertag Kap. 7. 
Herausforderung jedweder Auflehnung ${ }^{118}$. Lucien Pissarro, der wie sein Vater und die meisten anderen Neo-Impressionisten dem Anarchismus nahestand $^{119}$, verdeutlichte auf diese Weise subtile Herrschaftsmechanismen, die in der verabsolutierten Beanspruchung des Raumes ihren sinnfälligen Ausdruck finden ${ }^{120}$.

Die Kontrollfunktion der Republik im hierarchisch gegliederten Stadtraum stellt sich in symbolischer Übersteigerung in Stops Karikatur Girouettes et $\mathrm{Pa}$ ratonnerres von 1872 dar $^{121}$ (Abb.10): In der Mitte des Blattes steht ein hoher, schlanker Blitzableiter mit den Initialen » $\mathrm{RF}$, umgeben von vier weiteren Objekten, deren Funktion jeweils mehr oder weniger zwischen Blitzableiter und Wetterfahne schwankt, was auch durch die doppelte Verwendung des Plurals im Titel im unklaren bleibt. Rechts neben dem Republiksymbol stehen die noch halbwegs brauchbaren paratonnerres der Orleanisten bzw. Legitimisten - durch ihre Symbole Hahn bzw. Lilienwappen allerdings nicht völlig im Gleichgewicht - und somit in Gefahr, zu girouettes zu werden. Auf der linken Seite ist der verbogene und damit unbrauchbare Blitzableiter mit dem kaiserlichen Adler zu sehen, flankiert von der mit der phrygischen Mütze gekrönten girouette der Commune, die als Wahrzeichen eine Fahne trägt, auf der ein Petroleumbehälter abgebildet ist. Der Bildtext erklärt die Aufgabenverteilung: »Celles-ci sont le jouet des orages. / Celui-là nous protège contre eux «.

Allein der ganz den Gesetzmäßigkeiten seiner Aufgabe angepaßte paratonnerre der Republik, der übrigens als einziger geerdet ist, reicht weit genug, um seiner Schutzfunktion gerecht zu werden und das (revolutionäre) Gewitter abzuwenden. Dadurch wirkt Stops Blatt wie eine überlegene Antwort auf die Blitzableiter-Darstellung von Pilotell während der Commune. Der Gefahr des Blitzeinschlags wird besonnen vorgebeugt. Der taghelle, aufgeklarte Himmel erhöht überdies um ein Vielfaches die Übersichtlichkeit des darunter

118 Interessanterweise greift fast zeitgleich der ebenfalls zu den Neoimpressionisten gehörende Maler Paul Signac dieses Motiv auf: Das zwischen 1888 und 1890 entstandene Gemälde Dimanche parisien (Öl auf Leinwand, $150 \times 150 \mathrm{~cm}$, Paris, Privatsammlung) stellt die Frau wiederum vor das Fenster, dessen Vorhang sie mit der Hand leicht lüftet, während der Mann mit der Feuerzange im Kamin stochert. Bedenkt man, daß die Rückeroberung der Kontrolle über das Feuer - während der Commune Symbol der entgleisten Herrschaft von unten - ein tragendes Element der Restitution war, so erhält diese Genreszene eine nicht unerhebliche politische Komponente.

119 Dazu John G. Hurton, Neo-Impressionism and the Search for a Solid Ground: Art, Science and Anarchism in Fin-de-Siècle France, Baton Rouge 1994.

120 Tillier, La Commune de Paris, S. 353f., bringt auch die nach der Commune verbreiteten Ruinendarstellungen in direkten Zusammenhang mit der Rückeroberung des Raums: "la ruine dilua, absorba, puis éluda le paysage, pour en investir l'espace et en régir l'étendue. [...] À l'évidence, l'image de ruines joua avec les échelles et les rapports de proportions, d'autant que l'écrasante majorité de ces vues était désertée de toute présence humaine $\ll$.

121 Veröffentlicht am 11.3.1872 in Le Charivari. 


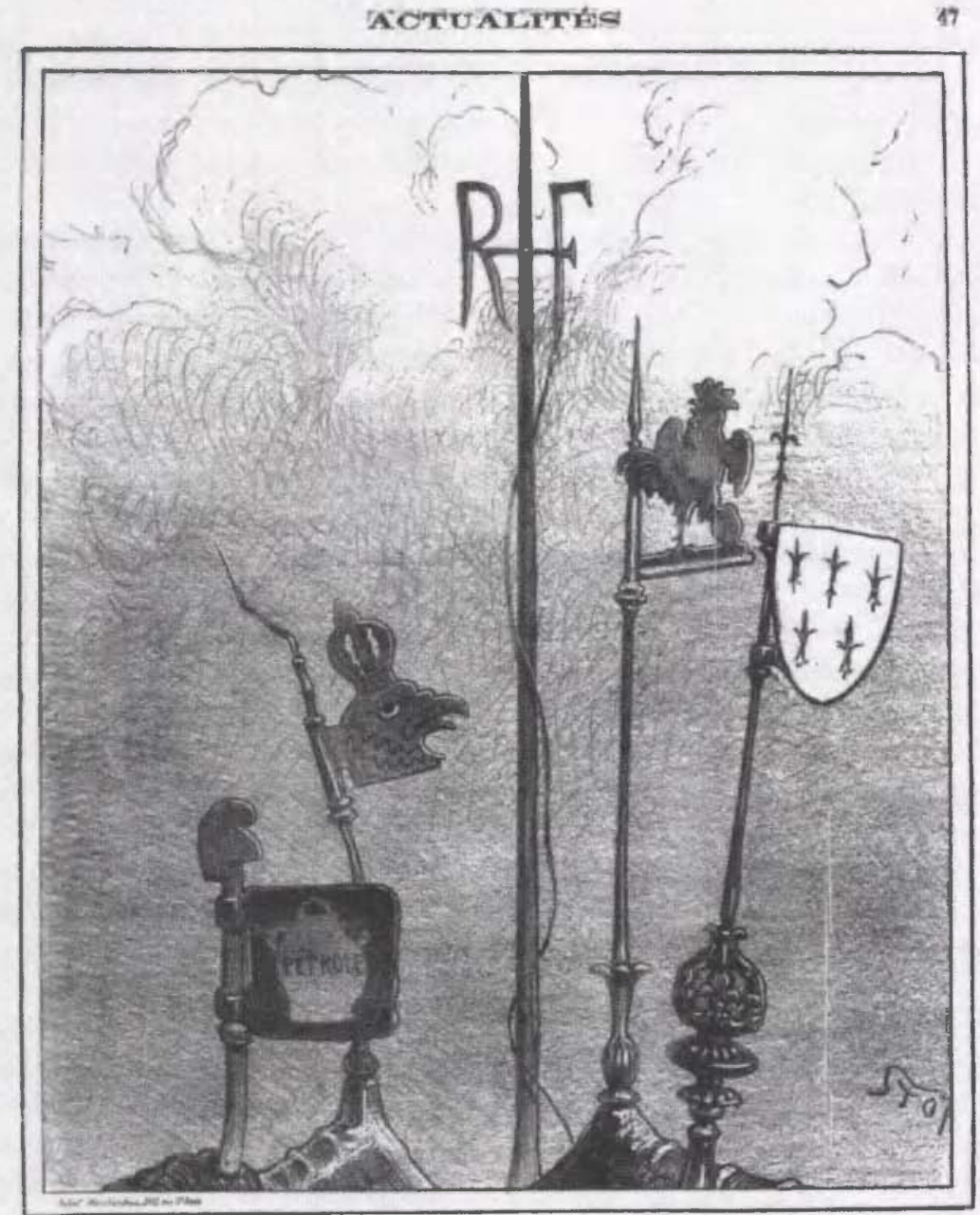

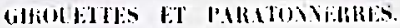

Cellos - ci sont le jouei des origne. Celui - là nous protege contie éux.

Abb. 10 Stop: Girouettes et Paratonnerres. Celles-ci sont le jouet des orages. Celui-là nous protege contre eux, in: Le Charivari, 11.3.1872. UB Frankfurt. 
liegenden Terrains ebenso wie den Herrschaftsanspruch über den in die Vertikale hinein verlängerten Raum. Als Blitzableiter schon aufgrund seiner Struktur völlig untauglich ist allein die Wetterfahne mit der phrygischen Mütze: Das zu dieser Zeit eindeutig negativ konnotierte Symbol ${ }^{122}$ und der Petroleumkanister stehen gleichermaßen für die völlige Unberechenbarkeit des Systems der revolutionären Republik, die ihrerseits die Kräfte, aus denen sie selbst hervorgegangen ist, nicht kontrollieren kann, sondern ihnen ebensowenig entgegenzusetzen hat wie die Wetterfahne dem Sturm; während die paratonnerres der drei monarchistischen Systeme zumindest eine begrenzte Zeit die Oberhand behalten konnten.

Die Abwesenheit der zu beherrschenden Kräfte selbst bringt zweierlei zum Ausdruck: Die als Verdienst der Republik propagierte momentane Sicherheit und darüber hinaus die absichtlich im unklaren gelassene Natur der Bedrohung. Der revolutionäre Sturm würde, sofern er nicht abgeleitet werden könnte, den darunter liegenden Raum infizieren und die befürchteten Reaktionen auslösen. Auch die symbolische Verlagerung >nach oben< kann also die Angst vor der Gefahr >von unten< nicht bannen, die hier in verschlüsselter Form anwesend ist: Die girouette der Commune, genauer gesagt, ihr den Petroleumbehälter tragendes Wappen, hat im Sturmwind erheblich an den paratonnerre des Empire geschlagen, der dadurch zusätzlich - von unten her ruiniert wurde. Diese Anspielung auf die Brandstiftungen und die Zerstörung des erneuerten Paris als wichtigster Hinterlassenschaft des Empire verdeutlicht noch einmal die untrennbare Verbindung von Terreur, revolutionärer Republik, Commune und Niedergang nicht nur im Bildbewußtsein. Um die etablierte Republik zu schädigen, genügt die Reichweite der revolutionären girouette indessen nicht.

Die hier angedeutete Domestizierung der Unterschichten wurde unmittelbar nach der Niederschlagung der Commune noch als Versöhnungsprozeß im Rahmen einer gesamtnationalen Restitution dargestellt, wie auf dem im Sommer 1871 publizierten Einblattdruck Le travail, c'est la liberté ${ }^{123}$. Flankiert von einem Bauern und einem Arbeiter steht eine weibliche Allegorie von Frankreich oder der Republik unter einer strahlenden Sonne, den Hintergrund bilden Idyllen des wirtschaftlichen Wohlstandes. »Liberated Paris is associated with revival of industry and the arts. The sky has cleared and the sun - no longer the sun of social revolution - is shining brightly «124. Die zwangsläufige Typisierung vergleichbarer Allegorien zeigt die Schwierigkeiten, das komplexe Geflecht von Ursache und Wirkung der Commune zu verbildlichen. Die Do-

122 Jean Garrigues, Images de la Révolution. L'imagerie républicaine de 1789 à nos jours, Paris 1988, S.77: Noch 1876 wurde unter der Regierung Mac-Mahon eine für die Stadt Dijon angefertigte Republikfigur von Cabet wieder abmontiert, mit der Begründung, sie sei »de type révolutionnaire, coiffée du bonnet phrygien«.

${ }^{123}$ Einblattdruck. BnF, Est. Vgl. Rürten u.a. (Hg.), Die Karikatur zwischen Republik und Zensur, S. 459, Abb.494, LeIrH, War of Images, S. 143, Abb. 96.

124 Ibid., S. $142 \mathrm{f}$. 
minanz des ländlichen Idylls auf diesem Blatt zeugt zudem von dem Bestreben, die ungelösten Konflikte innerhalb der Hauptstadt auszublenden ${ }^{125}$. Das revolutionäre Potential der Pariser Straße selbst zeigt sich innerhalb des angestrengt verfolgten Neuordnungs- und Wiederaufbauprozesses in der Bildpublizistik ebenso wie in der Malerei nur in indirekter, stark codierter Form, worin sich die halb verborgene Seite einer durch Haussmannsche Reformen und Veränderung der Arbeitsprozesse bedingten Sozialstruktur widerspiegelt. Die Pariser Arbeiterschicht erscheint nicht als geschlossener Block, sondern aufgrund der starken Durchmischung verschiedener industrieller Entwicklungsstufen mit traditionellen Arbeitsfeldern als »plèbe géographiquement et professionnellement éparpillée « ${ }^{126}$. Das Scheitern des durch die Commune erstrebten Vereinigungsprozesses dieser Kräfte spiegelt sich nicht zuletzt im Verlust des Lichts: Darstellungen der nach der semaine sanglante verhafteten Communarden auf ihrem Weg ins Ungewisse zeigen eindeutig Tendenzen des Verschwindens in die Dunkelheit ${ }^{127}$, woraus sich 20 Jahre später der Bildtypus des entwurzelten, orientierungslos umherirrenden Proletariers entwickeln sollte.

Überdies rissen Exekutionen und Verbannungen tatsächlich beträchtliche Lücken in das Sozialgefüge besonders der gut ausgebildeten Handwerker und Facharbeiter ${ }^{128}$, die somit im städtischen Raum weniger sichtbar waren, was wiederum die Verdrängung der sozialen Problematik im Rahmen des ideellen Renovationsprozesses begünstigte ${ }^{129}$.

Auf Gemälden wie Gustave Caillebottes ${ }^{130}$ Rue de Paris en temps de pluie ${ }^{131}$ von 1877 erscheinen Arbeiter nur als kaum wahrnehmbare Hintergrundfiguren, während das Gewicht der Bildaussage auf dem für die bürgerlichen Flaneure wieder sicheren Stadtraum liegt, dessen Reinigung hier durch den $\mathrm{Re}$ gen symbolisiert wird:

125 Besonders unter Thiers' Nachfolger Mac-Mahon und seiner Regierung des ordre moral (vgl. dazu Kap. 6.1.) wurde die Darstellung des ländlichen Idylls in der Malerei gefördert und - im Gegensatz zum immer unberechenbaren Paris - als der gesunde Kern der Nation dargestellt. Dazu John House, Die französische Landschaft 1877. "Le Village de Lavardin (Loir-et-Cher) « von Charles Busson, in: Fleckner (Hg.), Jenseits der Grenzen, S. 234-243.

126 Gaillard, Paris, la ville, S. 432.

127 Beispiele finden sich bei Milner, Art, S.183-187. Auch die nächtliche Aufsammlung der Leichen nach der Niederschlagung der Commune weist in diese Richtung. Dazu Frédéric Chauvaud, L'élision des traces. L'effacement des marques de la barricade à Paris (1830-1871), in: Alain Corbin, Jean-Marie Mayeur (Hg.), La barricade, Paris 1992, S.272: "L'obscurité, source de confusion, permet de voiler en partie l'étendue des massacres nocturnes. Des déflagrations sont entendues, mais les cadavres s'évanouissent avant le jour«.

128 Borme, Art and French Commune, S. 19.

129 Ibid.: "It was this absent but indexical body of militant manual workers, both male and female, and a physically present but psychologically intimited bourgeoisie, that populated the environment of early modernist visual practice «.

1301848 als Sohn eines Fabrikbesitzers geboren, erlebte der Maler die Commune als unmittelbare Bedrohung. Vgl. Borme, Art and French Commune, S. 77.

131 Öl auf Leinwand, $212 \times 276 \mathrm{~cm}$, Chicago, Art Institute. 
The sanitary action of the rain on the pavingstones was a gratifying recollection of the social scleansing a and purification of the streets once stained by the physical presence as well as by the blood of the Communards [...] The conspicious treatment of the paving stones and their rain-drenched and light-reflecting radiance symbolically constitute a Paris restored to its pristine Haussmannian appearance and a Paris recuperated for the bourgeoi$\operatorname{sie}^{132}$.

Das saubere, das Licht spiegelnde Straßenpflaster wird zur makellosen Projektionsfläche, auf der die revolutionäre Vergangenheit der pavés beim Barrikadenbau überblendet wird ${ }^{133}$.

Auch hierin wiederholt sich der Kampf gegen den als bedrohlich empfundenen Naturzustand, der sich dem bürgerlichen Ordnungsbedürfnis widersetzt ${ }^{134}$ :

Das Pflaster markiert aber nicht nur die Grenze zwischen Wildnis und Zivilisation, sondern auch zwischen oben und unten. Der durch Lage und Ausstattung ohnehin schon privilegierte Boulevard wird durch das intakte, saubere Pflaster von der Welt der erneut Marginalisierten abgetrennt - in gewolltem Kontrast zum »blutgetränkten« Pflaster der Commune: »Indeed, >les pavés sanglantes ' become a pervasive metaphor for [...] the enraged reactionnaries who wanted to scrub Paris clean of Communard traces « ${ }^{135}$. Die Überschreitung dieser symbolischen Grenze zwischen heller Ober- und dunkler Unterwelt $^{136}$ in der Commune verbildlicht mehr als zwanzig Jahre später zuerst Adolphe Willette auf der Titelseite des Satiremagazins Le Courrier français $^{137}$ (Abb.11): Anfang 1892 wurde General Gaston, Marquis de Galliffet, der maßgeblich für die gnadenlose Niederschlagung der Commune verantwortlich war, zum général en chef der französischen Truppen erhoben ${ }^{138}$. Während der General in stolzer Pose unweit des Arc de Triomphe posiert,

132 Bolme, Art and French Commune, S. 93.

133 In Anbetracht dessen, daß die Anlage der Grands Boulevards auch von der Absicht geleitet war, den Barrikadenbau zu erschweren, mußte die Commune besonders lange nachwirken. Zur Tilgung der Barrikaden zwischen 1830 und 1871 vgl. Chauvaud, L'élision, bes. S. 276-279: »La peur des traces«. Die Thematik der symbolischen Überblendung stellt eine spezifische Erscheinung der Lichtsymbolik dar, auf die besonders die Untersuchung von LE MEN, Lanterne magique, aufmerksam gemacht hat.

134 SCHIVElbusCh, Lichtblicke, S.105f., setzt in bezug auf die Revolution von 1830 die Zerstörung von Pflaster und Laternen als Widerherstellung des Naturzustandes zueinander in Beziehung: „Das Straßenpflaster, das aufgerissen und zu Barrikaden neu zusammengesetzt wurde, gab den >natürlichen Zustand der Erde wieder frei, der [...] zum Verschwinden gebracht worden war«. Während der Commune stimmt dieses Modell, wie gezeigt wurde, für das künstliche Straßenlicht nicht mehr. Erst durch die Abwendung vom Lichtmythos der Stadt und die Zuwendung zum Sonnenlicht in der sozialistischen und anarchistischen Symbolik wird sich dies wieder ändern. Vgl. Kap. 9.1. und 9.3.

135 Borme, Art and French Commune, S. 93.

${ }^{136}$ Dazu auch die Ausführungen über das Verhältnis von >oben und >unten $<$ im Zusammenhang mit der ans Licht strebenden Wahrheit in der Dreyfusaffäre in Kap.8.1. und 8.2. 137 Ausgabe vom 10.1.1892.

138 Zu Galliffet vgl. HutTon, Historical Dictionary, Bd.1, S. 410. 

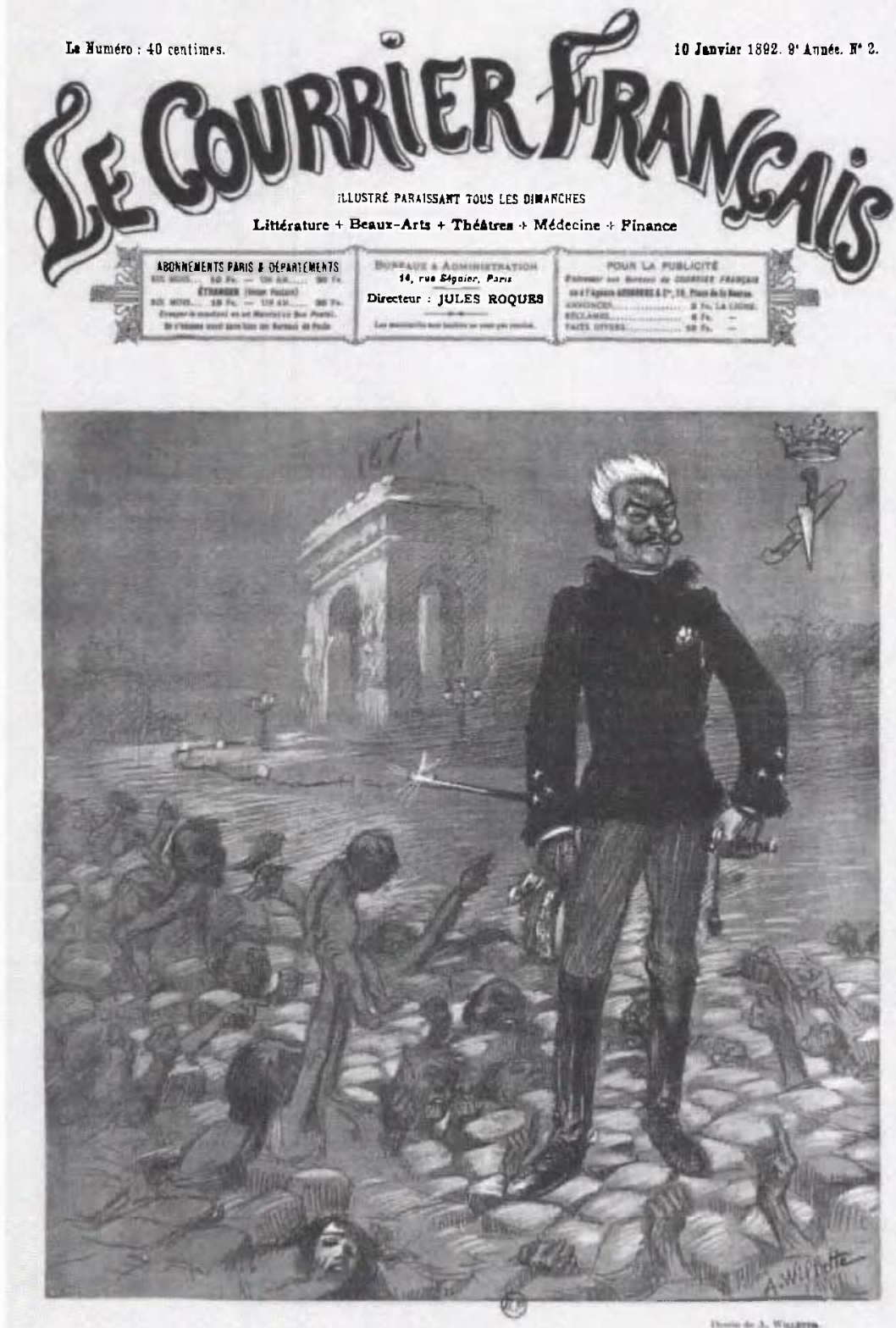

Abb. 11 Adolphe Willette: Le General de Galliffet (Titelbild), in: Le Courrier français, 10. 1.1892. Bibl. Forney, Paris. 
tauchen aus dem aufbrechenden Straßenpflaster die Toten empor, recken ihre Fäuste gen Himmel oder halten ihm leblose Kinder entgegen. Zwar scheint der General den Spuk nicht zu bemerken, doch wird deutlich, daß in der Vergangenheit begangenes Unrecht irgendwann ans Licht kommt und seine Verursacher einholen muß. Willettes Blatt ist vor allem eine Anklage für einen ungesühnt bleibenden Massenmord, der deshalb zwangsläufig auf die Republik zurückfällt, die sich dieses Versäumnisses schuldig gemacht hat ${ }^{139}$.

Ganz ähnlich interpretiert Théophile Alexandre Steinlen das Thema in der berühmten Allegorie Le Cri des pavés, die im Februar 1894 in Le Chambard socialiste erschien (Abb.12). Der Titel verdeutlicht, daß die sich mit Gewalt Gehör verschaffende Menge mit dem gleich ihr mit Füßen getretenen StraBenpflaster als Einheit gesehen wird. Die mit aller Gewalt nach oben - ans Licht - drängenden Menschen bringen die vormals ebenmäßige Steinfläche in Unordnung - und damit auch das System, das ihnen einen sogar noch darunter liegenden Platz zugewiesen hat ${ }^{140}$. Hinter der Commune-Allegorie verbirgt sich allerdings noch eine zweite Bedeutungsschicht, die das Wiederauftauchen der proletarischen Masse aus der gesellschaftlichen Versenkung in den 1890er Jahren reflektiert. Das von 1894 bis 1895 erscheinende Magazin Le Chambard socialiste ${ }^{141}$ stellte den ersten Versuch eines illustrierten sozialistischen hebdomadaire dar, das Bildpropaganda als didaktisches Material für den Bewußtmachungsprozeß eines angestrebten Klassenkampfes einsetzte. Die Commune wird in diesem ideologischen Kontext aus der Vergangenheit in eine ferne Zukunft verlegt, in der das begonnene Befreiungswerk sich vollenden wird, wie auch aus dem Kommentar des Chefredakteurs GéraultRichard zu Steinlens Blatt hervorgeht:

Quand elle [la Commune] luira de nouveau au firmament du peuple, nous pourrons dire: voici la délivrance, voici la paix! Le vol, le massacre, l'oppression s'évanouiront dans les

139 Steinlen stellte Galliffet in der Karikatur Dans toute sa gloire vor einem Leichenberg dar, der wohl an der berühmten mur des Fédérés aufgeschichtet ist: „Femmes, enfants, vieillards... rien ne lui résiste! (In: Le Chambard socialiste, 16.6.1894) Vgl. Gabriele Uelsberg (Hg.), Théophile Alexandre Steinlen. Zeichner für das Pariser Volk. Illustrationen und Karikaturen im Milieu der Jahrhundertwende, Ausstellungskatalog, Mühlheim 2000 , S. 46, Farbtafel X.

140 Zum Motiv der nach oben gereckten Hände vgl. Heinz Demisch, Erhobene Hände. Geschichte einer Gebärde in der bildenden Kunst, Stuttgart 1984, S. 169-184. Zum Komplex des Untergrundes vgl. Rosalind H. Williams, Notes on the Underground: An Essay on Technology, Society and Imagination, Cambridge 1990; speziell zum Pariser Untergrund vgl. Christopher Prendergast, Paris and the Nineteenth Century, Cambridge, Mass. 1992, S. 74-101.

$141 \mathrm{Zu}$ den Illustrationen für Le Chambard socialiste vgl. Phillip Dennis Cate, Susan GrLl, Théophile Alexandre Steinlen, Salt-Lake-City 1982, S.96: »For the didactic socialist periodical, he created obvious stereotypes and allegorical figures drawn with crisp outlines and occasional patches of color. This style represented Steinlen's commitment to reach a working class readership clearly. While the images may have appeared crude and oversimplified, they were effective propaganda for the working-class audience, imitated as such by subsequent contributors«. 


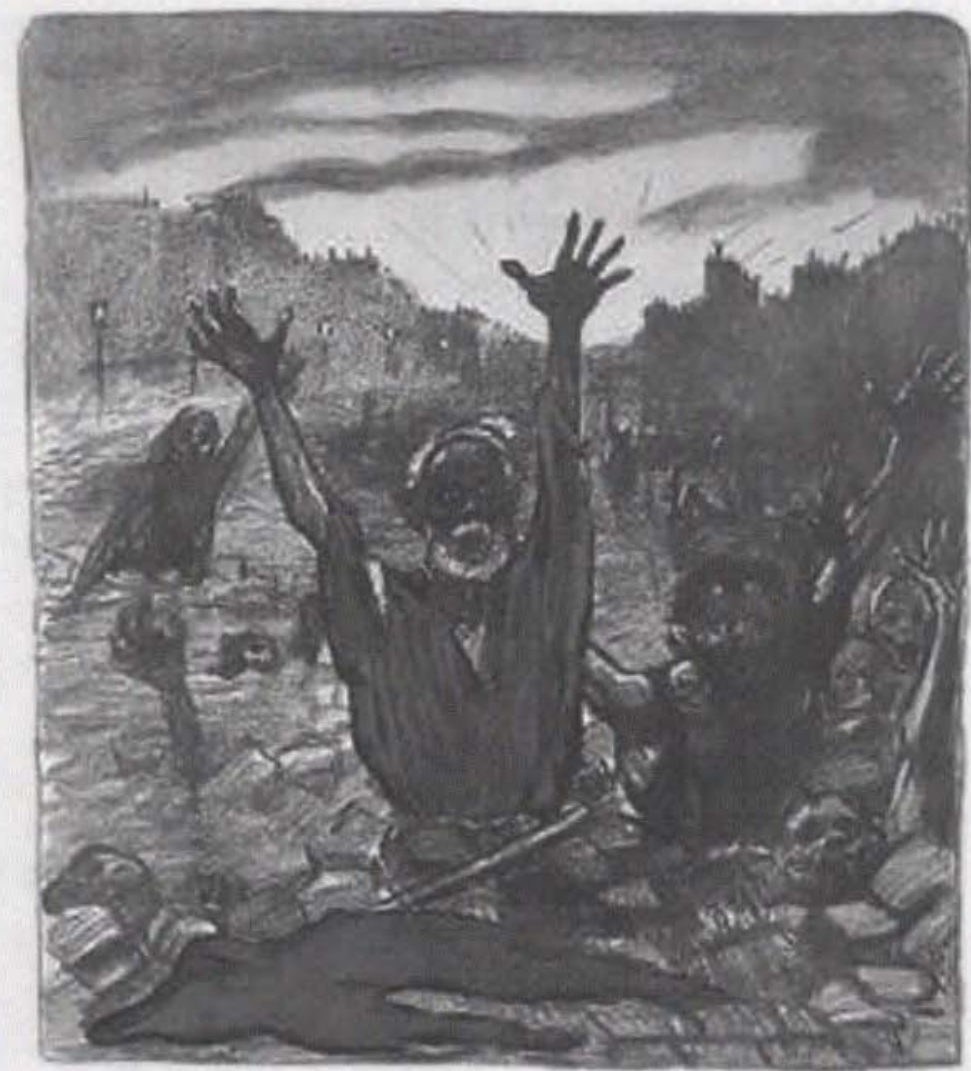

Abb. 12 Theophile Alexandre Steinlen: Le Cri des paves!, in: Le Chambard socialiste, 3. 2. 1894. Sammlung Daniela Kneißl (D.K.).

tenebres; les detritus du fumier bourgeois rouleront dans l'egout. [...] [l]'immense famille des desherites saluera l'aurore de l'universel bonheur ${ }^{142}$

Der hier als unüberbrückbar dargestellte Gegensatz zwischen dem peuple und den Vertretern der bürgerlichen Regierung kommt exemplarisch in einem weiteren Beitrag Steinlens für den Chambard zum Ausdruck, wo auch der Aspekt des als Bedrohung empfundenen Machtpotentials der Straße erneut ins Blickfeld rückt: La Sécurite des rues ${ }^{143}$ (Abb. 13) bezieht sich, wie aus dem Untertitel hervorgeht, auf den 1.Mai 1894: "Grâce à l'attitude pacifique de la police, le Premier Mai s'est passe sans incidents. (Les bons journaux)«.

142 Gerault-Richard, Cri odieux, in: Le Chambard socialiste, 3.2.1894, S. 2.

143 Le Chambard socialiste, 5. 5.1894. 


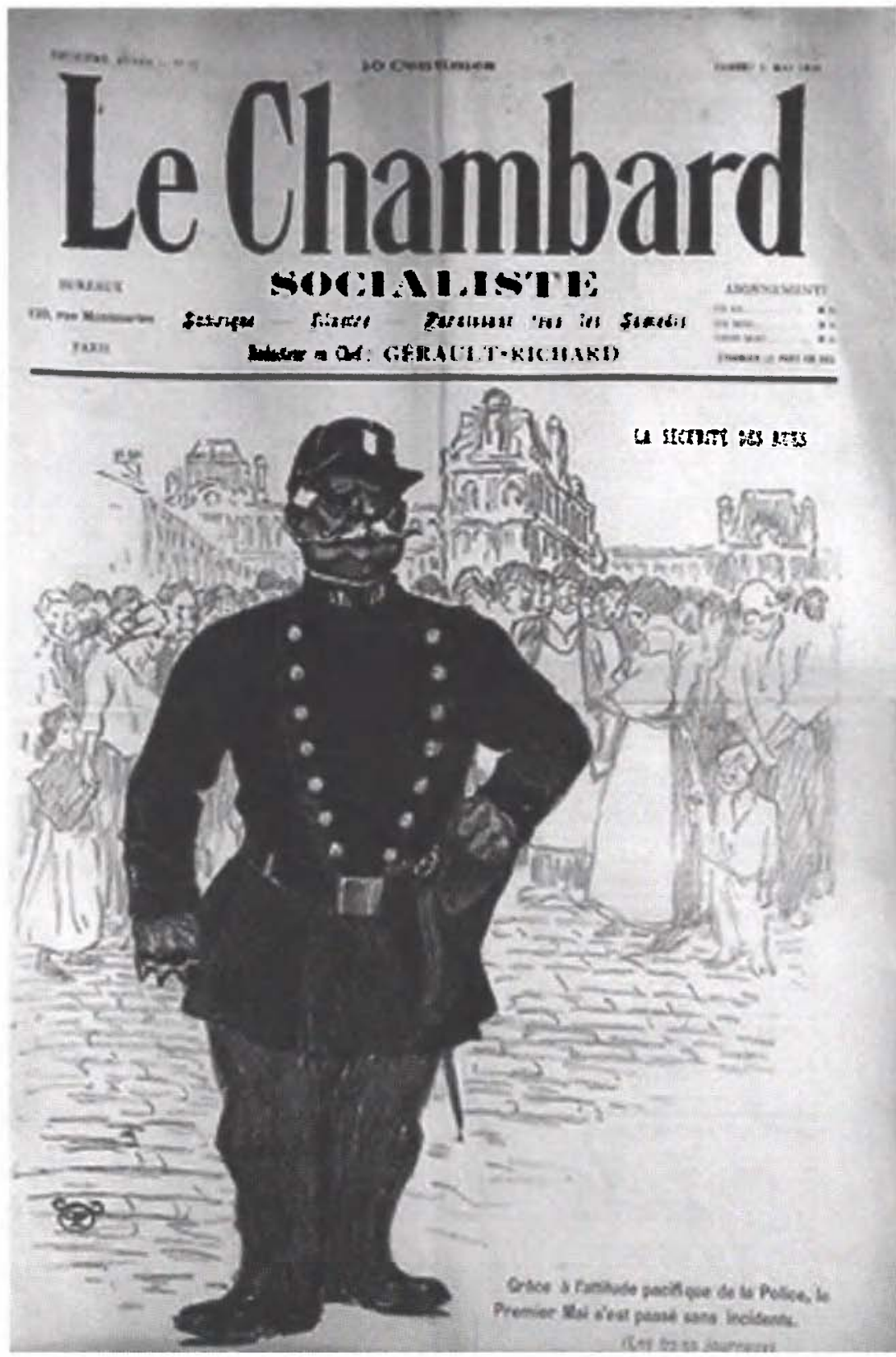

Abb. 13 Theophile Alexandre Steinlen: La Sécurite des rues. Grace a l'attitude pacifique de la police, le Premier Mai s'est passe sans incidents. (Les bons journaux), in: Le Chambard socialiste, 5.5.1894. UB Frankfurt. 
Struktur und Komposition des Blattes strafen diese Aussage jedoch Lügen. Der als massige schwarze Figur dargestellte Polizist im Vordergrund ist mit Pistole, Degen und Schlagring ausgestattet, während die hinter ihm zusammengedrängte Menge, in der auch viele Frauen mit kleinen Kindern zu erkennen sind, äußerst zart konturiert und fast farblos gehalten ist ${ }^{144}$. Der zwischen den beiden als Licht-Finsternis-Gegensatz gestalteten Bildelementen liegende freie Raum - mit dem intakten Pflaster - ist ein eindeutiges Symbol für ein System, das der Menge die Verfügung über diesen Raum nicht zugesteht: Der überschaubare Stadtraum darf nicht durch eine marschierende Menge in Besitz genommen werden. Die Zusammendrängung der Gruppe symbolisiert nicht nur die dargestellte Situation eines im Keim erstickten Aufmarsches zum 1.Mai, sondern auch die grundsätzliche Lebenssituation dieser Menschen: Die Konzentration auf engem Raum ermöglicht ihre Überwachung.

Das Gespenst des Volksaufstandes wurde in den Jahren der Entspannung nach der Amnestie vieler Communarden zunächst - auch mit den Mitteln der Karikatur - heruntergespielt, wobei der Versuch offenbar wird, eine breite Front gegen die Gegner der Republik zu bilden. Im Jahr 1879 zeigt Le Charivari ein Blatt von Baric, auf der ein Vertreter der Reaktion, der als Hut ein éteignoir trägt, vergeblich versucht, der als Kind dargestellten Republik mit einem guignol, einem Kasperltheater, Angst einzujagen ${ }^{145}$. Das Mädchen dagegen amüsiert sich sehr über die Handpuppe mit der Fahne der émeute, denn ihr Ährenkranz mit der Inschrift Concorde hebt hervor, daß ihre Wesensart die Zwistigkeit der Bürger von vorneherein ausschließt. Auch der im Hintergrund stehende Polizist hat für die Vorstellung des Reaktionärs nur nachsichtiges Schmunzeln übrig. Auffallend ist die Abwesenheit jeder ernst zu nehmenden Bedrohung und besonders der revolutionären Masse selbst - was bleibt, ist nur eine unglaubhafte Angstprojektion eines Finsterlings. Schon sieben Jahre zuvor stellte der Karikaturist Alfred Le Petit in Le Grelot das gefürchtete spectre rouge ${ }^{146}$ als zweidimensionale Attrappe dar: mit Holzwaffen und ebenfalls hölzerner torche ist der bedrohliche Anarchist zum Hampelmann verkommen, der alle verhöhnt, die ihn als ernsthaftes Argument benutzen: »Rengainez votre pantin, mon brave homme, le truc est usé, il n'effraye plus personne«. Damit ist das spectre rouge scheinbar wieder auf das Niveau zurückgesunken, das es vor der Commune schon einmal hatte: Ein artifizielles Konstrukt bürgerlicher Umsturzbefürchtungen ${ }^{147}$. Noch vor dem Krieg, im

$144 \mathrm{Zu}$ diesem Blatt vgl. Ralph Shikes, The Indignant Eye. The Artist as Social Critic in Prints and Drawings, Boston 1969, S.227, der zwar auf den Gegensatz zwischen dem Einzelvertreter der Obrigkeit und der durch diesen verdeckten Menge eingeht, aber nicht auf die Licht-Finsternis-Symbolik.

${ }^{145}$ C'est drôle! ça n'a plus l'air de lui faire peur, in: Le Charivari, 25.11.1879.

146 Le Grelot, 10.11.1872.

1471870 hatte auch Daumier das spectre rouge als Vogelscheuche dargestellt, die den Weg zur am Horizont aufstrahlenden Sonne versperren sollte. Vgl. dazu Kap. 3.2.2. 
Juni 1870 hatte Lemot für das Magazin Le Monde pour rire ${ }^{148}$ ein ganz ähnliches Bild dieses Schreckgespenstes mit brennender torche und roter Mütze entworfen. Interessant aber ist hierbei die Projektion mittels einer Laterna Magica, die einen dramatischen Beleuchtungs- und Vergrößerungseffekt des Phänomens bewirkt, nichts desto weniger aber eine Illusion ist und bleibt: Der Raum, den das spectre rouge hier vorgeblich beherrscht, existiert schlichtweg nicht, die fenstergleiche Öffnung wird lediglich vorgegaukelt ${ }^{149}$.

In Barics Puppentheater bleibt der Ernst des gesellschaftlichen Hintergrundes dagegen erhalten: Der Gendarm ist bereit, die bestehende Ordnung zu verteidigen, so, wie derjenige auf Steinlens Blatt La Sécurité des rues es schließlich tut. Die Sorglosigkeit der jungen Republik bedingt also bereits hier den von der Masse frei gehaltenen, leicht zu überblickenden Raum, dessen Unantastbarkeit der Gendarm überwacht und nach hinten abgrenzt nur wo gar kein peuple ist, kann letztlich kein Aufruhr stattfinden.

Im Rahmen dieses perfekt durchgehaltenen Verdrängungsprozesses muß die Aufarbeitung des Geschehenen offenbar einer völlig anderen Sphäre zugewiesen werden. Der Karikaturist Adolphe Willette versetzt die Konfrontation von Schuldigen und Opfern folgerichtig ins Jenseits. Am 19. Feburar 1893 zeigt die Titelseite des tendenziell anarchistischen Satiremagazins Le Courrier français eine Illustration, die geschickt zwei verschiedene Zeitebenen - die der Französischen Revolution und die der Commune - miteinander verknüpft. Neben einer geknickten (!) Laterne treffen sich zwei Diskurspaare: Marie-Antoinette und Robespierre sowie Adolphe Thiers und eine Communardin mit totem Kind. Der Königin ist der erste Teil des Bildtextes zuzuordnen: »Puisque la politique n'est pas notre affaire... pourquoi nous as-tu coupé le cou? « ${ }^{150}$ Die Haltung des Künstlers zu Marie-Antoinettes Frage, warum sie geköpft wurde (die Wunde zeigt sich als feiner Strich am Hals), ist angesichts ihrer Darstellung als frivoler, dekadenter Schäferin mit Lamm, kurzem Rokoko-Kostüm und entblößter Brust eher kritisch aufzufassen ${ }^{151}$. Die Königin wird hier weder als Herrscherin noch als heroisches Opfer gezeigt, sondern als eine Person, die zu Lebzeiten den irdischen Realitäten kaum weiter entrückt hätte sein können. Schäferkostüm und Lamm zeichnen sie ironisch als agneau innocent aus, was hier jedoch eher mit unmündiger Dummheit gleichzusetzen ist. Die Frage nach dem Warum stellt sich wesentlich aktueller und

148 11.6.1870. Vgl. Ducatel, Histoire, Bd.1, S.17, Abb.6.

149 Zum Motiv der Laterna Magica in der Karikatur vgl. Le MEN, Lanterne magique. Auf die illusionäre Öffnung eines Fensters geht der Aufsatz nicht ein, was jedoch ein wichtiger Aspekt ist, da sich hierin die Projektionsfläche in den dreidimensionalen Lichtraum ausweitet.

150 Dem Bildtext sind keinerlei Personen zugeordnet. Lediglich die Spiegelstriche weisen darauf hin, daß es sich um verschiedene Sprecher handelt. Die Zuordnung, die das Bild erst lesbar macht, bleibt aber dem Betrachter überlassen.

${ }^{151}$ Damit spielt Willette auf den Rückzug der Königin in ihre künstliche Bauernidylle in Trianon an. 
ernsthafter angesichts des im Hintergrund stehenden zweiten Diskurspaares: Thiers, mit der Jahreszahl 1871 auf der Stirn verbirgt sich entsetzt zwischen Königin und Robespierre, der im übrigen nahezu wirklichkeitsgetreu dargestellt ist und seiner Gegnerin stolz direkt ins Auge blickt. Dagegen hat sich Thiers soweit wie möglich von der namenlosen jungen Frau entfernt, die ein totes kleines Mädchen am Arm hält und dem Präsidenten folgende Frage stellt: »Pourquoi nous as-tu massacrées? « Die junge Frau mit den langen, aufgelösten Haaren trägt ein zerrissenes, blutbesudeltes Hemd, an der nackten Brust ist eine Stichwunde zu erkennen. Die Entblößung ist hier im Gegensatz zur Königin Zeichen von Armut, Vergewaltigung und Mord, der selbst vor dem nackten kleinen Mädchen nicht halt gemacht hat. Die Niederschlagung der Commune hat hier also eine ganz andere moralische Dimension als das Köpfen der Revolution, nämlich der Mord an den Unschuldigen. Die geschändete, ermordete Frau korrigiert somit das dämonisierte Bild der brandschatzenden pétroleuse ${ }^{152}$.

Die Markierung 1871 auf Thiers' Stirn macht darüber hinaus deutlich, daß hier auch die Opfer anderer ihm zur Last gelegten Massaker auftreten könnten, wie etwa das der Rue Transnonain 1834 oder des Juniaufstandes von $1848^{153}$. Der centenaire der Hinrichtung des Königspaares dient nur vordergründig ${ }^{154}$ für die Rückholung der semaine sanglante in das moralische Gewissen und das historische Bewußtsein. Auf diesem Umweg wird der Commune der ihr aberkannte Platz in der Geschichte zurückgegeben.

Die Zusammenkunft findet im Schatten einer Laterne statt, deren Mast geknickt ist, wodurch das Glasgehäuse zur Seite geklappt ist. Der nutzlos gewordene Lichtträger kann also nicht zur Erhellung der Umstände beitragen. In der Revolution diente die Laterne als Galgen zur Durchsetzung einer neuen Ordnung, in der Commune dominierte sie zunächst als Symbol der Teilhabe aller am Licht ${ }^{155}$. Beides wird hier nun als gescheitert erkannt. Dadurch wird die ungebrochene Aktualität der Commune und ihrer Anliegen betont. Das im Hintergrund erkennbare Plakat des Comité de salut public verdeutlicht noch einmal, daß der Erfolg einer Revolution an nichts anderem als dem Wohl aller zu messen ist. Der auf den Gräbern der Communarden gegründete Triumph der Republik muß an diesem Maß kläglich scheitern - was seinen

152 Vgl. dazu Kap.4.4.

153 Honoré Daumier schuf dazu die Lithographie Rue Transnonain, le 15 avril 1834 (Association mensuelle, Blatt 24, Juli 1834). Dazu Albrecht, ZBinden, Honoré Daumiers "Rue Transnonain«.

${ }^{154}$ In Anbetracht der Bildkomposition, die von Marie-Antoinette und Robespierre beherrscht wird, ist diese Vordergründigkeit durchaus wörtlich zu verstehen. Auch das Datum des 19.2.1893 offenbart die zum eigentlichen Kern des Blattes hinführende Funktion der Französischen Revolution: Weder die Hinrichtung von Ludwig XVI. am 16.1.1793 noch die von Marie-Antoinette am 16.10.1793 hatte zu diesem Zeitpunkt ein wirkliches Jubiläum.

155 Vgl. dazu Kap. 5.2. 
bildlichen Ausdruck in dem eklatanten Größenunterschied zwischen Thiers und Robespierre findet. Die Sicherheit im öffentlichen Raum, für die das Licht der Laterne ein unabdingbares Element ist, existiert nicht als unabhängige Größe, sondern wird durch die Herrschenden definiert und gewährt. Willette spielt damit keineswegs auf den gewaltsamen Umsturz der bürgerlichen Ordnung an, der vor der Zerschlagung der anarchistischen Bewegung 1894 durchaus denkbar schien ${ }^{156}$, sondern auf das völlige moralische Versagen der staatlichen Macht: Das bürgerliche Modell, das mit der Französischen Revolution begann, hat durch den Verrat am Volk seine Legitimation verloren - und dadurch auch die von oben legitimierten lumières, wie sie sich im den Raum ausleuchtenden Symbol der Straßenlaterne präsentieren ${ }^{157}$.

Die symbolische Bedeutung von oben und unten kennzeichnet auch die Darstellung der personifizierten Commune, die sich parallel zur Organisation der Arbeiterbewegung entwickelte. Der ehemalige Communarde Pilotell stellte diese 1879 in seinem Album Avant, pendant et après la Commune ${ }^{158}$ als am Boden liegende Tote dar, aus deren Brust Blut fließt. Der Titel ist ein Zitat nach Victor Hugo: Le cadavre est à terre et l'idée est debout ${ }^{159}$. Die am Horizont aufsteigende Sonne wird räumlich noch von der aus einem Haufen aufgetürmter Pflastersteine ragenden Fahne überragt, auf der die Verdienste der Commune zu lesen sind und auf welche die offenen Augen der Toten gerichtet sind:

La Commune de Paris / a sauvé la République / décrété la souveraineté / du travail, / l'athéisme, / la destruction des /monuments éternisant / la haine entre peuples.

Die bereits in der Raumgliederung angelegte letztendliche Unerreichbarkeit dieser Ideale für die Gegenmaßnahmen der bürgerlichen Reaktion knüpft sich ganz offensichtlich an die Erwartung einer Auferstehung der Commune selbst. Die jedoch wiederum in unbestimmte räumliche Ferne entrückte Sonne spielt auf die Unvorhersehbarkeit dieses Ereignisses an. ${ }^{160}$

Als historische Vorwegnahme des propagierten Siegs der Arbeiterklasse fand diese Auferstehung im Rahmen der sozialistischen Bildpropaganda statt.

156 Vgl. dazu Kap. 9.2.1.

157 Zur Bedeutung dieses Motivs Ende des 19. Jahrhunderts vgl. Kap. 8.1.1.

158 Avant, pendant et après la Commune, London 1879, BnF., Est., Neuauflage Paris 1969, hg. v. Charles Feld. Dazu Thulier, La Commune de Paris, S.323: "Si, pour Pilotell, la conception de ce recueil répond à celle d'un livre de deuil, elle relève aussi d'un livre de l'obscurité et de l'obscurantisme, où se joue en permanence le combat entre les ténèbres et la lumière«.

159 Abgebildet bei Leith, War of Images, S.129, Abb.54. Diese Zeile findet sich in der Ode La Voix de Guernesey, die Hugo im Jahre 1867 der Niederlage des italienischen Freiheitskämpfers Garibaldi gegen die Truppen Napoleons III. widmete. Ders., CEuvres complètes, Bd.5, Paris 1985, S. 1047.

160 Thllier, La Commune de Paris, S.317, spricht von einem "paradoxe d'une révolution étouffée mais survivante «: "Pilotell évoquait la violente répression de la Commune, mais prévenait aussi de la pérennité de son œuvre, et de l'actualité permanente de ses idéaux«. 
Im Jahr 1907 publizierte Steinlen seine Vision der Commune in der Zeitung L'Humanité, dem offiziellen Organ des Sozialistenführer Jean Jaurès: L'Anniversaire de la Commune ${ }^{161}$ zeigt eine sich zum Himmel streckende, monumentale Frauenfigur mit geballten Fäusten, von der ein Leuchten ausgeht. Mit aller Gewalt arbeitet sie sich aus einer nicht näher zu bestimmenden, felsenartigen schwarzen Formation hervor, die ihren Unterleib noch umklammert hält, während sich hinter ihr eine riesige Menschenmenge ansammelt.

Der nebenstehende Artikel von Jean Jaurès mit dem Titel Hier et demain beurteilt einerseits die Commune als nicht wiederholbares, an einzigartige historische Umstände geknüpftes Ereignis, das zudem zu spontan gewesen sei, um überleben zu können und seine eigentliche Fortsetzung in der Entwicklung des Gewerkschaftswesens gefunden habe. Andererseits aber betont er die ungebrochene Kraft des esprit de la Révolution, den er nicht zufällig mit dem Feuer vergleicht:

Libre et fluide comme la flamme, il se nourrit et se diversifie de la substance changeante des événements; et ce que le prolétariat aime et salue dans le dix-huit mars, ce n'est pas un type immuable et une forme figée de la révolution, c'est l'ardeur d'enthousiasme et d'espérance, c'est l'audace d'affirmation ouvrière qui a anticipé l'évolution ${ }^{162}$.

Gerade diese Unberechenbarkeit des revolutionären Gedankenguts und die auch hier offen ausgesprochene Übertragbarkeit auf die Masse waren es, die als Angstpotential das Denken der Republikgegner auf lange Sicht bestimmten.

${ }^{161}$ L'Humanité, 18.3.1907. Vgl. die retrodigitalisierte Ausgabe der Zeitung auf http:// gallica.bnf.fr.

162 Ibid. 


\section{4. »Du danger des illuminations au pétrole républicain« Das verderbliche Feuerlicht der Republik im Spiegel der rechten Presse}

Das Trauma des brennenden Paris blieb in der III. Republik lange lebendig, wobei das Feuer über seine traditionelle Revolutionsmetaphorik hinaus zur Synekdoche der plötzlich entartenden Bedrohung schlechthin wurde. Exemplarisch stehen dafür die Panoramen der Feuerinfernos an verschiedenen Stellen der Stadt, die Le Monde illustré in den Monaten nach dem Ende der Commune veröffentlichte ${ }^{163}$. Bilder wie diese prägten die Untrennbarkeit von Commune und Brandstiftung auf Jahrzehnte hinaus. Besonders evident werden diese Angstprojektionen innerhalb der kirchlich-konservativen Presse, die den extremen Antiklerikalismus der Commune als Tiefpunkt des gesellschaftlichen Niedergangs und die Brände als göttliche Strafe, als Hölle auf Erden, darstellten ${ }^{164}$. Apokalyptische Vergleiche sind typisch für die Entstehung der »légende noire de la Commune de Paris « ${ }^{165}$. Von konservativer Seite gerichtete Appelle an die nationale Einheit bedienten sich daneben zeitgleich durchaus der reinigenden Metaphorik des Feuers, das gleichsam als extremste Erscheinung des Restitutionsprozesses gesehen wurde ${ }^{166}$.

Demgegenüber betonte die kirchliche Presse die Straf- und Vernichtungsfunktion des Feuers, die zum Gradmesser der Dekadenz innerhalb der Gesellschaft wurde. Das wichtigste kirchliche Magazin Le Pèlerin entwickelte eine spezifische Bildsprache, die Feuerkatastrophen jeder Art - von außer

163 Vgl. z. B.: 10.6.1871: À la Bastille. Incendie des bâteaux de pétrole sous la voûte du canal Saint-Martin; 1.7.1871: Les Journées de mai. Incendie des docks de la Villette; 7.10.1871: Histoire de Paris. Les nuits de mai.

164 Zum katholischen Dekadenzgefühl: Koenraad Walter SwarT, The Sense of Decadence in Nineteenth Century France, Den Haag 1964, S.128f.: »Many catholics saw in the national disaster a form of divine punishment for the many aberration of the French people such as lack of faith, disintegration of the family, decline of the birth rate, and secularism in Church and State. Some of them predicted a miraculous turn of events including a restoration of pope and king to their legitimate positions if the French people were willing to expiate their sins«. Zum Feuer der Commune in kirchlicher Sicht vgl. David Harvey, Consciousness and the Urban Experience. Studies in the History and Theory of Capitalist Urbanization, Baltimore 1985, S. 237: "Within a year, the pope himself was describing the communards as $>$ devils risen up from hell bringing the fires of the inferno to the streets of Paris . The ashes of the city became a symbol of the Commune's crimes against the Church and were to fertilize the soil from which the energy to build Sacré-Coeur was to spring «. Allg. zum Antiklerikalismus unter der Commune vgl. Pierre Pierrard, L'Église et les ouvriers en France (1840-1940), Paris 1984, S.261-263.

165 Ibid., S. 261.

166 Vgl. Énault, Paris brûlé, S. 266: »On dit que la flamme purifie. Ah! s'il en est ainsi, sur ce bûcher funèbre de Paris qui brûle encore, jetons tout ce qui nous a perdus, tout ce qui est misérable et mauvais en nous, tout ce qui a produit l'abaissement funeste du caractère national 
Kontrolle geratenen Fest-Feuerwerken ${ }^{167}$ über im Flammeninferno endende Ausstellungen ${ }^{168}$ und Kinovorführungen ${ }^{169}$ bis hin zu den méfaits de l'électricité 170 - noch in den Jahren nach der Jahrhundertwende mit dem Unterton grundsätzlicher Fortschrittskritik darstellte und die Bedrohlichkeit der modernen Welt in aufwendigen, doppelseitigen Illustrationen implizit stets auf die paradigmatisch gewordenen Bilder der Brandkatastrophen des Jahres $1871 \mathrm{zu}-$ rückbezog ${ }^{171}$. Auf dieselbe Weise wurden anarchistische Attentate auf kirchliche Güter kommentiert, die so nur eine weitere Komponente einer aus den Fugen geratenen Welt repräsentierten ${ }^{172}$. Auch ausartende Streiks wurden als unmittelbare Fortsetzung der Commune gefürchtet, wobei die Plünderung und Verbrennung sakraler Gegenstände als alarmierendes Vorzeichen wahrgenommen wurden ${ }^{173}$. Das aufrührerische Potential der Unterschichten schien einem Damoklesschwert gleich ständig über der Gesellschaft zu schweben ${ }^{174}$. Auf ultrakonservativer Seite konzentrierte sich diese Furcht lange im Zerrbild der pétroleuse ${ }^{175}$ :

\author{
167 Le Pèlerin, 27. 9. 1908: Tragique feu d'artifice (Louvain, Belgien). \\ 168 Le Pèlerin, 28.8.1910: Incendie de l'exposition de Bruxelles. \\ 169 Le Pèlerin, 26.1.1908: Théâtre en feu (Kinobrand in Pennsylvania). \\ 170 Le Pèlerin, 20.9.1908: Les méfaits de l'électricité. Incendie de l'hôtel des Postes à \\ Grenoble.
}

171 Grundlegend zum Verhältnis von Kirche und technischem Fortschritt in der III. Republik: Michel Lagrée, La bénédiction de Prométhée. Religion et technologie, XIX ${ }^{\mathrm{e}}-\mathrm{XX}^{\mathrm{e}}$ siècle, Paris 1999. Die internationale Durchmischung in Le Pèlerin läßt darauf schließen, daß weltweite Feuerkatastrophen bewußt ausgesucht wurden, um den Eindruck eines apokalyptischen Weltenbrandes zu erwecken.

172 U.a. Le Pèlerin, 26.6.1904: "Attentat anarchiste. Après les églises de Paris, d'Aubervilliers, de Toulon, l'église de Suresnes a été profanée et incendiée par les anarchistes«. Die doppelseitige Illustration zeigt den Vorgang der Brandstiftung. Vgl. auch Le Pèlerin, 2.10.1904: "À Graçay, des malfaiteurs brûlent une statue de la Vierge « (mit doppelseitiger Illustration).

${ }^{173}$ Le Pèlerin, 19.4. 1906. Vgl. dazu die großformatige Illustration und den Kommentar: "Contre les églises. C'est bien ce que l'on prédisait, les grèves tournent à la révolution; on attaque les gendarmes et les soldats, on brûle les maisons et les églises. Dans le Pas-deCalais, les mineurs grévistes ont placé une cartouche de dynamite contre les murs de l'église de Montigny-en-Gohelle. [...] L'église de Saint-Nicolas vient d'être incendiée«. Zur Feuersymbolik des Anarchismus vgl. Kap. 9.2.1.

174 Dieses Potential wurde oft auch als selbstzerstörerisch dargestellt: So berichtete Le Pèlerin im Jahr 1910 von der Explosion, die vier Kinder aus Belleville mit einer zufällig gefundenen Dynamitkartusche ausgelöst hatten. Die Illustration zeigt eine gewaltige Feuerwolke, die ihre Verursacher mit ins Verderben reißt. Le Pèlerin, 7.8.1910: Imprudence d'enfants.

175 Allg. zu den pétroleuses vgl. Édith Thomas, Les pétroleuses, Paris 1963. Zu den symbolischen Aspekten vgl. Gullickson, Pétroleuse, sowie DiEs., Unruly Women. Vgl. auch Caron, Les feux de la discorde, S. 81-87 und Patricia-Pia CÉlérier, Les pétroleuses de la Commune de Paris ou le mythe terroriste, in: Romance Quarterly 44 (1997), S.93-98. Zur Bedeutung des Bildes v.a. in der zeitgenössischen Geschichtsschreibung vgl. Jeannene M. Przyblyski, Between Seeing and Believing. Representing Women in Appert's Crimes de la Commune, in: Dies., Dean De La MotTe (Hg.), Making the News. Modernity and the Mass Press in Nineteenth-Century France, University of Massachusetts 1999, S.233-278. 
This representation of the dangerous, unruly woman - the female incendiary - became an international symbol, not only of the Commune itself, but also of the evils of revolution, and played a pivotal role in creating a long-lasting emotional response to what was a shortlived (ten-week) revolution in France ${ }^{176}$.

Als Frau der Unterschicht, die sich in der Öffentlichkeit Geltung verschaffen und an der Macht teilhaben will, ist die pétroleuse die äußerste Konsequenz der revolutionären Raumeroberung ${ }^{177}$.

Die Bildpublizistik überbot sich geradezu mit Darstellungen der zu allem entschlossenen Megäre, die, ausgerüstet mit rauchender Brandfackel und Petroleumkanister, ihr zerstörerisches Werk betreibt ${ }^{178}$. Dabei verwischten sich schnell die Grenzen zwischen Karikatur und vorgeblicher Bilddokumentation tatsächlicher Ereignisse: Nicht zuletzt Darstellungen in Le Monde illustré, wie etwa das Blatt Les Pétroleuses et leurs complices ${ }^{179}$ von Frédéric Lix, schmückten das Bild der gewissenlosen Brandstifterin immer weiter aus, obwohl nachweislich die meisten Feuer von Männern gelegt wurden ${ }^{180}$. Bestimmte Charaktere, wie besonders die Communardin und Frauenrechtlerin Louise Michel, standen dabei auch in der republikanischen Presse als ständig schwelender Gefahrenherd für die (patriarchalische) Republik. Die Verschmelzung von Louise Michel mit der pétroleuse gewann nach ihrer Rückkehr aus der neukaledonischen Verbannung neue Brisanz: Am 18. März 1883 stellte Émile Cohl die Feministin in La Nouvelle Lune als L'Ange de la liberté dar, bewaffnet mit Petroleumflasche und torche und bereit, die sie umtanzenden Winzlinge der republikanischen Presse - die für ihre Amnestie eingetreten war - zu verbrennen ${ }^{181}$ (Abb.14). In ihrer mythischen Struktur erscheint die pétroleuse

176 Gullickson, Pétroleuse, S. 241.

177 DiEs., Unruly Women, S. 223: »She embodied the message that men could expect anarchy and destruction if women escaped the home and the bonds of civilisation and were allowed to give rein to their worse instincts. Freed women, they revealed, would forget their feminity $[\ldots]$ and destroy civilisation «.

178 Paul KLENCK, Une pétroleuse, Einblattdruck, 1871. BnF, Est., vgl. Gullickson, Unruly Women, S.222, Abb.23; Paul Bertall, La Barricade, Blatt 37 des Albums Les Communeux 1871, abgebildet bei LeITH, War of Images, S.136, S.73; Eugène GiRARD, La femme, émancipée, repandant la lumière sur le monde, Einblattdruck, 1871. BnF, Est., vgl. MarieClaude SchapIRA, Die Fahnenträgerin in der Ikonographie der Pariser Commune, in: RütTen u. a. (Hg.), Die Karikatur zwischen Republik und Zensur, S.486, Abb.528, sowie Gullickson, Unruly Women, S.185, Abb.17.

179 Le Monde illustré, 3.6.1871. Vgl. Gullickson, Unruly Women, Abb.auf S.2, sowie BoIme, Art and French Commune, Abb.16.

180 Gullickson, Unruly Women, S.170. Vgl. auch CARon, Les feux de la discorde, S.84: "Le rôle des pétroleuses a été volontairement surévalué, afin de délégitimer la Commune«. 181 Louise Michel war zwar schon am 16.10.1879 begnadigt worden, wovon die Verwaltung der Gefangenenkolonie in Neukaledonien am 23.2.1880 in Kenntnis gesetzt wurde, doch die Bürgerrechtlerin wollte nicht vor dem Erlaß der Generalamnestie für alle Kommunarden, die am 11.7.1880 in Kraft trat, nach Frankreich zurückkehren. Vgl. dazu Édith Thомas, Louise Michel ou la Velléda de l'anarchie, Paris 1971, S. 182. Zur Darstellung der Feministin als pétroleuse vgl. auch ein Blatt, das Luque $1880 \mathrm{im}$ supplément von Le Monde parisien veröffentlichte: Darauf ist Louise Michel mit torche und bluttriefendem Messer 


\section{LANGE DE LA LIBERTE, par Em. GOHL}

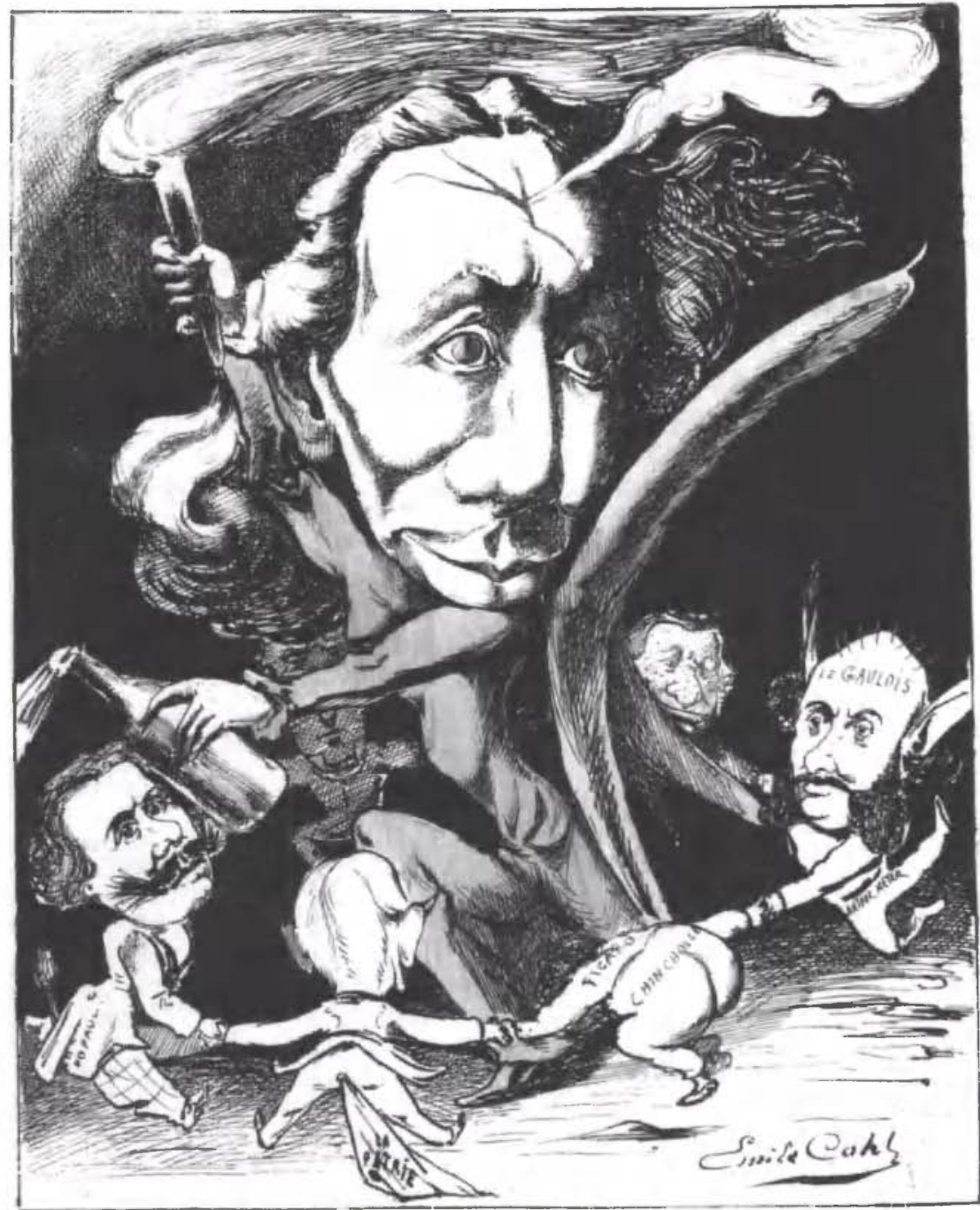

Des ailes' Des ailes?

Abb. 14 Emile Cohl: L'Ange de la liberte, in: La Nouvelle Lune, 18.11. 1883. Univ. de Lyon II, Bibl. arts et lettres. 
als rein destruktives Antibild zur heroischen Licht- und Freiheitsbringerin, das spätestens durch Delacroix' Gemälde zum Archetypus geworden war ${ }^{182}$. Für ihre Gegner war die Republik die verkommene, versoffene Brandstifterin, die, stets ausgerüstet mit einer torche, ihre Macht mißbraucht. In Anbetracht der Tatsache, daß Frauen und Alkoholiker nach Überzeugung der Zeitgenossen die übelste Ausprägung der Masse darstellten ${ }^{183}$, war die Republik in dieser Erscheinung eine Akkumulation der aus der Commune in die République opportuniste hinübergelangten Aufrührer, die der Republik ihr häßliches Gesicht verliehen.

Schon in den 1830er Jahren wurde die Republik als typische tricoteuse der Terreur dargestellt, die durch ihr Alter zugleich eine dunkle Vergangenheit repräsentierte und in direktem Gegensatz zur traditionell republikanischen Lichtsymbolik des Fortschritts stand:

Das Geschichtsbild einer 'Schreckensherrschaft , das hier festgeschrieben wird, nimmt die Ikonographie des Republikanismus dergestalt in Beschlag, daß jedwede Aussage [...] über eine Positivität des Zukünftigen eingeholt wird von der Negativität des immergleichen< Alten. Die Republik ist die >Alte ${ }^{184}$.

Dieses Schreckensbild erhielt mit der pétroleuse eine weitere, gruselige Komponente und durchzog die antirepublikanische Bildpublizistik wie ein roter $\mathrm{Fa}$ den $^{185}$ : Als Symbol der stets latenten Gefahr einer neuen Commune ist die zur pétroleuse gewordene République zugleich Führerin und beliebig erweiterbare Projektionsfläche der ihre Zeit abwartenden Masse: So zeigt das legitimistischroyalistische Satiremagazin Le Triboulet im Jahr $1879^{186}$ die zerlumpte Personifikation der Commune, die mit der torche in der Hand aus dem Grab steigt,

dabei, ihre politische Tätigkeit wiederaufzunehmen. Vgl. Ducatel, Histoire, Bd.2 (1975), S. 117.

182 Gullickson, Unruly Women, S.219: »the symbolic inversion of Delacroix’ liberty «. Zur Bedeutung von Delacroix' Liberté als Lichtbringerin vgl. Jörg TRAeger, L'Épiphanie de la Liberté. La Révolution vue par Eugène Delacroix, in: Revue de l'art 98 (1992), S. 9-28. Zur Übertragung dieses Mythos auf die heroischen weiblichen Allegorien der Commune vgl. ScHAPIRA, Fahnenträgerin, S.477-488. Das Bild der Communardin wurde darüber hinaus direkt von der Allegorie der kämpferischen France beeinflußt: Nach der Kapitulation zeigt Alfred Le Petit diese noch als heldenhafte Fahnenträgerin mit entblößter Brust, die vor der Sonne der Vengeance nach Vergeltung schreit (La France, in: La Charge, 13.8.1870). Drei Jahre später, anläßlich des lang ersehnten Abzugs der Besatzungstruppen, ist France dagegen zur schwachen, leidenden Frau geworden, die wie aus einem Alptraum erwacht, während die Sonne am Horizont hochsteigt (Le Réveil, in: Le Grelot, 23.9.1873).

183 Barrows, Distorting Mirrors, S. 43.

184 Rürten, Republikanische Opposition, in: Ders. u.a. (Hg.), Die Karikatur zwischen Republik und Zensur, S. 89. Vgl. auch Fuchs, Karikatur, S. 358 zu Le Triboulet: »Er machte Marianne zur wüsten, abstoßenden, keifenden Megäre, zu einer widerlichen ralten Schlampe $[$.... - die altgewordene Nana, das ist die dritte Republik «. Erstaunlicherweise erwähnt Fuchs jedoch die Nähe der meisten Darstellungen zur pétroleuse nicht.

${ }_{185}$ Zur Bedeutung dieses Gegenbildes als Kritik an der republikanischen Festkultur vgl. Kap. 7.2.

186 La Résurrection, in: Le Triboulet, 14.9.1879. Abgebildet bei SÁnchez, Challenge, S. 484, Abb. 20. 
dessen steinerne Abdeckung die mit Lorbeerkranz und phrygischer Mütze bekrönte Republik selbst anhebt. In dieser Résurrection - so der Titel des Blattes - kommt unmittelbar die Angst vor einer Rückkehr der unteren Schichten an die Macht zum Ausdruck, der die Republik angeblich Vorschub leistete. Die Wiederkehr nach oben hat dabei absolut nichts mit der Gewinnung von Licht im Sinne von Erkenntnis zu tun ${ }^{187}$. Im Gegenteil, die abstoßende Gestalt bringt ihr eigenes gefährliches Licht mit, das die Welt ins Chaos stürzen soll. Unbeirrt und unbelehrbar verfolgt sie ihren Weg nach vorn - in die zu zerstörende Zukunft. Die im Hintergrund stehende Republik hat mit der Öffnung des Grabes auch ihr eigenes Schicksal besiegelt: Sie war nur Mittel zum Zweck, nun werden die unkontrollierbaren Kräfte an ihr vorbeiziehen. Die Zugehörigkeit zu den tiefsten gesellschaftlichen und moralischen Abgründen kennzeichnet auch die mit Fledermausflügeln als Nachtgeschöpfe gebrandmarkten Communarden, die vor ihrem Idol auf die Knie fallen. Der Status einer veritablen Ersatzreligion, den die Commune genießt, spielt nicht zuletzt durchaus treffend auf die Ähnlichkeiten von sozialistischer Verklärung der (irdischen) Zukunft und christlicher Erlösungserwartung an, um sofort die Schreckensvision ihrer Verwirklichung in den düstersten Farben auszumalen: Auch der säkularisierte dies irae bringt das brennende Inferno, aber die tiefe Verderbtheit der Commune und ihrer Anbeter schließt jedwede Möglichkeit eines gerechten letzten Gerichtes von vorneherein aus. Die Wechselwirkung zwischen heroisierter Erinnerung an die Commune, der Konstruktion eines Abgottes und der $\mathrm{Zu}$ kunftsprojektion stellte eine Karikatur in Le Triboulet drei Jahre später dar (Abb.15): Drei ehemalige Communarden, darunter ein Nationalgardist, malen hingebungsvoll an einem Ganzkörperporträt der Commune: Diese ist wiederum die bullige pétroleuse mit der Brandfackel, die phrygische Mütze auf dem Kopf, der von einem strahlenden Nimbus umgeben ist. Die baldige Vollendung des Werkes wird im Bildtext angekündigt: "Socio, mon ami, encore une ou deux petites retouches comme celle-ci et je crois que notre œuvre sera parfaite!« Gemalt wird das düstere Bild nicht mit Öl, sondern mit essence de pétrole, was verdeutlicht, daß die hier dargestellte Idee und Vision in ihrem Innersten destruktiven Charakter hat ${ }^{188}$. Das Petroleum, das unter der Commune vom Leuchtmittel zur gegen Ordnung und Fortschritt gerichteten Waffe mutierte, behielt seinen fatalen Ruf über Jahrzehnte hinweg ${ }^{189}$ :

${ }^{187}$ Darin zeigt sich die völlige Negierung des republikanischen Erziehungsideals als Vermittlung der lumières. Vgl. dazu Kap.6.2.

188 Das Malen in Petroleum statt in Öl negiert in sich bereits den Vorgang des Schaffensprozesses, da es ja nur auf die Zerstörung abzielt. Auch Cham bedient sich dieses Bildes in seinen Commune-Karikaturen in L'Ouvrier, 8.8.1874: Angesichts eines Ölbildes kommentiert eine ehemalige pétroleuse: »Moi aussi, j'en ai fait de la peinture, et à l'huile encore! de pétrole. En ai-je badigeonné de ces monuments, sous ma chère Commune«. (Nathan, Cham, S.210, Abb. 189).

189 Vgl. LagréE, Bénédiction, S. 136: Besonders in der Provinz kam es vor, daß Händlern, die Petroleum als Petroleum und nicht als luciline, saxoléine oder unter einem anderen 


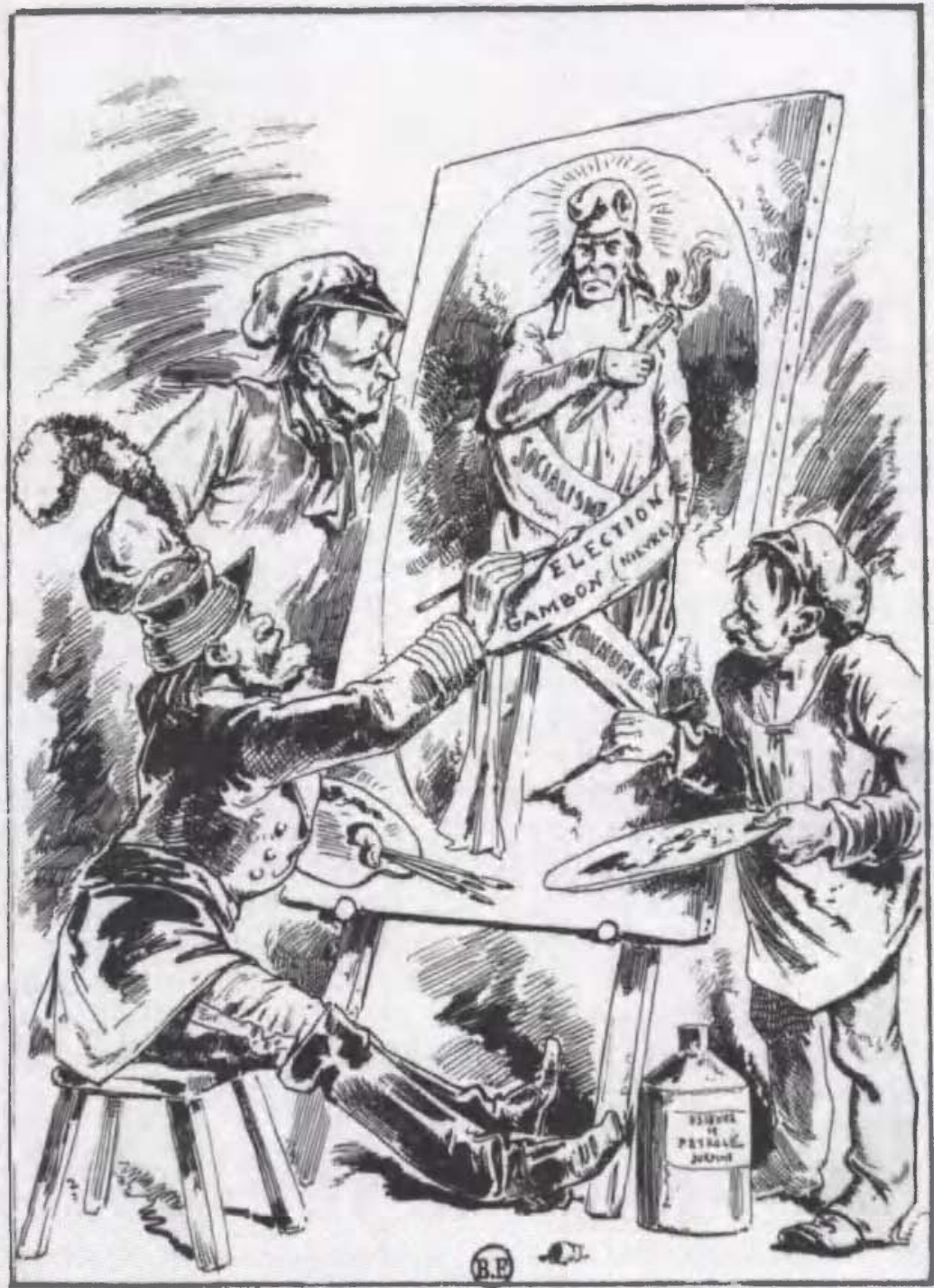

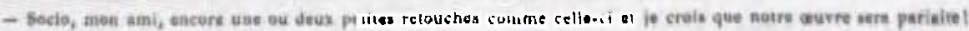

Abb. 15 Anonym: Socio, mon ami, encore une ou deux petites retouches comme celle-ci et je crois que notre auvre sera parfaite!, in: Le Triboulet, 2.7. 1882. Bibl. Forney, Paris. 
Le succès du pétrole lampant pâtit fâcheusement des événements de 1871: Commune de Paris et invasion prussienne, qui lui procurèrent finalement [...] une connotation infernale. [...] En France, [...] le pétrole était une épouvante, une horreur, une proscription ${ }^{190}$.

Noch unmittelbar an der Wende zum 20. Jahrhundert spielte die Werbung mit diesem negativen Mythos, indem sie den Teufel als Werbeträger einsetzte ${ }^{191}$.

Die Rückübertragung dieser Konnotation auf die Zeit der Belagerung, als das Petroleum für die Notbeleuchtung auf den Straßen unabdingbar war, zeigt die bereits erwähnte Darstellung L'éclairage ${ }^{192}$ aus dem Album Paris assiégé von Draner, das nach der Niederschlagung der Commune Szenen aus dem Krieg in Erinnerung rufen sollte (Abb.6, S.96): Das Petroleum wird in der Rückschau zum Symbol des Niedergangs, die Umrüstung der Gaslaternen zu Petroleumlampen zu einem bösen Omen für die Entartung der lichtbringenden flambeau zur verzehrenden torche. Für die Ultrakonservativen aber ist das Petroleum das republikanische Licht schlechthin - die einzige 'Erleuchtung, die von dieser Seite zu erwarten ist. Eine Karikatur des Triboulet von 1880 etwa greift auf die berühmte Anekdote des Treffens zwischen Alexander dem Großen und dem Philosophen Diogenes zurück ${ }^{193}$ (Abb.16). Auf die Frage, ob er ihm einen Wunsch erfüllen könne, antwortet der bedürfnislose, in einem Faß lebende Kyniker: „Ôte-toi de mon soleil!« Die Frage Alexanders ist im Bildtext nur mit Punkten angedeutet. Sie könnte theoretisch auch anders lauten und ist ohnehin vollkommen bedeutungslos. Denn die Antwort des besessenen Communarden in der Gestalt des heruntergekommenen Diogenes wird immer dieselbe bleiben, ganz gleich, was ihm der als Alexander kostümierte Gambetta auch anbietet. Entschieden schiebt Diogenes ihn von den Petroleumkanistern weg, auf die sein irrer Blick fixiert ist. Das Thema der völligen Bedürfnislosigkeit, die zur völligen Freiheit führen soll, wird hier radikal umgedeutet: Die Ablehnung von Kultur und Zivilisation wird zur potentiellen Gefahr, die freiwillig gewählte Existenz des antiken Philosophen am Rande der Gesellschaft mutiert zur Parabel für die Bewohner der quartiers de l'est. Einmal mehr tritt deutlich hervor, daß die Zusammenhänge zwischen der Protestbewegung und der miserablen materiellen Situation der Unterschicht mehr oder weniger negiert wurden. Das elende Erscheinungsbild ist nicht mehr die Konsequenz der wenig erfreulichen Lebensumstände,

euphemistischen Namen anboten, die Schaufenster eingeschlagen wurden. In der katholischen Presse verlor das Petroleum seinen Status als Brennstoff des Höllenfeuers erst nach der Jahrhundertwende.

190 Ibid., S. 136. Vor 1871 genoß das Petroleum gerade in kirchlichen Kreisen ein positives Image, da es als Bestätigung für den Wahrheitsgehalt der Bibel angesehen wurde: In Deut 32, 13 verwenden die Juden im Gelobten Land „Öl aus harten Steinen«, worüber sich Voltaire lustig machte (ibid., S.135).

191 Dazu Daniela KNEISsL, Marchandise tentatrice - marchandise infernale? Le diable dans la publicité de la Belle Époque, in: Ridiculosa 12 (2005), S.77-79.

192 Vgl. dazu Kap. 5.2. Vgl. zu diesem Blatt auch Kap.6.2.2.

193 BLass, Alexandre et Diogène, in: Le Triboulet, 13.5.1880. 


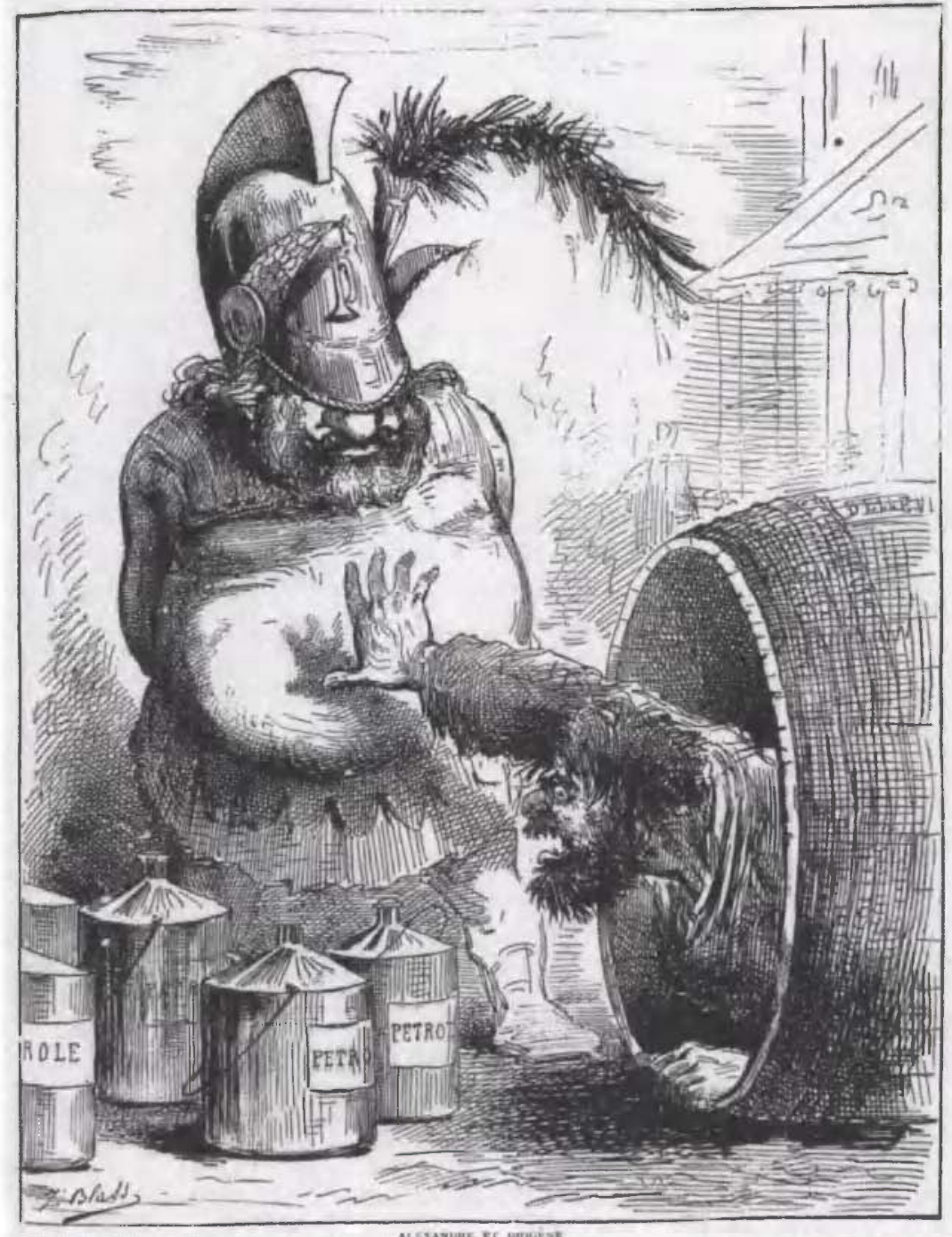

Ac.sง

Z oiciol de uen wowil!

Abb. 16 Blass: Alexandre et Diogene. ? - Otè-toi de mon soleil!, in: Le Triboulet, 13. 5.1880. Bibl. Forney, Paris. 
sondern das Symbol eines durch und durch verdorbenen Charakters. Die aus dem umgestürzten $\mathrm{Fa} ß$ hervorkriechende Gestalt gehört voll und ganz - sowohl räumlich als auch ideell - in den Bereich der >Unterwelt . Für die wirkliche Sonne hat dieser Diogenes keinen Sinn: Sein fatales >Licht steht in Form des in Kanister abgefüllten Petroleums vor ihm ${ }^{194}$.

Die Verderblichkeit dieses Lichts kann auch sozialkritische Züge annehmen - dann, wenn hohe Petroleumpreise Elend verschulden. Die antisemitische Zeitschrift La Libre Parole illustrée zeigte am 11. Mai 1895 das Titelbild Rothschild le pétroleur von Chanteclair ${ }^{195}$. Eine Frau mit einem Baby auf dem Arm und einem Petroleumbehälter in der Hand beschuldigt den vorbeigehenden Baron Rothschild, den Armen das Licht zu stehlen: "LA FEMmE: Après le blé, le pétrole! Ah! brigand, tu finiras par nous voler jusqu'à la lumière du jour. L'номме: Patience, la bourgeoise, son tour viendra 'd'éclairer « «. Im radikal nationalistischen Kontext wird die Frau mit dem Petroleumkanister von der Megäre zur treu sorgenden Mutter, während die Bedrohung von einem pétroleur ausgeht, der sein Werk mit legalen Mitteln betreibt. Die Stunde der Abrechnung, auf die der Mann anspielt, verweist dabei auf das Motiv der gewaltsamen Erleuchtung zurück, das im Feuer der Commune seinen bildlichen Ausdruck findet und das hier auf das übersteigerte Feindbild des jüdischen Kapitalisten projiziert wird.

Die Symbolik des fatalen Petroleums machte auch vor der ab 1880 immer beliebter werdenden Petroleumlampe nicht halt ${ }^{196}$. Schon Anfang Januar jenes Jahres nimmt Draner diese Problematik in seine Skizzenfolge Souvenirs de la foire du Jour de l'an auf ${ }^{197}$. Eine der kleinformatigen Karikaturen zeigt ein ältliches Ehepaar, das entsetzt vor einem Stand Reißaus nimmt, an dem die neuartigen Lampen angeboten werden. Der Kommentar des Ehemannes erklärt das Schreckensbild des Petroleums in einer Weise, die keines Kommentars mehr bedarf: "Rentrons vite, Angélique; dès demain nous quitterons Paris. Ça sent le pétrole«. 1885 zeigt Le Triboulet das Blatt $D u$ danger des illuminations au pétrole républicain ${ }^{198}$, in dem anläßlich der Festbeleuchtung zum 14. Juli ${ }^{199}$ das Motiv der verlockenden Kerze variiert wird (Abb. 17): Schmet-

194 In der Bildpublizistik der Französischen Revolution trat Diogenes besonders als Lichtund Menschensucher hervor. Dieses Motiv taucht auch in der III. Republik in vielfältigen Zusammenhängen auf. Vgl. dazu Kap. 8.2.2.

$195 \mathrm{Zu}$ Chanteclair vgl. Kap.4.2.

196 Zur zunehmenden Verbreitung der Petroleumlampe vgl. WILLIOr, Naissance, S. 527: »La lampe à pétrole $[\ldots]$ connut un réel développement à la fin du siècle, malgré les taxes, droits de douane et octroi qui pesaient sur le prix. [...] D'abord éclairage modeste, le coût de la matière première étant compensé par l'absence de frais secondaires d'abonnement, le pétrole lampant apparut à la Belle Époque comme un éclairage luxueux. La simplicité de fonctionnement des lampes était un atout majeur. Plus de 300000 hectolitres destinés à l'éclairage passaient les barrières de l'octroi au début des années 1890 dans la capitale «.

${ }^{197}$ Le Charivari, 8. 1.1880.

198 Le Triboulet, 19.7.1885.

199 Vgl. dazu Kap. 7.3. 


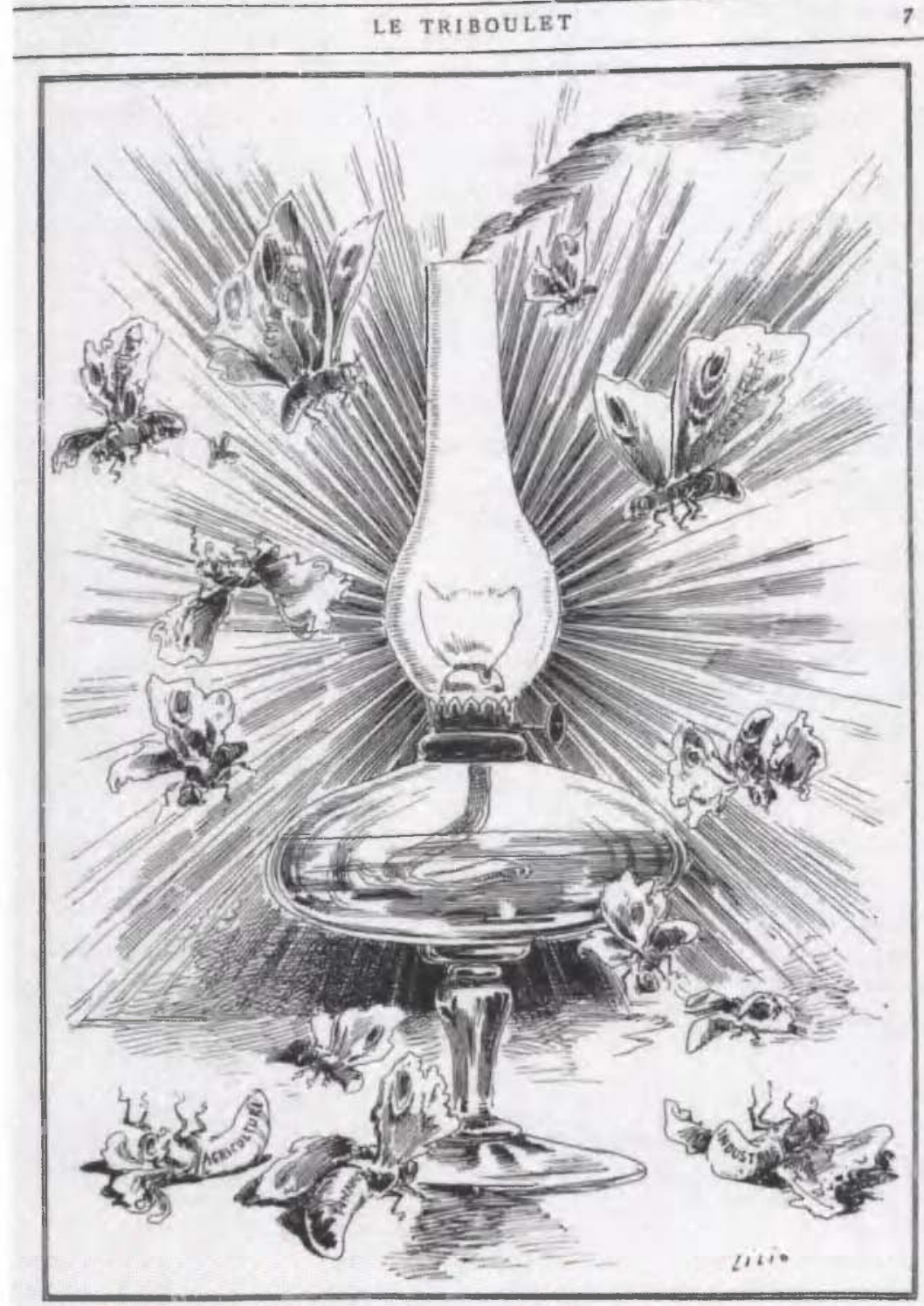

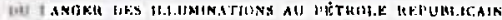

Abb. 17 Lilio: Du danger des illuminations au petrole republicain, in: Le Triboulet, 19.7. 1885. Bibl. Forney, Paris. 
terlinge werden von einer hell leuchtenden Petroleumlampe magisch angezogen, stürzen geblendet ab und finden den Tod. Zwei der toten Falter sind gekennzeichnet als Agriculture und Industrie. Die Petroleumlampe stellt dabei schon durch ihre Konstruktion die ideale Republikmetapher für die Reaktion dar: Das im unteren Bereich der Lampe eingefüllte Petroleum bringt unmißverständlich zum Ausdruck, daß die Republik als Staatsform sich unmittelbar aus der Commune herleitet. Das so genährte Licht kann nur fatal sein. Die eingebaute Schraube, mit der die Lichtstärke theoretisch reguliert werden kann, steht für die wohl als illusorisch angesehene Sicherheit durch gesetzliche Regelungen. Der durch die obere Öffnung austretende schwarze Rauch als Nebenprodukt des Lichts erinnert schlieBlich an die rauchende Brandfackel. Tatsächlich war der austretende Rauch ein sicheres Zeichen für den Benutzer, die Lampe mit Vorsicht zu gebrauchen. Wie eng diese praktische Notwendigkeit unterschwellig noch mit der Erinnerung an die Commune verknüpft blieb, muß dahingestellt bleiben. Erstaunlich aber ist, wie sehr noch Robert Burnand in seiner 1955 veröffentlichten Geschichte des Alltagslebens von 1870-1900 persönliche Erinnerungen an die Vor- und Nachteile der Petroleumlampe mit entsprechenden Formulierungen mischt:

L'éclairage au pétrole, vers 1890 , parut un progrès remarquable: simplification de l'appareil, augmentation de la puissance lumineuse. À vrai dire, la lampe à pétrole exigeait [...] une surveillance étroite: un moment d'inattention et elle remplissait la pièce d'un noir et puant nuage, couvrait les meubles, les étoffes, les visages, d'une armée de minuscules bruchons, rebelles au torchon comme au plumeau: ,Attention, la lampe file‘, l'appel à la vigilance ponctuait nos soirées ${ }^{200}$.

Um so mehr dürften um 1880 die noch weniger ausgereiften Lampenmodelle $\mathrm{zu}$ gedanklichen Verbindungen zwischen der Kontrolle von rebellischen Armeen « durch das republikanische System und dem in der Lampe ebenfalls nur scheinbar domestizierten Petroleum angeregt haben. Im Petroleum als Requisit des Alltags, als Beleuchtungsmittel in einer Zeit, die ihren Fortschritt nicht zuletzt am Helligkeitsgrad der erleuchteten Nacht maß, blieb die Erinnerung an die Commune deshalb um so länger allgegenwärtig. Dies gilt jedoch auch für andere Bereiche: In der klerikalen Karikatur entwickelt sich das Bild der pétroleuse vor dem Hintergrund der lange absehbaren séparation und des erstarkenden Sozialismus zu einer nur noch vage $\mathrm{zu}$ identifizierenden Allegorie des Schreckens. Am 12. Oktober 1902 zeigt Le Pèlerin die Bilder-

200 Robert Burnand, La Vie quotidienne en France de 1870 à 1900, Paris 1955, S. 124. Zu Anfangsschwierigkeiten beim Gebrauch der Petroleumlampe vgl. Ulrike LoofT-GaudE, Petroleumlampen, in: Jutta Matz, Heinrich MEHL (Hg.), Vom Kienspan zum Laserstrahl. Zur Geschichte der Beleuchtung von der Antike bis heute, Husum 2000, S. 46: "Es gab bei aller Freude über das helle Licht vor allem in den ersten Jahren auch zahlreiche Unfälle durch Unachtsamkeit oder Unwissen, da die Entflammbarkeit unterschätzt wurde. So goß man zum Beispiel, während die Lampen brannten, Petroleum nach, weil das bei den schwerer brennbaren Ölen möglich gewesen war. Das Sprichwort ,Öl aufs Feuer gießen، hat noch heute seine dramatische Bedeutung nicht verloren«. 
folge Le Morne rouge von Henriot, die den Vulkanausbruch auf Martinique mit der schwelenden Gefahr des bloc révolutionnaire in Verbindung bringt ${ }^{201}$. Die furchtbaren Konsequenzen der nicht absehbaren Naturkatastrophe dienen als Metapher für die extreme Linke, der von der Regierung kein ausreichender Widerstand entgegengesetzt wird. Die deshalb triumphierende Revolution ist wiederum die furiose Brandstifterin mit der torche und der phrygischen Mütze:

Une large flamme rouge dévaste les propriétés, ravage les champs et les fermes... [...] C'est la montagne révolutionnaire qui est en éruption... S'arrêtera-t-elle? Comme les autres volcans, après avoir semé les ruines et multiplié les victimes.

Die hier zum Ausdruck gebrachte Hoffnung, daß nach dem Gewaltausbruch des revolutionären Vulkans zwangsläufig wieder Ruhe einkehren wird, projiziert die Erfahrungen aus der Revolutionsgeschichte auf die Zukunft, um so der Angst vor der révolution rouge Herr zu werden. Denn die demonstrative Wiederbelebung des bürgerlichen Schreckensbildes Commune durch die anarchistische Bildsprache schien diese Vermutung zu bestätigen: In dem anarchistischen Blatt Le Père peinard erschien 1890 die Darstellung der personifizierten Commune als Rächerin, in den hochgereckten Händen die Fahne mit der Jahreszahl 1871 und die Brandfackel, während hinter ihr die brennende Silhouette einer Stadt aus der Finsternis ragt und sich vom Boden die Unterdrückten erheben. Die Hoffnung auf die Wiederkehr dieses feurigen Gerichts kommt zum Ausdruck in den Worten: »Elle n'est pas morte, foutre!!! « ${ }^{202}$ Die Gleichsetzung von Vergangenheit und Zukunft erklärt die Commune zum gesellschaftlichen Modell. Während aber, wie gezeigt, die sozialistische Bildpropaganda die Commune vom verabscheuungswürdigen Verbrechen in den Rang eines noch zu vollendenden Emanzipierungsversuches der unteren Schichten erhob, betont die anarchistische Bildsprache allein die rächende, zerstörende Funktion der Pariser Commune. Die Darstellung lehnt sich somit nicht zufällig eng an die Beschreibung an, die Gravelot und Cochin in ihrer 1791 erschienenen Iconologie für die zerstörerische Anarchie vorschlagen ${ }^{203}$. Nicht mehr die Rückeroberung des Lichtzentrums ist das Ziel, sondern erst die völlige Auslöschung der alten Welt soll und kann der lichterfüllten Zukunft den Weg ebnen ${ }^{204}$.

201 Zur Symbolik des Vulkanausbruchs in der Französischen Revolution vgl. Kap. 3.1.2.

202 Le Père peinard, 25.5.1890. Der Titel bezieht sich auf das Lied „Elle n'est pas morte«, in dem eine Textzeile überdies präzisiert: »Qu'la Commune n'est pas morte«. Vgl. Histoire de la France par les chansons, hg. v. France Vernillat, Pierre Barbier, Paris 1982, S. 265.

203 Bd. 2, S.77f. Vgl. dazu Kap.5.2., Anm. 71.

204 Vgl. dazu Kap.9.2.1. 